\title{
The Guerbet Coupling of Ethanol into Butanol over Calcium Hydroxyapatite Catalysts
}

A Dissertation
Presented to
The faculty of the School of Engineering and Applied Science
University of Virginia
In Partial Fulfillment
of the requirement for the Degree
Doctor of Philosophy (Chemical Engineering)

Sabra Hanspal

May 2016 


\begin{abstract}
Drawbacks posed by corn-based bioethanol as a gasoline fuel additive have called attention to its catalytic transformation into a higher-value fuel or chemical, such as butanol. The catalytic conversion of bio-derived ethanol to butanol occurs via the so-called Guerbet reaction a multi-step sequence of reactions that ultimately couples two short-chain alcohols to produce a longer chain saturated alcohol. Recent studies have demonstrated unusually high activity and high butanol selectivity during the Guerbet coupling of ethanol over calcium hydroxyapatite (HAP; $\left.\mathrm{Ca}_{10}\left(\mathrm{PO}_{4}\right)_{6}(\mathrm{OH})_{2}\right)$ catalysts; however the nature and composition of the active site(s) on these materials have not been clearly defined and therefore a detailed, molecular-scale understanding of the reaction mechanism is lacking.

In this work, hydroxyapatite catalysts of varying chemical compositions $(\mathrm{Ca} / \mathrm{P}=1.50$, $1.66,1.88)$ were synthesized via co-precipitation and compared to typical solid base metal oxides (e.g. $\mathrm{MgO}$ and $\mathrm{CaO}$ ). Acid-base surface characterization using adsorption microcalorimetry and IR spectroscopy of various adsorbed molecular probes combined with gas-phase reactivity testing were used to identify key structure-function relationships of the catalytic materials. The results conclusively showed that the excellent performance of stoichiometric HAP is the result of a high surface density of acid-base site pairs of intermediate strength that facilitate all of the steps in the Guerbet sequence.
\end{abstract}

Additionally, multiproduct steady-state isotopic transient kinetic analysis (SSITKA) of the ethanol coupling reaction was used for the first time over stoichiometric HAP (613 K) and results were compared to those obtained with $\mathrm{MgO}(653 \mathrm{~K})$. The SSITKA results provided a direct quantification of important intrinsic kinetic parameters of the reaction, i.e. surface concentrations of reaction intermediates, mean surface residence times, and turnover frequencies. 
Given the generally accepted mechanism for Guerbet coupling that involves aldol condensation of acetaldehyde, the SSITKA results revealed that a greater fraction of the acetaldehyde produced during the reaction proceeds toward coupling products on HAP relative to $\mathrm{MgO}$. The TOF associated with intermediates that form butanol on $\operatorname{HAP}\left(0.016 \mathrm{~s}^{-1}\right)$ was lower than that of $\mathrm{MgO}\left(0.059 \mathrm{~s}^{-1}\right)$. Therefore, the higher rates of butanol formation observed over HAP compared with $\mathrm{MgO}$ is a consequence of a much higher coverage of surface intermediates leading to butanol during the steady-state reaction. This finding is consistent with the considerably higher surface density of appropriate-strength acid-base site pairs measured on the HAP surface compared with $\mathrm{MgO}$.

To advance our scientific understanding of the active site on the surface of HAP required for butanol formation, the ethanol coupling reaction was investigated at $633 \mathrm{~K}$ over beta tricalcium phosphate $\left(\beta-\mathrm{TCP} ; \beta-\mathrm{Ca}_{3}\left(\mathrm{PO}_{4}\right)_{2}\right)$ and fluorine-substituted hydroxyapatite (FAP; $\left.\mathrm{Ca}_{10}\left(\mathrm{PO}_{4}\right)_{6} \mathrm{~F}_{2}\right)$ catalysts. Both $\beta$-TCP and FAP were catalytically active for C-C bond formation suggesting that the $\mathrm{PO}_{4}{ }^{3-}$ group is likely the base site in the active acid-base site pair for butanol formation during ethanol coupling over $\mathrm{HAP}$. Water co-feeding experiments over $\mathrm{MgO}$ revealed that water irreversibly adsorbed onto Lewis acid-strong base site pairs that were catalytically active for butanol formation whereas weak and reversible interactions were observed between water and the HAP surface.

Finally, the influence of Lewis acidity was explored by comparing the catalytic activity during reactions of ethanol over $\mathrm{Mg}_{3}\left(\mathrm{PO}_{4}\right)_{2}, \beta-\mathrm{Ca}_{3}\left(\mathrm{PO}_{4}\right)_{2}$, and $\mathrm{Sr}_{3}\left(\mathrm{PO}_{4}\right)_{2}$. Of the three phosphates tested, $\beta-\mathrm{Ca}_{3}\left(\mathrm{PO}_{4}\right)_{2}$ was the most selective for Guerbet coupling, indicating $\mathrm{Ca}^{2+}$ cations have the appropriate Lewis acid strength for the reaction. Interestingly, exceptional activity and selectivity of $\mathrm{Sr}_{3}\left(\mathrm{PO}_{4}\right)_{2}$ for ethanol dehydrogenation was also observed. 


\section{Acknowledgements}

I would like to thank the many people who have contributed to the successful completion of this degree. First and foremost, I would like to express my deepest gratitude to Dr. Robert J. Davis for his endless guidance and advice throughout this dissertation. Not only has Professor Davis served as my $\mathrm{PhD}$ advisor, but also as my mentor, career counselor, and life coach. The knowledge and wisdom he has imparted upon me are invaluable to my future and I will forever be grateful for his kindness and for everything he has taught me.

I would like to thank my $\mathrm{PhD}$ committee members for all of their insightful comments and suggestions: Dr. David Green, Dr. Gary Koenig, Dr. Joshua Choi, and Dr. Brent Gunnoe. Many thanks go out to the staff of the UVa Chemical Engineering Department: Ms. Vickie Faulconer, Ms. Teresa Morris, Ms. Jennifer Davis, and Mr. Ricky Buchanan who consistently go above and beyond to meet the needs of the department and the graduate student body. I acknowledge the source of funding for this work, the U.S. Department of Energy, Office of Science, Office of Basic Energy Sciences - Chemical Sciences, Geosciences, and Biosciences Division, Grant No. DE-FG02-95ER14549.

I am so grateful to all past and present Davis Lab members for their support, technical assistance, and camaraderie particularly Dr. Joseph Kozlowski, for his guidance and mentorship, Dr. Sara Bowman, Dr. Matthew Ide, Dr. Heng Shou, Dr. Juan Lopez, and Dr. Derek Falcone. I would like to thank Dr. Ian Hill for his collaboration with the DRIFTS experiments. A very special thank you to my HAP teammate and collaborator, Zachary Young, for listening to me practice my presentation over 50 times. Words cannot describe how appreciative I am of his time and dear friendship. I would like to acknowledge my two office mates of the past 4 years, Kehua 
Yin and Benjamin Huang - we are an inseparable team. I am thankful for their daily jokes, humor, laughter, generosity with food, and for the help they have given me along the way.

Thank you to all of the close friends I have made within the Chemical Engineering Department who have served as my Charlottesville family over the past 5 years. I sincerely appreciate their companionship and will forever cherish our Boylan happy hours, trivia nights, potlucks, and Easter brunches. I thank my non-UVa friends for their continual love and support and for still being my friend after all of the birthdays, bridal showers, bachelorette parties, and other special life events I have missed because of this document.

I never would have been able to endure the struggles of graduate school without the support, patience, and love from Robert Renzulli. I thank him for financially supporting our long-distance relationship with frequent flights to and from Denver. I am incredibly grateful to him for the long, late-night phone conversations at the lab, for taking the time to listen to my frustrations (and occasional rants) about grad school, and for always being able to put a smile on my face, no matter what I was going through and when I needed it the most. His flexibility, patience, and compassion are unparalleled. I am so fortunate to have him by my side as we embark on this new endeavor of our lives together.

And last, but certainly not least, my sincerest gratitude to my mother, Dr. Manjit Hanspal for her unconditional love and friendship. I thank her for dropping everything and driving from DC to Charlottesville on countless occasions the second I told her I needed her. I am unbelievably grateful to her for being the one that often got the backlash of the lab's frustrations and for patiently and lovingly dealing with my crankiness. I couldn't ask for a more supportive, loving, and understanding mother. I owe her a lifetime of gratitude for the constant encouragement and assistance she has given me throughout this process. 


\section{Table of Contents}

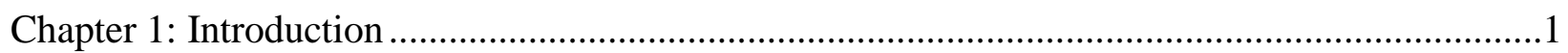

1.1. Ethanol: A platform feedstock for higher-value fuels and chemicals.....................................1

1.2. The Guerbet Coupling of Ethanol into Butanol.....................................................................

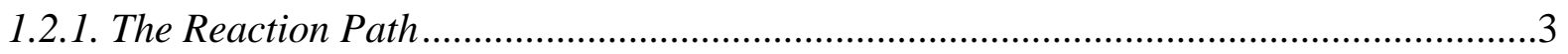

1.2.2. Side Reactions and By-product Formation ............................................................6

1.2.3. Heterogeneous Catalysts for Guerbet Coupling ...........................................................

1.3. Hydroxyapatite: A highly active and selective catalyst for alcohol coupling .........................11

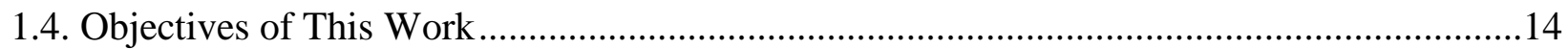

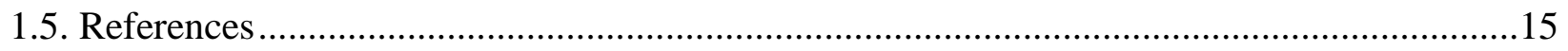

Chapter 2: Effects of Calcium Hydroxyapatite Composition on the Ethanol Coupling

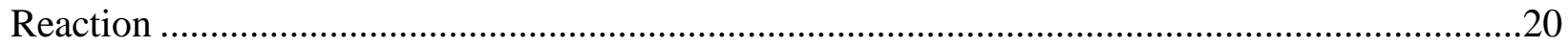

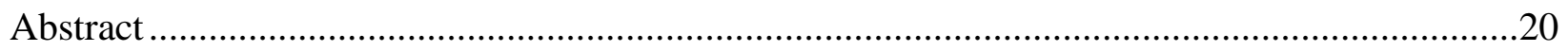

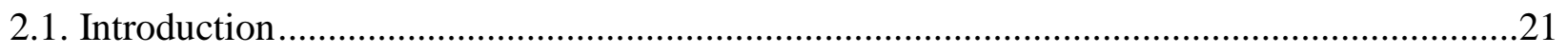

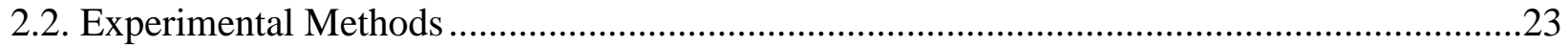

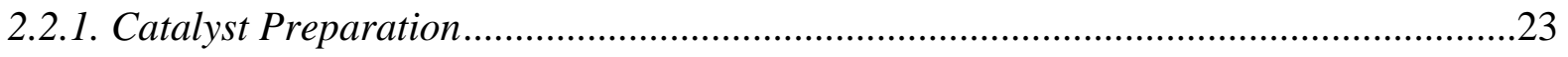

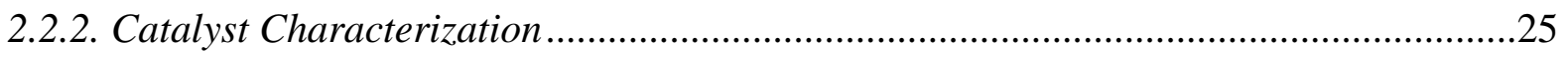

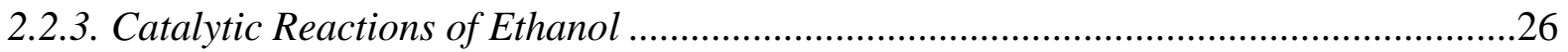

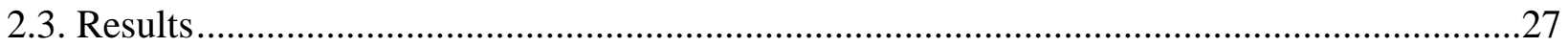

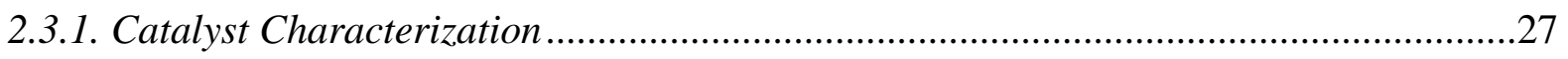

2.3.2. Steady-State Conversion of Ethanol ………………................................................28

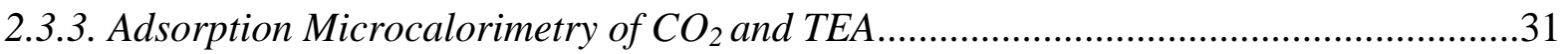

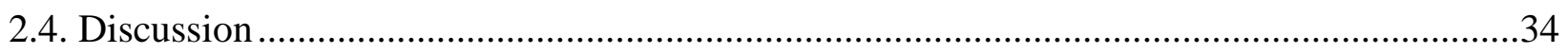

2.4.1. Surface Properties and Reactivity of Basic Sites ...........................................................34

2.4.2. Surface Properties and Reactivity of Acid Sites ...........................................................

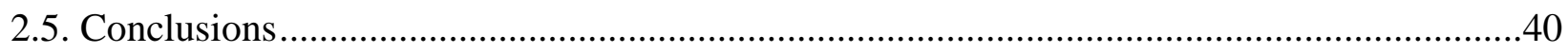

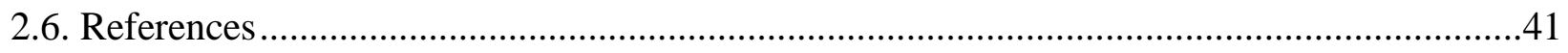


Chapter 3: Multiproduct Steady-State Isotopic Transient Kinetic Analysis of the Ethanol Coupling Reaction over Hydroxyapatite and Magnesia

Abstract.

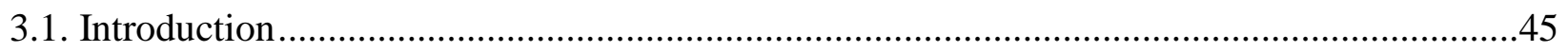

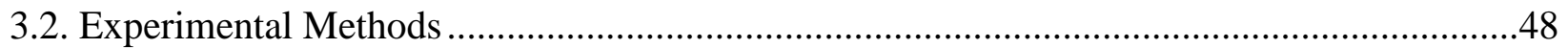

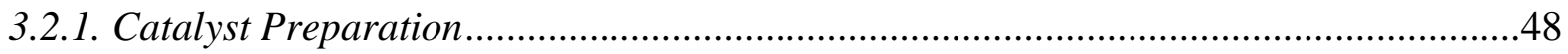

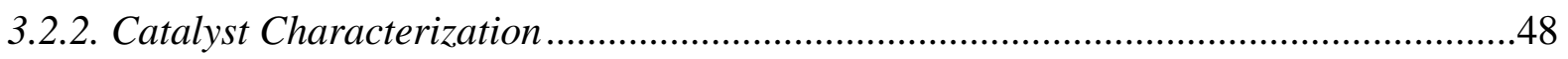

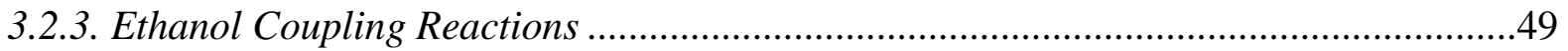

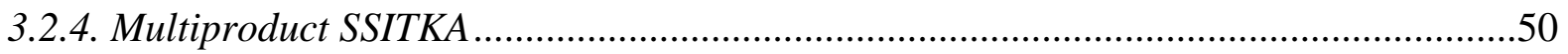

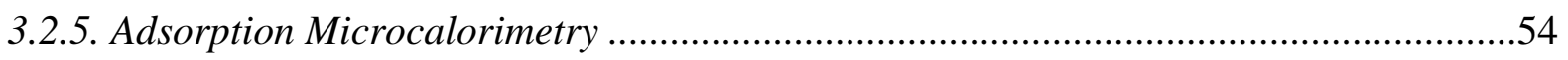

3.2.6. Diffuse Reflectance Infrared Fourier Transform Spectroscopy (DRIFTS) ..................54

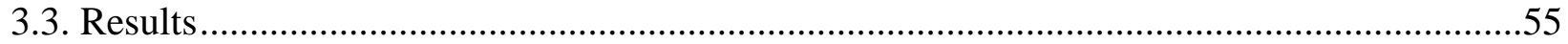

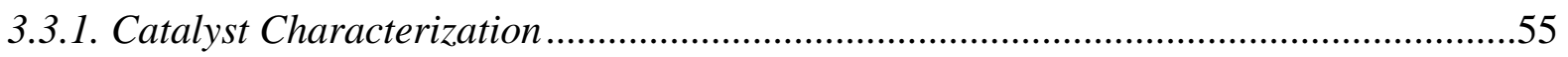

3.3.2. Steady-State Conversion of Ethanol .......................................................................56

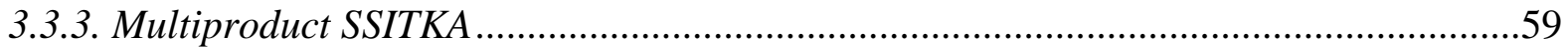

3.3.4. STPD of Adsorbed Ethanol Monitored by DRIFTS .................................................62

3.3.5. Adsorption Microcalorimetry of Carbon Dioxide, Triethylamine, and Ethanol ...........64

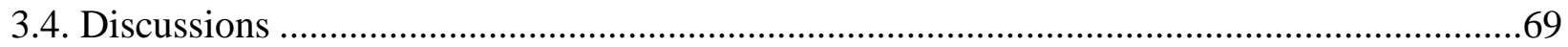

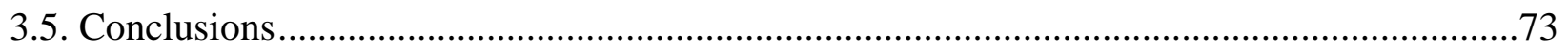

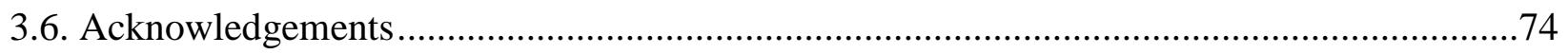

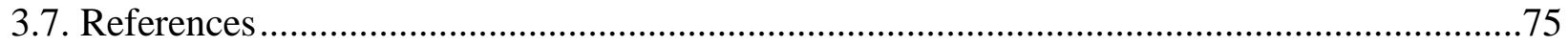

Chapter 4: Mechanistic Insights into the Ethanol Coupling Reaction over Metal Phosphate

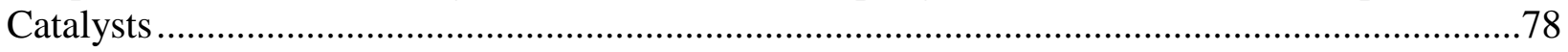

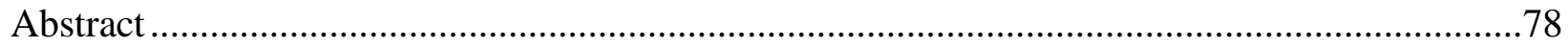

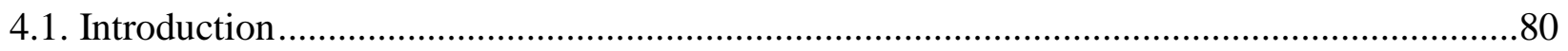

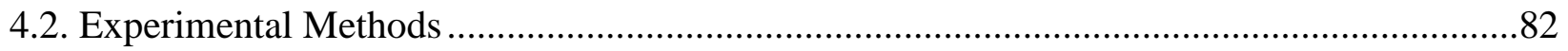

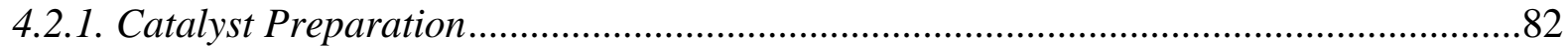

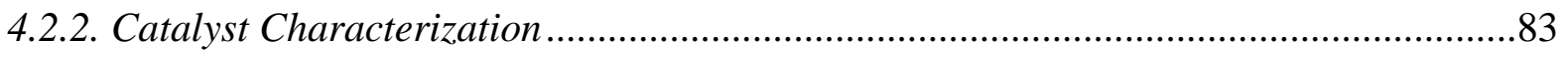

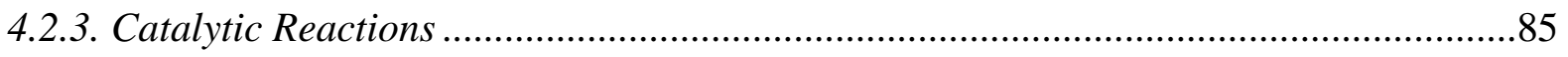

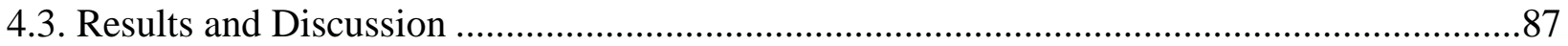

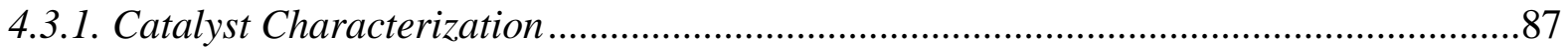




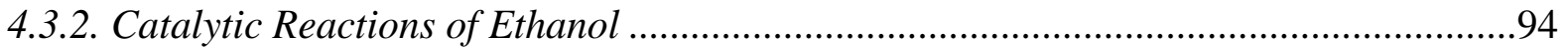

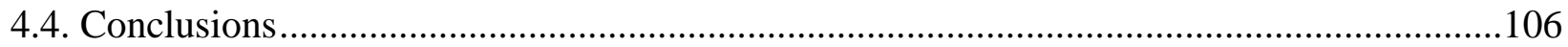

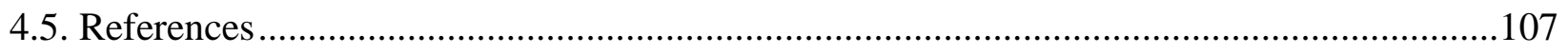

Chapter 5: Conclusions and Future Directions ...................................................................111

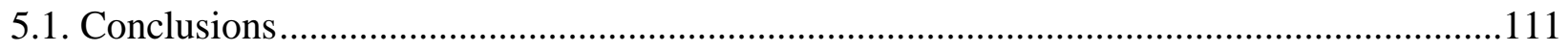

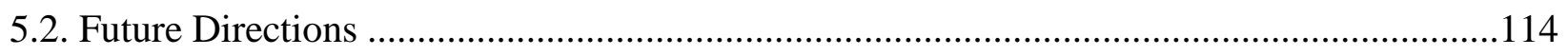

5.2.1. Lewis Acid Probe for Metal Phosphate Catalysts ......................................................114

5.2.2. Further Investigation into Strontium Phosphate …………….....................................115

5.2.3. Combining Multiple Single-Function Catalysts..........................................................116

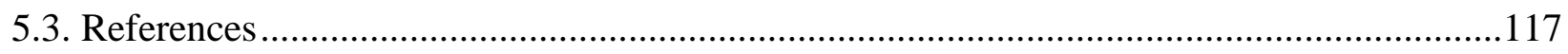

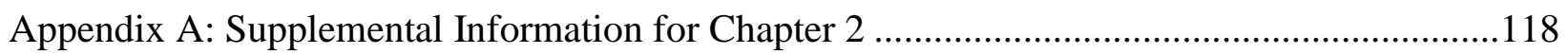

Appendix B: Supplemental Information for Chapter 3 ………...............................................120

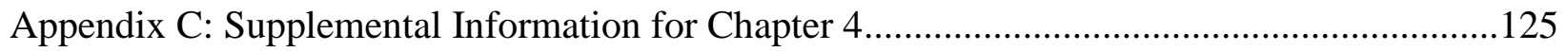

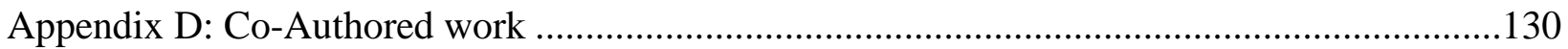

D.1. DRIFTS of Probe Molecules Adsorbed on Magnesia, Zirconia, and Hydroxyapatite

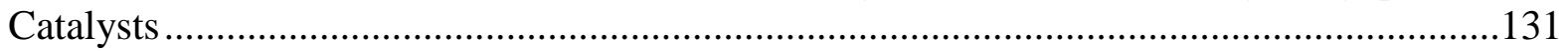

D.2. Aldol Condensation of Acetaldehyde over Titania, Hydroxyapatite, and Magnesia.....132 


\section{List of Figures}

Figure 1.1. Structure of stoichiometric calcium hydroxyapatite projected on the $\boldsymbol{a}, \boldsymbol{b}$ plane [47].12

Figure 2.1. Powder X-ray diffraction patterns of hydroxyapatite of varying $\mathrm{Ca} / \mathrm{P}$ molar ratios and $\beta$-TCP. Patterns are offset for clarity

Figure 2.2. Conversion of ethanol as a function of inverse reactant flow rate during the coupling

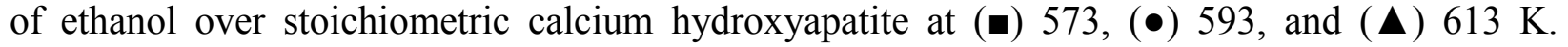
Differential conversion conditions are observed below $\sim 7 \%$ ethanol conversion.....

Figure 2.3. Adsorption microcalorimetry of carbon dioxide on the catalytic materials at $303 \mathrm{~K}$; (a) adsorption isotherms of carbon dioxide (b) differential heats of adsorption as a function of coverage

Figure 2.4. Adsorption microcalorimetry of triethylamine (TEA) on the catalytic materials at 303 $\mathrm{K}$; (a) adsorption isotherms of triethylamine (b) differential heats of adsorption as a function of coverage

Figure 3.1. Reaction system for multiproduct SSITKA. This figure is adapted from Shou and Davis [29]......

Figure 3.2. Normalized isotopic transient response curves following the switch from unlabeled ethanol to doubly labeled ${ }^{13} \mathrm{C}$-labeled ethanol with a total flow of $50 \mathrm{~cm}^{3} \mathrm{~min}^{-1}$ at $613 \mathrm{~K}$ during the coupling of ethanol over HAP. ( $\mathbf{(})$ argon, $(\bullet)$ acetaldehyde, $(\bullet)$ ethanol, $(\boldsymbol{\Delta})$ butanol ..........53

Figure 3.3. X-ray diffraction patterns of (a) $\mathrm{MgO}$ and (b) stoichiometric HAP (catalysts were calcined at $873 \mathrm{~K}$ for $2 \mathrm{~h}$ in air). Patterns are offset for clarity ..............................................56

Figure 3.4. The conversion of ethanol as a function of inverse reactant flow rate during the coupling of ethanol over $\mathrm{MgO}$ and stoichiometric HAP at $653 \mathrm{~K}$ and $613 \mathrm{~K}$, respectively. The observed linear dependence confirms differential reactor conditions .58

Figure 3.5. Normalized isotopic transient response curves for butanol following the switch from unlabeled ethanol to doubly labeled ${ }^{13} \mathrm{C}$-labeled ethanol with a total flow of $50 \mathrm{~cm}^{3} \mathrm{~min}^{-1}$ during the coupling of ethanol over $\mathrm{MgO}$ at $653 \mathrm{~K}$ and HAP at $613 \mathrm{~K}$. Curves have been fit using a twoterm exponential decay function

Figure 3.6. DRIFTS spectra of adsorbed ethanol at $303 \mathrm{~K}$ on $\mathrm{MgO}$ (left) and $\mathrm{HAP}$ (right) collected after heating to various temperatures: (a) $303 \mathrm{~K}$, (b) $373 \mathrm{~K}$, (c) $473 \mathrm{~K}$, (d) $573 \mathrm{~K}$, (e) 673 K. Spectra are offset for clarity.

Figure 3.7. Adsorption microcalorimetry of carbon dioxide on $(\Delta) \mathrm{MgO}$ and $(\bullet)$ stoichiometric hydroxyapatite (HAP) catalysts at $303 \mathrm{~K}$; (a) adsorption isotherms of carbon dioxide (b) differential heats of adsorption as a function of coverage 
Figure 3.8. Adsorption microcalorimetry of triethylamine (TEA) on $(\Delta) \mathrm{MgO}$ and $(\bullet)$ stoichiometric hydroxyapatite (HAP) catalysts at $303 \mathrm{~K}$; (a) adsorption isotherms of triethylamine (b) differential heats of adsorption as a function of coverage....

Figure 3.9. Adsorption microcalorimetry of ethanol on $(\Delta) \mathrm{MgO}$ and $(\bullet)$ stoichiometric hydroxyapatite (HAP) catalysts at $303 \mathrm{~K}$; (a) adsorption isotherms of ethanol (b) differential heats of adsorption as a function of coverage .68

Figure 4.1. X-ray diffraction patterns of (a) stoichiometric hydroxyapatite (HAP; $\left.\mathrm{Ca}_{10}\left(\mathrm{PO}_{4}\right)_{6}(\mathrm{OH})_{2}\right)$, (b) fluorine-substitued hydroxyapatite (FAP; $\left.\mathrm{Ca}_{10}\left(\mathrm{PO}_{4}\right) \mathrm{F}_{2}\right)$, (c) periclase $\mathrm{MgO}$, and (d) strontium phosphate $\left(\mathrm{Sr}_{3}\left(\mathrm{PO}_{4}\right)_{2}\right)$. Patterns are offset for clarity .88

Figure 4.2. Powder X-ray diffraction pattern of calcium-deficient hydroxyapatite at (a) room temperature and (b) after calcination at $1073 \mathrm{~K}$ for $2 \mathrm{~h}$. in flowing air. Patterns are offset for clarity

Figure 4.3. Powder $\mathrm{X}$-ray diffraction pattern of $\mathrm{Mg}_{3}\left(\mathrm{PO}_{4}\right)_{2} \mathrm{xH}_{2} \mathrm{O}$ at (a) room temperature and (b) after calcination at $873 \mathrm{~K}$ for $2 \mathrm{~h}$. in flowing air. Patterns are offset for clarity.....

Figure 4.4. Thermogravimetric analysis (TGA) profile of magnesium phosphate hydrate $\left(\mathrm{Mg}_{3}\left(\mathrm{PO}_{4}\right)_{2} \times \mathrm{H}_{2} \mathrm{O}\right)$.

Figure 4.5. Adsorption microcalorimetry of carbon dioxide on the catalytic materials at $303 \mathrm{~K}$; (a) adsorption isotherms of carbon dioxide (b) differential heats of adsorption as a function of coverage

Figure 4.6. The total rate of ethanol conversion ( $\boldsymbol{\bullet})$ and the production rates of butanol $(\bullet)$ and acetaldehyde $(\boldsymbol{\Delta})$ as a function of the initial ethanol concentration during the steady-state conversion of ethanol over stoichiometric calcium hydroxyapatite at $613 \mathrm{~K}$ .94

Figure 4.7. The effect of increasing gas-phase dihydrogen on the total rate of ethanol conversion $(\boldsymbol{\Delta})$ and the butanol selectivity $(\bullet)$ during the steady-state coupling of ethanol over stoichiometric hydroxyapatite at $613 \mathrm{~K}$

Figure 4.8. Production rates of $(\bullet)$ butanol and $(\square)$ acetaldehyde obtained during the steady-state conversion of ethanol over stoichiometric hydroxyapatite at $613 \mathrm{~K}$ with the addition and removal of water

Figure 4.9. Production rates of $(\bullet)$ butanol, $(\square)$ acetaldehyde, and $(*)$ ethene obtained during the steady-state conversion of ethanol over $\mathrm{MgO}$ at $673 \mathrm{~K}$ with the addition and removal of water .98

Figure 4.10. DRIFTS of adsorbed pyridine on $\mathrm{Mg}_{3}\left(\mathrm{PO}_{4}\right)_{2}$ at $373 \mathrm{~K}$ after purging with He for 20 min. The observed peaks are characteristic of pyridine coordinately bonded to Lewis acid sites 


\section{List of Tables}

Table 2.1. Specific Surface Areas of Catalysts and Results from Elemental Analyses ................28

Table 2.2. Catalyst Performance during the Steady-State Conversion of Ethanol .........................31

Table 3.1. Specific surface areas of stoichiometric hydroxyapatite and magnesia catalysts ........56

Table 3.2. Product distribution during the catalytic conversion of ethanol over $\mathrm{MgO}$ at $653 \mathrm{~K} . .57$

Table 3.3. Product distribution during the catalytic conversion of ethanol over stoichiometric $\mathrm{HAP}$ at $613 \mathrm{~K}$

Table 3.4. Time constants and surface coverages of ethanol $\left(\mathrm{N}_{\text {ethanol }}\right)$ during the steady-state Guerbet coupling of ethanol over $\mathrm{MgO}$ and $\mathrm{HAP}$ at 653 and $613 \mathrm{~K}$, respectively

Table 3.5. Time constants and surface coverages of reactive intermediates leading to acetaldehyde $\left(\mathrm{N}_{\mathrm{AcH}}\right)$ during the steady-state Guerbet coupling of ethanol over $\mathrm{MgO}$ and $\mathrm{HAP}$ at 653 and $613 \mathrm{~K}$, respectively.

Table 3.6. Time constants and surface coverages of reactive intermediates leading to butanol $\left(\mathrm{N}_{\text {butanol }}\right)$ during the steady-state Guerbet coupling of ethanol over $\mathrm{MgO}$ and $\mathrm{HAP}$ at 653 and 613 $\mathrm{K}$, respectively .62

Table 4.1. Specific Surface Areas of Catalysts and Results from Elemental Analyses .................87

Table 4.2. Product Distribution during Ethanol Coupling at $633 \mathrm{~K}$............................................100

Table 4.3. Initial Rates of Aldol Condensation of Acetaldehyde at 553 K.................................105 


\section{Chapter 1:}

\section{Introduction}

\subsection{Ethanol: A platform feedstock for higher-value fuels and chemicals}

The use of biomass as a renewable source of carbon for the production of liquid fuels and chemicals is essential to meet the growing energy demands of our industrial society and for the sustainable development of future generations [1]. Corn-based bioethanol is a biomass-derived fuel that has been widely adopted by countries such as the United States and Brazil as a gasoline fuel oxygenate and as a domestic and renewable transportation fuel alternative to traditional petroleum-based fuels. The United States Renewable Fuel Standard, that was set forth by Congress under the U.S. Energy Policy Act of 2005 and later expanded in 2007, spurred the start of the country's ethanol industry and is largely responsible for the dramatic growth in U.S. ethanol production seen over the last decade [2]. In 2015, fuel ethanol production in the U.S. reached a record-breaking 14.8 billion gallons, accounting for nearly $60 \%$ of the total global output, making the United States currently the largest producer of fuel ethanol in the world [3].

Unfortunately, due to several critical issues, ethanol does not adequately fulfill the requirements as an effective transportation fuel. Ethanol is hydrophilic, miscible with water, corrosive, and is highly volatile - chemical properties that prevent its distribution using modern fuel pipelines, causing significant transportation challenges [4-7]. These properties also limit the amount of ethanol that can be safely blended into standard grade petroleum to $10 \%$ to maintain compatibility with existing engine technology and fuel infrastructure (e.g. storage tanks, pipes, dispensers). Furthermore, ethanol has a lower volumetric energy density compared to traditional gasoline, which imposes a compromise on fuel economy for consumers [4,8]. 
Considering the many drawbacks posed by ethanol as a gasoline fuel additive combined with its existing capacity in the U.S., the use of bioethanol as a platform feedstock for the production of higher-value fuels and chemicals has attracted increased interest in recent years. Currently, a wide range of catalytic processes for ethanol conversion are actively being investigated including ethanol steam reforming (ESR) to hydrogen, ethanol to hydrocarbons from $\mathrm{C}_{2}-\mathrm{C}_{4}$ light olefins (e.g. ethylene, propylene, isobutene, 1,3-butadiene) to gasoline-range liquid hydrocarbons (ETG), as well as the production of smaller oxygenated molecules such as acetaldehyde, acetic acid, and ethyl acetate $[9,10]$. The catalytic conversion of ethanol into longer-chain alcohols, particularly n-butanol, has also become increasingly popular in recent years due to their superior fuel properties over ethanol.

Butanol has generated interest as a potential gasoline fuel additive because, compared to ethanol, it has a lower vapor pressure, lower solubility in water, and is less corrosive [6]. These properties allow butanol to be easily transported using the existing fuel distribution infrastructure and to be blended with gasoline at higher concentrations than ethanol, without requiring additional automobile upgrades or significant retrofitting of refueling stations. Additionally, the energy content of butanol is closer to that of conventional petroleum, which allows for improved gas mileage for biofuel-blended gasoline [6,8].

The current global butanol market is worth over 5 billion (USD) per year and extends well beyond just the fuel sector $[11,12]$. Butanol is a highly versatile commodity chemical used in a wide range of industrial applications, including: as an ingredient in perfumes, cosmetics, and artificial flavorings; as a solvent for dyes, paints, coatings, and resins; and as an industrial intermediate for the manufacture of polyacrylates and acetates [6]. 
Currently the mainstream method of synthesizing butanol in the petrochemical industry is by hydroformylation of propylene via the oxo process. This process however uses fossil fuelderived feedstocks and often requires expensive catalytic materials and extreme reaction conditions, leading to high energy input and substantial operating costs $[13,14]$. Butanol may also be obtained via ABE (acetone, butanol, ethanol) fermentation, but there are many challenges associated with this process that make it industrially unattractive compared to petrochemical routes. These challenges include high substrate costs, low butanol product yields, solvent toxicity to the bacteria, and costly downstream processing [6].

Because of its many applications in a variety of different industries, worldwide production of butanol is projected to increase to meet growing demands and therefore more energy- and cost-efficient methods of production are needed [5,14]. One potentially economically viable and environmentally-conscious alternative for butanol synthesis is the catalytic conversion of bioethanol via the Guerbet reaction.

\subsection{The Guerbet Coupling of Ethanol to Butanol}

\subsubsection{The Reaction Path}

The Guerbet reaction has developed into a well-known industrial route for higher alcohol synthesis since its discovery in 1899 by Marcel Guerbet [15]. The reaction couples two shortchain primary or secondary alcohols to produce a longer-chain, saturated alcohol that contains the sum of the carbons of the reactant molecules, with the release of water. The most commonly accepted path in the literature for this reaction involves a series of consecutive steps, as depicted in Scheme 1.1 for ethanol (Steps $1-4)$ : 


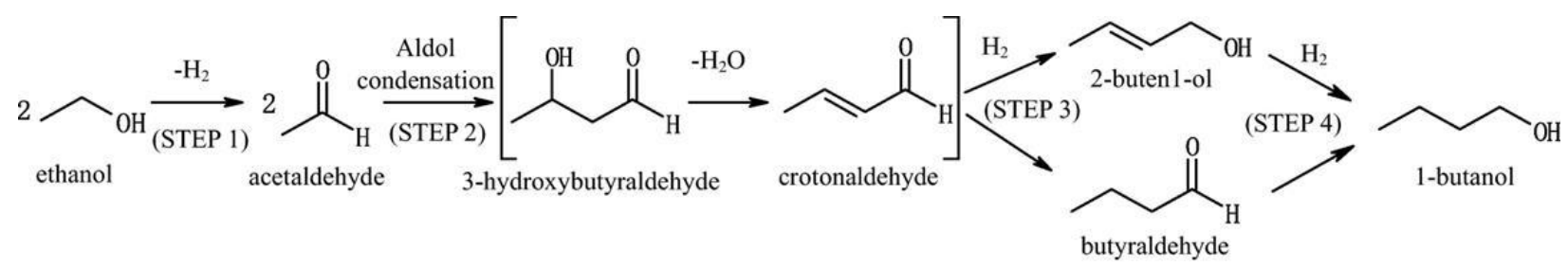

Scheme 1.1. The most commonly accepted reaction path for the Guerbet coupling of ethanol [16].

In Step 1, ethanol is dehydrogenated to form acetaldehyde. Acetaldehyde then couples with itself and undergoes an aldolization reaction forming, 3-hydroxybutyraldehyde, which is subsequently dehydrated to form crotonaldehyde (Step 2). Steps 3 and 4 consist of hydrogenation reactions of the unsaturated condensation products to give the fully saturated higher alcohol, butanol [17].

Although the formation of 1-butanol from ethanol is widely thought to occur via an aldol intermediate (Scheme 1.1), a second possible reaction pathway has been proposed by researchers, causing some disagreement within the Guerbet scientific community. The alternative mechanism, which was first proposed in 1993 by Yang and Meng [18] after studying alkali cation-exchanged zeolite catalysts, involves a "direct" biomolecular condensation of two ethanol molecules to form butanol as a primary reaction product, without the intermediate formation of acetaldehyde. In this mechanism, the $\mathrm{C}-\mathrm{H}$ bond in the $\beta$-position of one ethanol molecule is activated and condenses with a second ethanol molecule with the abstraction of a hydroxyl group, resulting in $\mathrm{C}-\mathrm{C}$ bond formation with the elimination of one molecule of water.

This "direct" route was later supported in 2003 by Ndou et al. [19] who studied alkaline earth metal oxides and modified $\mathrm{MgO}$ catalysts after no increase in butanol production was observed upon flowing pure acetaldehyde as the reactant. However, the set of experiments presented in that work has been highly criticized because the researchers failed to take into 
account critical factors such as the concentration of surface aldol intermediates or the amount of hydrogen present in the system during ethanol coupling conditions [20].

Alternative mechanisms were reinvestigated more recently by Scalbert et al. [21,22] using commercial hydroxyapatite as an ethanol coupling catalyst. The researchers used a combined kinetic and thermodynamic approach to also conclude that the production of butanol at high temperatures $(623$ - $683 \mathrm{~K})$ proceeds primarily through the "direct" bimolecular condensation of ethanol without self-aldolization of acetaldehyde. This conclusion was mainly attributed to the inability of metal-free surfaces (i.e. hydroxyapatite and basic metal oxides) to facilitate hydrogenation (Steps 3 and 4, Scheme 1.1) of the unsaturated intermediates formed via the aldol condensation pathway. These materials, however, can readily participate in hydrogen transfer reactions, analogous to Meerwein-Ponndorf-Verley (MPV)-like mechanisms, in which hydrogen is directly transferred from the alcohol to an adsorbed aldol intermediate [23]. The authors acknowledge this occurrence as a possible "minor" route in which ethanol condenses with acetaldehyde (produced by ethanol dehydrogenation) to form butenol which is then hydrogenated to butanol via hydrogen transfer from ethanol [21].

Although a direct pathway may be plausible in some systems, there are several pieces of evidence that support the idea that acetaldehyde is a key intermediate in the coupling of ethanol into butanol. Iglesia and co-workers [24] investigated reaction mixtures of ${ }^{13} \mathrm{C}$-labeled acetaldehyde with unlabeled ethanol over $\mathrm{K}-\mathrm{Cu} / \mathrm{MgCeO}_{\mathrm{x}}$ catalysts and observed that the majority of coupling products formed were labeled. Additionally, earlier work out of our lab by Birky et al. [25] showed that the rate of butanol production over $\mathrm{MgO}$ depends linearly on the concentration of acetaldehyde measured at the exit of the reactor. Ho et al. [26] also observed a positive effect on the butanol production rate with increasing acetaldehyde partial pressures over 
hydroxyapatite catalysts. An increase in gas-phase acetaldehyde concentration likely facilitates chain-growth via aldol condensation pathways leading to higher observed formation rates of coupled products.

Despite a growing consensus of the aldol condensation mechanism, it is obvious from the discussion presented here that the ethanol coupling reaction network is still a matter of debate, therefore mechanistic studies are ongoing.

\subsubsection{Side Reactions and By-product Formation}

Depending on the reaction conditions and the surface properties of the catalyst, a number of competitive reactions may occur during ethanol conversion, leading to unwanted by-product formation. The most commonly observed side reaction that competes with the coupling of ethanol into butanol is the dehydration of ethanol into olefins and ethers. Dehydration of alcohols typically occurs over acid sites whereas dehydrogenation is facilitated by basic sites. Therefore it is generally observed during ethanol coupling that increasing the number or strength of acid sites of the catalyst shifts the product distribution from acetaldehyde and coupling products towards undesirable dehydration products like ethene and diethyl ether. This is particularly evident when observing selectivity trends over tunable acid-base bifunctional materials (e.g. $\mathrm{Mg}-\mathrm{Al} / \mathrm{Zr}$ mixed oxides, hydroxyapatite), which are discussed in greater detail in the next section [27-30].

Increasing the concentration of acid sites during ethanol conversion over acid-base catalysts has also been shown to facilitate the formation of 1,3-butadiene through the competing Lebedev reaction $[29,30]$. The Guerbet and Lebedev reactions are mechanistically very similar with overlapping elementary steps and thus the catalytic systems employed for the reactions share common features [31]. Hence, care must be taken to properly balance the acid-base surface 
properties of the catalyst to favor high selectivity towards butanol and prevent undesired Lebedev pathways to 1,3-butadiene production.

Water is a by-product in the coupling of ethanol into butanol and can have detrimental effects on the reaction. These negative effects are more prevalent in liquid-phase, batch systems because water accumulates in the reaction vessel and can lead to catalyst deactivation and/or undesirable side reactions [20]. Marcu et al. [32] investigated the effect of water on the reaction in liquid-phase over $\mathrm{Cu}-\mathrm{Mg}-\mathrm{Al}$ mixed oxide catalysts and observed that the inclusion of water dramatically decreased selectivity towards butanol. Likewise, the removal of water from the reaction medium resulted in an increase in ethanol conversion and selectivity to butanol. The researchers attributed the inhibitory effect of water to the protonation of strong base sites (from $\mathrm{O}^{2-}$ to $\mathrm{OH}^{-}$) required for aldol condensation and ultimately for butanol formation.

Free water molecules produced by the Guerbet reaction may also induce undesired side reactions that lead to ester formation via base-catalyzed Tishchenko- or Cannizzaro-type pathways [33]. Acetates are formed via the Tishchenko route, which involves reactions of adsorbed aldehydes and alkoxide species, while the Cannizzaro reaction is a disproportionation reaction where one aldehyde is reduced to its corresponding alcohol and the other aldehyde is oxidized to a carboxylic acid [34,35]. These acids can neutralize active base centers on the catalytic surface. In an effort to minimize these side reactions in liquid-phase systems, researchers typically add a desiccant to the reaction vessel (e.g. 3A molecular sieves, $\mathrm{CaO}, \mathrm{MgO}$ ) which has been shown to decrease ester production and improve catalytic activity and selectivity to butanol $[8,20,33]$. The Tishchenko/Cannizzaro reactions also likely play a role in vapor-phase systems over solid base catalysts as acetate product species have been detected by GC analysis [27] and IR spectroscopy [36] under continuous-flow, gaseous conditions. Despite the widely 
known inhibiting effect of water in liquid-phase reactions, the effect of the water formed during ethanol coupling in the gas-phase on the catalytic performance and the overall reaction has not been adequately addressed in the literature and is not well understood.

At high ethanol conversions and elevated reaction temperatures, successive coupling reactions are regularly observed in the gas-phase which lead to high molecular-weight byproducts and decreased selectivity to butanol. Under these conditions, it is typical for 1-butanol to cross-couple with ethanol leading to $\mathrm{C}_{6}$ products, namely 2-ethyl-1-hexanol, or to self-couple to form $\mathrm{C}_{8}$ species [34]. These chain-growth or propagation reactions were observed by Tsuchida and co-workers [37] during ethanol conversion over hydroxyapatite at $723 \mathrm{~K}$ and resulted in a mixed alcohol, gasoline-like product mixture mostly comprised of $\mathrm{C}_{6}, \mathrm{C}_{8}, \mathrm{C}_{10}$ alcohols and hydrocarbons. These higher boiling compounds tend to remain on the catalyst surface and are the leading cause of catalyst deactivation observed under these operating conditions.

In summary, the catalyst composition and operating conditions employed during the Guerbet reaction must be carefully optimized to achieve minimal by-product formation, prevent unwanted side reactions, and reduce water inhibition while maintaining high activity, butanol selectivity, and low deactivation rates. A brief discussion regarding effective heterogeneous catalytic materials for the Guerbet coupling of alcohols is provided in the next section.

\subsubsection{Heterogeneous Catalysts for Guerbet Coupling}

The Guerbet coupling reaction has been extensively studied over a wide range of catalytic systems. For a more thorough description and comparison of alcohol coupling catalysts please consult recent reviews [5,20,34]. In particular, solid-base materials such as basic metal oxides, like $\mathrm{MgO}$, are effective catalysts for Guerbet coupling reactions and have therefore been 
investigated in great detail. Magnesium oxide became a popular alcohol coupling material out of work performed by Ueda and co-workers in the early 1990s that reported its exceptional catalytic activity and selectivity during the cross-coupling of methanol and ethanol $[38,39]$. These studies spurred considerable interest within the Guerbet scientific community and has since made $\mathrm{MgO}$ a reference base catalyst for the reaction that is often compared to today.

Although $\mathrm{MgO}$ is an effective catalyst for ethanol coupling, it requires high reaction temperatures $(>673 \mathrm{~K})$ and produces butanol with low rates and with poor selectivity $(\sim 40 \%)$, leaving much room for improvement [20]. Interestingly, basic metal oxides, like $\mathrm{MgO}$, are highly active catalysts in the second step of the Guerbet sequence - the base-catalyzed aldol condensation reaction, which readily proceeds at room temperature over these materials [20]. Thus, it is postulated that the rate of Guerbet coupling over $\mathrm{MgO}$ is inhibited by the initial dehydrogenation of ethanol to acetaldehyde (Step 1, Scheme 1.1). Consequently, many attempts have been made by researchers to enhance the catalytic performance of $\mathrm{MgO}$ by modifying its surface to promote dehydrogenating activity. One approach is to incorporate a transition metal component to the basic $\mathrm{MgO}$ support.

Catalytic materials that contain a transition metal promotor, primarily used in (de)hydrogenation reactions, coupled with a basic metal oxide support, like $\mathrm{MgO}$, that is active in aldol condensation serves dual purposes and are referred to as metal-base bifunctional catalysts [40]. The use of metal-base bifunctional materials has been shown to have a positive effect on the Guerbet coupling of ethanol into butanol compared to purely basic or non-metal materials. Gines and Iglesia [24] investigated the ethanol coupling reaction over copper- $(\mathrm{Cu})$ and potassium- $(\mathrm{K})$ promoted magnesia ceria mixed oxides $\left(\mathrm{Mg}_{5} \mathrm{CeO}_{\mathrm{x}}\right)$. Rates of ethanol dehydrogenation and aldol condensation were significantly higher on copper-containing 
materials compared to those observed over un-promoted $\mathrm{Mg}_{5} \mathrm{CeO}_{\mathrm{x}}$. Copper sites catalyzed ratelimiting elementary steps in ethanol dehydrogenation which lead to higher surface acetaldehyde concentrations. The higher observed aldol condensation rates and selectivity towards coupled products over copper promoted catalysts were attributed to an increase in surface hydrogen migration and $\mathrm{H}-\mathrm{H}$ recombinative desorption as $\mathrm{H}_{2}$, which occurs rapidly on $\mathrm{Cu}$ sites, compared to non-metal catalysts such as $\mathrm{MgO}$ or $\mathrm{Mg}_{5} \mathrm{CeO}_{\mathrm{x}}$. Hydrogen removal by $\mathrm{Cu}$ allowed active sites required for hydrogen abstraction steps in consecutive chain growth pathways to become available, leading to higher observed rates of butanol formation.

Another approach to enhance the catalytic activity of $\mathrm{MgO}$ is to increase the number of acid-base site pairs on the surface by incorporating acidity into the predominantly basic $\mathrm{MgO}$ lattice. This has been accomplished by synthesizing mixed metal oxides of magnesium and a second metal that is a stronger Lewis acid than magnesium, such as aluminum $(\mathrm{Al})[28,30]$ or zirconium (Zr) [41]. Like metal-base catalysts, materials that contain both acid and base sites (i.e. acid-base bifunctional catalysts) have also been shown to be more effective in ethanol coupling reactions compared to purely basic surfaces. For example, Di Cosimo and co-workers [28] investigated the effect of increasing $\mathrm{Al}$ concentration during ethanol conversion over hydrotalcite derived $\mathrm{Mg}$-Al mixed oxides. The addition of small amounts of $\mathrm{Al}$ to $\mathrm{MgO}$ increased the rate of ethanol dehydrogenation by an order of magnitude, compared to pure $\mathrm{MgO}$. The dehydrogenation of ethanol involves the initial dissociative adsorption of ethanol onto a cooperative acid-base site pair forming a surface ethoxide intermediate that is stabilized by a Lewis acid site (i.e. coordinately unsaturated $\mathrm{Al}^{3+} / \mathrm{Mg}^{2+}$ cations) and proton-like hydrogen coordinated to an adjacent Brønsted base site. The researchers ascribed the poor coupling activity observed over $\mathrm{MgO}$ to isolated strong base sites $\left(\mathrm{O}^{2-}\right)$ that are disproportionate in strength and 
accessibility to the weakly acidic Lewis acid sites on the surface. The addition of $\mathrm{Al}^{3+}$ to $\mathrm{MgO}$ significantly increased the surface density of Lewis acid-strong base site pairs that were catalytically active in rate-limiting dehydrogenation steps, leading to increased rates of formation of acetaldehyde and condensation products. As expected, catalyst samples with high $\mathrm{Al}$ content exhibited characteristic acid-like behavior and favored undesired dehydration products leading to significant ethene and diethyl ether production [28].

Recent studies have demonstrated unusually high activity and high butanol selectivity for the Guerbet coupling of ethanol over hydroxyapatite catalysts [29,42]. Hydroxyapatite catalytic systems represent a new and exciting class of tunable acid-base bifunctional materials for selective coupling of short-chain alcohols.

\subsection{Hydroxyapatite: A highly active and selective catalyst for alcohol coupling}

Calcium hydroxyapatite (HAP; $\left.\mathrm{Ca}_{10}\left(\mathrm{PO}_{4}\right)_{6}(\mathrm{OH})_{2}\right)$ is a naturally occurring mineral and is the main component found in human teeth and bone tissue [43]. For this reason, it is most commonly studied within bioengineering and medical fields for biological applications, mainly as a bioceramic coating material for implants and prosthetics [44]. Other uses of hydroxyapatite include as a chromatography resin for the separation of biomolecules $[45,46]$ and as an acid-base bifunctional catalyst for a variety of chemical reactions [14,47-49].

Hydroxyapatite has a hexagonal crystal structure with $P 6_{3} / m$ space group and unit cell dimensions: $a=b=9.432, c=6.881 \AA$ [50]. The unit cell of stoichiometric HAP contains 10 $\mathrm{Ca}^{2+}$ cations that are divided into two different sites, denoted $\mathrm{Ca}_{\mathrm{I}}$ and $\mathrm{Ca}_{\mathrm{II}}$ as shown in Figure 1.1. There are 4 cations that exist in the $\mathrm{Ca}_{\mathrm{I}}$ site, which are aligned in a column and are sometimes referred to as the "columnar" $\mathrm{Ca}$. These cations are coordinated to 9 oxygens belonging to $\mathrm{PO}_{4}{ }^{3-}$ 
tetrahedra. The remaining 6 cations that make up the HAP unit cell are located in the $\mathrm{Ca}_{\text {II }}$ site and are oriented in two sets of equilateral triangles. These cations are coordinated to 6 phosphate oxygens and 1 oxygen belonging to a hydroxyl group [43,47].

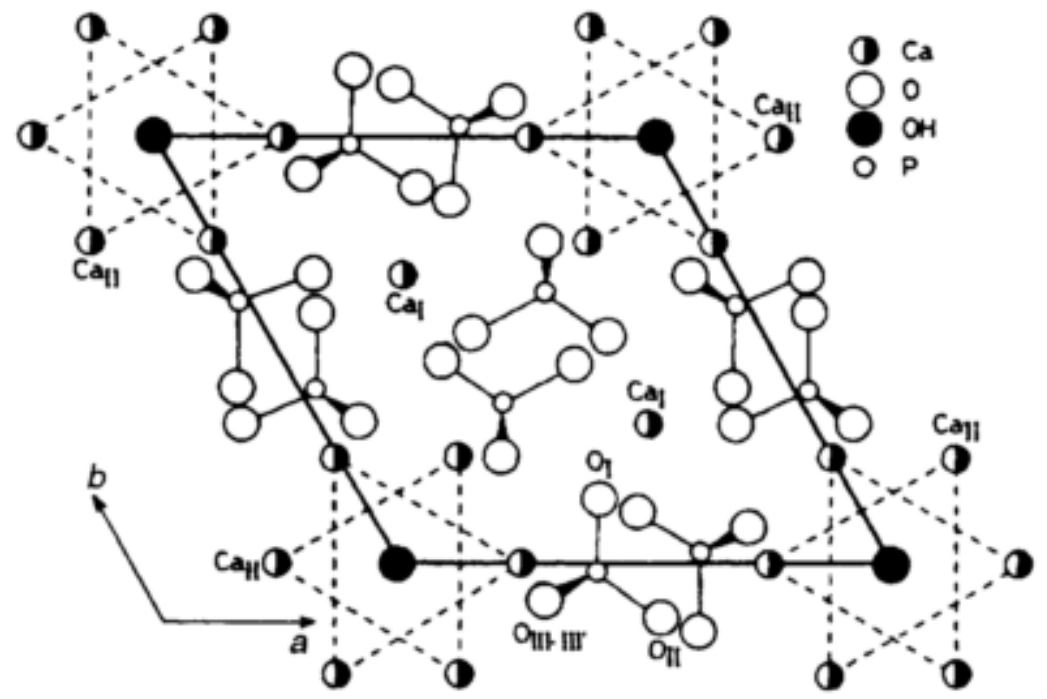

Figure 1.1. Structure of stoichiometric calcium hydroxyapatite projected on the $\boldsymbol{a}, \boldsymbol{b}$ plane [47].

The unit cell of stoichiometric hydroxyapatite has a $\mathrm{Ca} / \mathrm{P}$ molar ratio equal to 1.67 , however, it is susceptible to ion substitutions within its crystal lattice and can therefore easily exist in non-stoichiometric forms as well. The nature and composition of non-stoichiometric HAP, particularly calcium-deficient HAP, was extensively studied and debated in the 1960's and 70's [51-53]. Today, it is generally accepted that the non-stoichiometry of HAP can be represented by the following chemical formula: $\mathrm{Ca}_{10-\mathrm{z}}\left(\mathrm{HPO}_{4}\right)_{\mathrm{z}}\left(\mathrm{PO}_{4}\right)_{6-\mathrm{z}}(\mathrm{OH})_{2-\mathrm{z}} ; 0<\mathrm{z} \leq 1$ giving a $\mathrm{Ca} / \mathrm{P}$ molar ratio that can vary from 1.50 to 1.67 [29,52]. According to this model, as calcium ions are depleted from the HAP structure (decreasing $\mathrm{Ca} / \mathrm{P}$ ratios) the resulting charge imbalance is corrected or neutralized by the addition of protons, as $\mathrm{HPO}_{4}{ }^{2-}$ groups, and the loss of hydroxide ions. The apatite framework is also flexible to cationic substitutions for $\mathrm{Ca}^{2+}\left(\mathrm{Sr}^{2+}\right.$, 
$\left.\mathrm{Ba}^{2+}, \mathrm{Mg}^{2+}, \mathrm{Zn}^{2+}\right)[42,54,55]$, anionic substitutions for $\mathrm{PO}_{4}{ }^{3-}\left(\mathrm{VO}_{4}{ }^{3-}, \mathrm{WO}_{4}{ }^{2-}, \mathrm{SO}_{4}{ }^{2-}\right)[42,56]$, and $\mathrm{OH}^{-}$replacement $\left(\mathrm{F}^{-}, \mathrm{Cl}^{-}\right)[43]$.

Hydroxyapatite exposes both acid and base sites in its crystal lattice. The distribution and strength of these sites are strongly influenced by the $\mathrm{Ca} / \mathrm{P}$ molar ratio of the material, which in turn dictates its catalytic performance in chemical reactions. For example, it is has been shown in the literature that HAP materials with low $\mathrm{Ca} / \mathrm{P}$ surface molar ratios behave primarily as acidic catalysts and facilitate dehydration reactions whereas HAP catalysts with high $\mathrm{Ca} / \mathrm{P}$ molar ratios, close to stoichiometric, exhibit basic properties and favor the dehydrogenation of alcohols over dehydration $[29,48,52,57]$. The ability to easily tune the acid-base surface properties of HAP by varying its $\mathrm{Ca} / \mathrm{P}$ molar ratio allows for product selectivities to be carefully controlled and optimized and provides HAP with the versatility and flexibility to catalyze a wide range of chemical reactions.

In particular, recent reports by Tsuchida et al. [14,29] have demonstrated the exceptional catalytic performance of hydroxyapatite in the Guerbet coupling of ethanol into butanol. Stoichiometric HAP catalyzed the reaction with unusually high activity and high butanol selectivity (70\%) at significantly lower reaction temperatures than what has been previously reported in the literature. However, little is known about why this catalyst is so active and selective towards butanol in the Guerbet coupling of ethanol, which complicates catalyst design and optimization. In particular, the active sites on these materials responsible for butanol formation have not been clearly identified and therefore a detailed, molecular-scale understanding of the reaction mechanism is lacking. 


\subsection{Objectives of This Work}

The overall goal of this work is to develop a fundamental, molecular-level understanding of how hydroxyapatite functions as a catalyst in the Guerbet coupling of ethanol into butanol. In particular, this dissertation strives to advance scientific understanding of the acid-base surface chemistry of ethanol conversion over hydroxyapatite catalysts compared to solid bases, solid acids, and other acid-base bifunctional materials. The specific objectives of this dissertation are outlined below:

1. Synthesize hydroxyapatite materials of varying chemical compositions and investigate the effect of composition on acid-base surface properties and catalytic behavior during reactions of ethanol.

2. Measure intrinsic kinetic parameters (e.g. mean surface residence times, turnover frequencies, surface coverages) of the ethanol coupling reaction over hydroxyapatite, using in situ isotopic labeling techniques.

3. Determine the role of the anion $\left(\mathrm{OH}^{-}\right)$of HAP catalysts and whether it participates in the active site during the ethanol coupling reaction by exploring the activity of fluorine-substituted HAP and metal phosphate catalysts during the reaction.

4. Investigate the effect of water during the steady-state gas-phase conversion of ethanol over HAP compared to $\mathrm{MgO}$ catalysts.

Ethanol conversion studies were conducted at ambient total pressures in a gas-phase, fixed-bed reactor system equipped with an on-line gas chromatograph for product analysis. The nature and composition of the acid and base sites on catalytic surfaces were investigated using analytical techniques such as adsorption microcalorimetry and IR spectroscopy of various adsorbed molecular probes. Results from surface characterization, steady-state reactivity testing of ethanol, and isotopic transient studies were used to identify key structure-function relationships of the catalytic materials. Particular emphasis was made throughout this work on 
gaining a molecular-scale understanding of how the acid-base surface properties of HAP catalysts facilitate all of the steps of the Guerbet sequence, leading to exceptionally high activity and butanol selectivity. This knowledge is paramount for predicting catalytic behavior and makes future catalyst design and optimization more efficient.

\subsection{References}

[1] J.N. Chheda, G.W. Huber, J. a Dumesic, Liquid-phase catalytic processing of biomassderived oxygenated hydrocarbons to fuels and chemicals., Angew. Chem. Int. Ed. Engl. 46 (2007) 7164-7183.

[2] United States Environmental Protection Agency, Renewable Fuel Standard Program, (2016). https://www.epa.gov/renewable-fuels-standards-program.

[3] Renewable Fuels Association, Industry Statistics: World Fuel Ethanol Production, (n.d.). http://www.ethanolrfa.org/resources/industry/statistics/.

[4] N. Savage, Fuel options: the ideal biofuel, Nature. 474 (2011) S9-S11.

[5] A. Galadima, O. Muraza, Catalytic Upgrading of Bioethanol to Fuel Grade Biobutanol: A Review, Ind. Eng. Chem. Res. 54 (2015) 7181-7194.

[6] C. Jin, M. Yao, H. Liu, C.F. Lee, J. Ji, Progress in the production and application of nbutanol as a biofuel, Renew. Sustain. Energy Rev. 15 (2011) 4080-4106.

[7] United States Department of Energy, Alternative Fuels Data Center: Ethanol Production and Distribution, (n.d.). http://www.afdc.energy.gov/fuels/ethanol_production.html.

[8] T. Riittonen, E. Toukoniitty, D.K. Madnani, A.-R. Leino, K. Kordas, M. Szabo, A. Sapi, K. Arve, J. Wärnå, J.-P. Mikkola, One-Pot Liquid-Phase Catalytic Conversion of Ethanol to 1-Butanol over Aluminium Oxide-The Effect of the Active Metal on the Selectivity, Catalysts. 2 (2012) 68-84.

[9] J. Sun, Y. Wang, Recent Advances in Catalytic Conversion of Ethanol to Chemicals, ACS Catal. 4 (2014) 1078-1090.

[10] J.M.R. Gallo, U. Schuchardt, Catalytic Transformations of Ethanol for Biorefineries, 25 (2014) 2229-2243.

[11] I. Elcriton, Elcriton Markets, (n.d.). http://elcriton.com/Markets.html. 
[12] C. Technologies, Butanol's High Value Markets, (n.d.). http://www.cobalttech.com/biobutanol.html.

[13] K. Koda, T. Matsu-ura, Y. Obora, Y. Ishii, Guerbet Reaction of Ethanol to n-Butanol Catalyzed by Iridium Complexes, Chem. Lett. 38 (2009) 838-839.

[14] T. Tsuchida, S. Sakuma, T. Takeguchi, W. Ueda, Direct Synthesis of $\mathrm{n}$-Butanol from Ethanol over Nonstoichiometric Hydroxyapatite, Ind. Eng. Chem. Res. 45 (2006) 86348642.

[15] M. Guerbet, Action des alcools ethylique, isobutylique, isoamylique sur leurs derives sodes, C.R. Acad. Sci. Paris. (1899) 1002-1004.

[16] S. Ogo, A. Onda, K. Yanagisawa, Selective synthesis of 1-butanol from ethanol over strontium phosphate hydroxyapatite catalysts, Appl. Catal. A Gen. 402 (2011) 188-195.

[17] C. Carlini, M. Di Girolamo, A. Macinai, M. Marchionna, M. Noviello, A.M. Raspolli Galletti, G. Sbrana, Selective synthesis of isobutanol by means of the Guerbet reaction:: Part 2. Reaction of methanol/ethanol and methanol/ethanol/n-propanol mixtures over copper based/MeONa catalytic systems, J. Mol. Catal. A Chem. 200 (2003) 137-146.

[18] C. Yang, Z.Y. Meng, Bimolecular condensation of ethanol to 1-butanol catalyzed by alkali cation zeolites, J. Catal. 142 (1993) 37-44.

[19] A.S. Ndou, N. Plint, N.J. Coville, Dimerisation of ethanol to butanol over solid-base catalysts, Appl. Catal. A-Gen. 251 (2003) 337-345.

[20] J.T. Kozlowski, R.J. Davis, Heterogeneous Catalysts for the Guerbet Coupling of Alcohols, ACS Catal. 3 (2013) 1588-1600.

[21] J. Scalbert, F. Thibault-Starzyk, R. Jacquot, D. Morvan, F. Meunier, Ethanol condensation to butanol at high temperatures over a basic heterogeneous catalyst: How relevant is acetaldehyde self-aldolization?, J. Catal. 311 (2014) 28-32.

[22] F. C. Meunier, J. Scalbert, F. Thibault-Starzyk, Unraveling the mechanism of catalytic reactions through combined kinetic and thermodynamic analyses: Application to the condensation of ethanol, Comptes Rendus Chim. 18 (2015) 345-350.

[23] C.L. Kibby, W.K. Hall, Dehydrogenation of Alcohols and Hydrogen Transfer from Alcohols to Ketones Over Hydroxyapatite Catalysts, J. Catal. 31 (1973) 65-73.

[24] M.J.L. Gines, E. Iglesia, Bifunctional condensation reactions of alcohols on basic oxides modified by copper and potassium, J. Catal. 176 (1998) 155-172.

[25] T.W. Birky, J.T. Kozlowski, R.J. Davis, Isotopic transient analysis of the ethanol coupling reaction over magnesia, J. Catal. 298 (2013) 130-137. 
[26] C.R. Ho, S. Shylesh, A.T. Bell, Mechanism and Kinetics of Ethanol Coupling to Butanol over Hydroxyapatite, ACS Catal. 6 (2016) 939-948.

[27] J. Di Cosimo, C. Apesteguía, M. Ginés, E. Iglesia, Structural requirements and reaction pathways in condensation reactions of alcohols on MgyAlOx catalysts, J. Catal. 190 (2000) 261-275.

[28] J.I. Di Cosimo, V.K. Díez, M. Xu, E. Iglesia, C.R. Apesteguía, Structure and Surface and Catalytic Properties of Mg-Al Basic Oxides, J. Catal. 178 (1998) 499-510.

[29] T. Tsuchida, J. Kubo, T. Yoshioka, S. Sakuma, T. Takeguchi, W. Ueda, Reaction of ethanol over hydroxyapatite affected by $\mathrm{Ca} / \mathrm{P}$ ratio of catalyst, J. Catal. 259 (2008) 183189.

[30] M. León, E. Díaz, S. Ordóñez, Ethanol catalytic condensation over Mg-Al mixed oxides derived from hydrotalcites, Catal. Today. 164 (2011) 436-442.

[31] A. Chieregato, J. Velasquez Ochoa, C. Bandinelli, G. Fornasari, F. Cavani, M. Mella, On the chemistry of ethanol on basic oxides: revising mechanisms and intermediates in the Lebedev and Guerbet reactions., ChemSusChem. 8 (2015) 377-88.

[32] I.-C. Marcu, D. Tichit, F. Fajula, N. Tanchoux, Catalytic valorization of bioethanol over Cu-Mg-Al mixed oxide catalysts, Catal. Today. 147 (2009) 231-238.

[33] R.L. Wingad, P.J. Gates, S.T.G. Street, D.F. Wass, Catalytic Conversion of Ethanol to nButanol using Ruthenium P-N ligand complexes, ACS Catal. 5 (2015) 5822-5826.

[34] D. Gabriëls, W.Y. Hernández, B. Sels, P. Van Der Voort, A. Verberckmoes, Review of catalytic systems and thermodynamics for the Guerbet condensation reaction and challenges for biomass valorization, Catal. Sci. Technol. 5 (2015) 3876-3902.

[35] M.E. Sad, M. Neurock, E. Iglesia, Formation of C-C and C-O bonds and oxygen removal in reactions of alkanediols, alkanols, and alkanals on copper catalysts., J. Am. Chem. Soc. 133 (2011) 20384-20398.

[36] Z.D. Young, S. Hanspal, R.J. Davis, Aldol Condensation of Acetaldehyde over Titania, Hydroxyapatite, and Magnesia, ACS Catal. 6 (2016) 3193-3202.

[37] T. Tsuchida, T. Yoshioka, S. Sakuma, T. Takeguchi, W. Ueda, Synthesis of Biogasoline from Ethanol over Hydroxyapatite Catalyst, Ind. Eng. Chem. Res. 47 (2008) 1443-1452.

[38] W. Ueda, T. Kuwabara, T. Ohshida, Y. Morikawa, A low-pressure guerbet reaction over magnesium oxide catalyst, J. Chem. Soc. Chem. Commun. (1990) 1558-1559.

[39] W. Ueda, T. Ohshida, T. Kuwabara, Y. Morikawa, Condensation of alcohol over solidbase catalyst to form higher alcohols, Catal. Letters. 12 (1992) 97-104. 
[40] G.F. Froment, K.B. Bischoff, J. De Wilde, Chemical Reactor Analysis and Design, 3rd ed., John Wiley \& Sons, Inc., 2011.

[41] J.T. Kozlowski, M. Behrens, R. Schlogel, R.J. Davis, Influence of Precipitation Method on Acid-Base-Catalyzed Reactions over Mg-Zr Mixed Oxides, ChemCatChem. 5 (2013) 1989-1997.

[42] S. Ogo, A. Onda, K. Yanagisawa, Selective synthesis of 1-butanol from ethanol over strontium phosphate hydroxyapatite catalysts, Appl. Catal. A-Gen. 402 (2011) 188-195.

[43] J.C. Elliott, Structure and Chemistry of the Apatites and Other Calcium Orthophosphates, ELSEVIER SCIENCE BV, 1994.

[44] Z.H. Cheng, A. Yasukawa, K. Kandori, T. Ishikawa, FTIR Study of Adsorption of CO2 on Nonstoichiometric Calcium Hydroxyapatite, Langmuir. 14 (1998) 6681-6686.

[45] G. Bernardi, [29] Chromatography of Proteins on Hydroxyapatite, Methods Enzymol. (1971) 325-339.

[46] E. Schröder, T. Jönsson, L. Poole, Hydroxyapatite chromatography: altering the phosphate-dependent elution profile of protein as a function of $\mathrm{pH}$, Anal. Biochem. 313 (2003) 176-178.

[47] S. Sugiyama, T. Minami, T. Moriga, H. Hayashi, K. Koto, M. Tanaka, J.B. Moffatd, Surface and bulk properties, catalytic activities and selectivities in methane oxidation on near-stoichiometric calcium hydroxyapatites, J. Mater. Chem. 6 (1996) 459-464.

[48] D. Stošić, S. Bennici, S. Sirotin, C. Calais, J.-L. Couturier, J.-L. Dubois, A. Travert, A. Auroux, Glycerol dehydration over calcium phosphate catalysts: Effect of acidic-basic features on catalytic performance, Appl. Catal. A Gen. 447 (2012) 124-134.

[49] Y. Matsuura, A. Onda, K. Yanagisawa, Selective conversion of lactic acid into acrylic acid over hydroxyapatite catalysts, Catal. Commun. 48 (2014) 5-10.

[50] M.I. Kay, R.A. Young, A.S. Posner, Crystal Structure of Hydroxyapatite, Nature. 204 (1964) 1050-1052.

[51] E.E. Berry, The Structure and Composition of Some Calcium-deficient Apatites, J. Inorg. Nucl. Chem. 29 (1967) 317-327.

[52] S.J. Joris, C.H. Amberg, The Nature of Deficiency in Nonstoichiometric Hydroxyapatites . I . Catalytic Activity of Calcium and Strontium Hydroxyapatites, 75 (1971) 3167-3171.

[53] S.J. Joris, C.H. Amberg, The Nature of Deficiency in Nonstoichiometric Hydroxyapatites . 11 ., 142 (1971) 3172-3178. 
[54] S. Diallo-garcia, D. Laurencin, J. Kra, S. Casale, M.E. Smith, Influence of Magnesium Substitution on the Basic Properties of Hydroxyapatites, (2011) 24317-24327.

[55] R.M.B. Faria, D. V. César, V.M.M. Salim, Surface reactivity of zinc-modified hydroxyapatite, Catal. Today. 133-135 (2008) 168-173.

[56] K. Ramesh, E. Goh, Y. Ling, C.G. Gwie, T.J. White, A. Borgna, Structure and Surface Reactivity of WO $42-$, SO 42 - , PO 43 - Modified Ca- Hydroxyapatite Catalysts and Their Activity in Ethanol Conversion, J. Phys. Chem. C. 116 (2012) 18736-18745.

[57] C.L. Kibby, W.K. Hall, Studies of acid catalyzed reactions XII. Alcohol decomposition over hydroxyapatite catalysts, J. Catal. 29 (1973) 144-159. 


\title{
Chapter 2:
}

\section{Effects of Calcium Hydroxyapatite Composition on the Ethanol Coupling Reaction}

\begin{abstract}
The catalytic conversion of ethanol at $633 \mathrm{~K}$ was investigated over calcium hydroxyapatites $\left(\mathrm{HAP} ; \mathrm{Ca}_{10}\left(\mathrm{PO}_{4}\right)_{6}(\mathrm{OH})_{2}\right)$ of varying chemical composition $(\mathrm{Ca} / \mathrm{P}=1.50,1.66,1.88)$. The acidbase surface properties of the catalysts and product selectivities observed during the reaction were strongly influenced by the $\mathrm{Ca} / \mathrm{P}$ molar ratio of the material. The nearly stoichiometric HAP catalyst (1.66) exposed a high concentration of intermediate-strength acid and base sites, as measured by triethylamine (TEA) and carbon dioxide $\left(\mathrm{CO}_{2}\right)$ adsorption microcalorimetry, respectively, which lead to the highest observed rate and selectivity to butanol (81\%) among all the catalysts tested. High-strength base sites measured on Ca-rich HAP (1.88), likely formed by a well-dispersed $\mathrm{CaO}$ phase at the surface, were disproportionate in strength to surface acid sites and lead to decreased catalytic activity and higher observed acetaldehyde formation, relative to stoichiometric HAP. In contrast, calcium-deficient HAP (1.50) exposed a low surface density of weak base sites and thus the surface acid sites dominated the catalytic performance leading to undesirable acid-catalyzed ethanol dehydration to ethene (70\% selectivity) and diethyl ether. The relative strengths of the active acid and base sites that participate in the Guerbet coupling of ethanol must be carefully balanced to achieve high activity and selectivity to butanol while minimizing unwanted by-product formation. Thus the excellent performance of HAP is likely the result of a high density of acid-base site pairs of balanced strength that facilitate all of the steps in the Guerbet sequence.
\end{abstract}




\subsection{Introduction}

Calcium hydroxyapatite (HAP; $\left.\mathrm{Ca}_{10}\left(\mathrm{PO}_{4}\right)_{6}(\mathrm{OH})_{2}\right)$ is a naturally occurring mineral and is the main constituent in human teeth and bone tissue [1]. For this reason it is most commonly studied in the biological and medical fields for its use as a bioceramic coating material for implants and prosthetics. However, hydroxyapatite has recently generated interest as a heterogeneous catalyst for the production of fuels and commodity chemicals [2-5].

Stoichiometric hydroxyapatite has a $\mathrm{Ca} / \mathrm{P}$ molar ratio equal to 1.67 but it is susceptible to ion substitutions within its crystal lattice and can therefore easily exist in non-stoichiometric forms as well. It is generally accepted that the non-stoichiometry of HAP can be represented by the following chemical formula: $\mathrm{Ca}_{10-\mathrm{z}}\left(\mathrm{HPO}_{4}\right)_{\mathrm{z}}\left(\mathrm{PO}_{4}\right)_{6-\mathrm{z}}(\mathrm{OH})_{2-\mathrm{z}} ; 0<\mathrm{z} \leq 1$ giving a $\mathrm{Ca} / \mathrm{P}$ molar ratio that can vary from 1.50 to $1.67[6,7]$. The catalytic behavior of HAP depends highly on its $\mathrm{Ca} / \mathrm{P}$ molar ratio. For example, it is has been shown in the literature that HAP materials with low $\mathrm{Ca} / \mathrm{P}$ surface molar ratios primarily behave as acidic catalysts whereas HAP catalysts with high $\mathrm{Ca} / \mathrm{P}$ molar ratios tend to exhibit basic catalytic features [8]. The ability to easily tune the acidbase surface properties of HAP by varying its $\mathrm{Ca} / \mathrm{P}$ molar ratio allows for product selectivities to be carefully controlled and optimized and provides HAP with the versatility and flexibility to catalyze a wide range of reactions.

Recent reports by Tsuchida et al. [2,8] have demonstrated the exceptional catalytic performance of hydroxyapatite in the Guerbet coupling of ethanol into butanol. The Guerbet reaction is a multi-step, cascade of reactions that likely involves an initial dehydrogenation step to form acetaldehyde, which then undergoes an aldol self-condensation reaction to crotonaldehyde, followed by hydrogenation of the condensation product to give butanol. Stoichiometric HAP catalyzed the reaction with unusually high activity and high butanol 
selectivity (70\%) at significantly lower reaction temperatures than what has been previously reported in the literature. However, the active sites on these materials have not been identified and therefore a detailed understanding of the reaction mechanism is lacking. Extensive surface characterization of adsorption sites on HAP is critical before active sites can be effectively assigned.

Tsuchida and co-workers investigated HAP catalysts of different $\mathrm{Ca} / \mathrm{P}$ molar ratios (1.59 - 1.67) and observed that varying the chemical composition of the material greatly affected the acid-base surface properties and thus the catalytic behavior during reactions of ethanol [8]. Unfortunately, the characterization and discussion of the acid-base surface properties of the HAP materials in this work were limited. Firstly, acid-base surface characterization was performed using temperature-programmed desorption (TPD) of probe molecules. Although this method is used extensively for catalyst characterization, it has several limitations. Experiments that involve TPD are not performed at thermal equilibrium and thus kinetic parameters will change with changes in temperature and coverage, which may affect desorption processes and quantification of adsorption sites. Additionally, no information was provided in the text regarding the strength of the HAP adsorption sites and thus quantitative information describing the energetics of the hydroxyapatite surface is needed.

Adsorption microcalorimetry is a more thorough and reliable method for acid-base surface characterization that allows for the simultaneous determination of the number and strength of adsorption sites on catalytic surfaces. In this work, adsorption microcalorimetry of carbon dioxide $\left(\mathrm{CO}_{2}\right)$ and triethylamine (TEA) was used for an in-depth comparison of the acidbase surface properties of hydroxyapatite catalysts of varying chemical compositions $(\mathrm{Ca} / \mathrm{P}=$ $1.50,1.66,1.88)$. Surface characterization combined with gas-phase catalytic reactions of ethanol 
were used to identify key composition-reactivity relationships of the HAP catalysts in the Guerbet coupling reaction of ethanol into butanol. A thorough understanding of the nature, density, and strength of acid and base sites on the HAP surface will provide valuable insight into how HAP functions catalytically in alcohol coupling reactions.

\subsection{Experimental Methods}

\subsubsection{Catalyst Preparation}

The stoichiometric calcium hydroxyapatite catalyst was prepared using a controlled coprecipitation method based on the procedure described by Tsuchida et al. [9]. First, two aqueous solutions were prepared: $200 \mathrm{~cm}^{3}$ of $0.5 \mathrm{M}$ calcium nitrate tetrahydrate $\left(\mathrm{Ca}\left(\mathrm{NO}_{3}\right)_{2} \bullet 4 \mathrm{H}_{2} \mathrm{O}\right.$, Acros Organics) and $200 \mathrm{~cm}^{3}$ of $0.3 \mathrm{M}$ diammonium phosphate $\left(\left(\mathrm{NH}_{4}\right)_{2} \mathrm{HPO}_{4}\right.$, Aldrich, >99.99\%). These compositions corresponded to a stoichiometric molar ratio of $\mathrm{Ca} / \mathrm{P}$ (1.67) in the resulting mixed solution. Both solutions, previously adjusted with aqueous ammonia to $\mathrm{pH}=10.5$, were simultaneously added dropwise to a round-bottom glass flask that contained $100 \mathrm{~cm}^{3}$ of distilled deionized water (DDI) held at $353 \mathrm{~K}$. The temperature of the vessel was controlled using a heated silicone oil bath. Sufficient aqueous ammonia was added continuously during the precipitation to maintain a $\mathrm{pH}$ of 10.5 . The resulting suspension was stirred for $24 \mathrm{~h}$ at $353 \mathrm{~K}$ under reflux. The precipitate was recovered by vacuum filtration, washed 3 times with DDI water, and dried in stagnant air at $400 \mathrm{~K}$ overnight.

The calcium-rich, non-stoichiometric hydroxyapatite catalyst $(\mathrm{Ca} / \mathrm{P}=1.88)$ was prepared in the same manner described above, despite the stoichiometric compositions of the precursors. The precursor solutions in this case were not adjusted to a $\mathrm{pH}$ of 10.5 prior to precipitation, which made it more difficult to control the $\mathrm{pH}$ during the synthesis. This likely caused inhomogeneities within the solution that affected the precipitation $\mathrm{pH}$ and thus the composition 
of the final HAP product. The nature and composition of this material is addressed in the Discussion section.

A calcium-deficient, non-stoichiometric hydroxyapatite catalyst $(\mathrm{Ca} / \mathrm{P}=1.50)$ was purchased from Sigma-Aldrich (CAS \#7758-87-4, $\geq 98$ ). All of the HAP powders were calcined at $873 \mathrm{~K}$ for $2 \mathrm{~h}$ in flowing air using a $10 \mathrm{~K} \mathrm{~min}^{-1}$ ramp rate prior to use.

Beta-tricalcium phosphate $\left(\beta\right.$-TCP, $\left.\mathrm{Ca}_{3}\left(\mathrm{PO}_{4}\right)_{2}\right)$ was chosen as a reference phosphate catalyst because of its similar chemical composition to HAP. This material was obtained by heating calcium-deficient hydroxyapatite (Sigma-Aldrich, CAS \#7758-87-4, $\geq 98 \%$ ) in flowing air to $1073 \mathrm{~K}$ using a thermal ramp rate of $2.5 \mathrm{~K} \mathrm{~min}^{-1}$ from room temperature and holding at $1073 \mathrm{~K}$ for $2 \mathrm{~h}$. The phase transformation from calcium-deficient HAP to its low temperature polymorph, $\beta$-TCP, upon heating is well-known and can be described by the following equation [10]:

$$
\mathrm{Ca}_{9}\left(\mathrm{HPO}_{4}\right)\left(\mathrm{PO}_{4}\right)_{5}(\mathrm{OH}) \rightarrow 3 \mathrm{Ca}_{3}\left(\mathrm{PO}_{4}\right)_{2}+\mathrm{H}_{2} \mathrm{O}
$$

Calcium oxide $(\mathrm{CaO}$, Fisher Scientific) and magnesium oxide ( $\mathrm{MgO}$, Ube Material Industries, Ltd) were used as reference solid base metal oxide catalysts. The oxides were calcined at $873 \mathrm{~K}$ for $2 \mathrm{~h}$ in flowing air using a $10 \mathrm{~K} \mathrm{~min}^{-1}$ heating rate from room temperature.

All catalytic materials were compressed under 6 metric tons of weight, crushed, and sieved to $106-180 \mu \mathrm{m}$ pellets prior to characterization and reactivity measurements. 


\subsubsection{Catalyst Characterization}

Crystalline phases of the catalytic materials were confirmed by powder X-ray diffraction (XRD) on a PANalytical X'Pert Pro Multi-Purpose Diffractometer using monochromatic $\mathrm{Cu} \mathrm{K} \alpha$ radiation $(\lambda=1.54 \AA)$. Scans were collected at $2 \theta=10-100^{\circ}$ with a $0.05^{\circ}$ step size. Specific surface areas were obtained by $\mathrm{N}_{2}$ adsorption at $77 \mathrm{~K}$ on a Micromeritics ASAP 2020 automated analyzer using the BET method after evacuation at $723 \mathrm{~K}$ for $4 \mathrm{~h}$.

Elemental analyses of the HAP powders were performed by Galbraith Laboratories, Inc. (Knoxville, TN) using inductively coupled plasma optical emission spectroscopy (ICP-OES) for calcium and phosphorus content in the bulk material. Surface compositions were analyzed by Xray photoelectron spectroscopy (XPS) using a ThermoFisher ESCALab 250 apparatus. The binding energies were corrected using adventitious carbon $(\mathrm{C}(1) \mathrm{s})$ set to a binding energy of $284.6 \mathrm{eV}$.

The acid-base surface properties of the catalysts were characterized using adsorption microcalorimetry of carbon dioxide and triethylamine. The experiments were conducted at $303 \mathrm{~K}$ using a heat-flow microcalorimeter. Experimental procedures [11] as well as a detailed description of the apparatus [12] used for the calorimetry measurements have been reported in previous work. The samples were first outgassed at $773 \mathrm{~K}$ for $16 \mathrm{~h}$ under vacuum to a pressure below $10^{-3}$ Torr then cooled to room temperature. Incremental doses of the gas probe molecule (carbon dioxide and triethylamine) were introduced to the catalyst via a volumetric dosing system and each dose was allowed to equilibrate with the sample for 15 min. Liquid

triethylamine was purified by several freeze-pump-thaw cycles prior to use. Adsorption isotherms and differential enthalpies of adsorption were obtained by measuring the amount of adsorbed species on the catalytic surface and the heats evolved for each dose. 


\subsubsection{Catalytic Reactions of Ethanol}

Catalytic reactions of gas-phase ethanol were conducted using a fixed-bed, stainless steel, tubular reactor (ID: $0.46 \mathrm{~cm}$ ). The catalyst pellets were supported on a quartz wool plug in the reactor tube with a K-type thermocouple positioned at the center of the catalyst bed. Prior to reaction the catalysts were thermally treated in situ at $773 \mathrm{~K}$ for $1 \mathrm{~h}$ in flowing $\mathrm{N}_{2}\left(100 \mathrm{~cm}^{3} \mathrm{~min}^{-1}\right)$ after a $10 \mathrm{~K} \mathrm{~min}^{-1}$ thermal ramp. All catalytic experiments were performed at atmospheric total pressure. Anhydrous ethanol (Aldrich, 99.99\%) was introduced to the $\mathrm{N}_{2}$ carrier gas stream using a liquid syringe pump with a mole fraction of ethanol in the gas phase equal to $7 \%$. Octane was added to the ethanol feed (5 wt.\%) as an internal standard for gas chromatography (GC) analysis. The reactor effluent streams were analyzed using an online Agilent 7890A gas chromatograph equipped with a Varian CP-PoraPLOT Q-HT column (25 m x $0.32 \mathrm{~mm}$ x $10 \mu \mathrm{m})$ and a flame ionization detector.

The peak areas of reactants and products identified by GC were used to determine the ethanol conversion and selectivity of products. The conversion of ethanol was calculated as follows:

$$
\text { conversion }(C \%)=\left(\frac{\sum n_{i} M_{i}}{2 M_{0}}\right) \times 100
$$

where $n_{i}$ is the number of carbon atoms in product $i, M_{i}$ is the molar flow rate of product $i$, and $M_{0}$ is the initial molar flow rate of ethanol. The selectivity towards product $i$ was calculated on the basis of the total number of carbon atoms in the product and is therefore defined as:

$$
\text { selectivity }(C \%)=\left(\frac{n_{i} M_{i}}{\sum n_{i} M_{i}}\right) \times 100
$$




\subsection{Results}

\subsubsection{Catalyst Characterization}

Three different hydroxyapatite materials of varying compositions were investigated: a non-stoichiometric calcium-deficient sample (Ca-def. HAP), a stoichiometric sample (Stoich. HAP), and a calcium enriched sample (Ca-rich HAP). The powder X-ray diffraction patterns of the three HAP materials and $\beta$-TCP are presented in Figure 2.1 The diffraction patterns are consistent with the known hexagonal dipyramidal crystal structure of hydroxyapatite and confirm no other crystalline phases were present. The $\beta$-TCP catalyst was also found to be phase pure and exhibited an XRD pattern that was in agreement with the reference pattern for $\beta$-TCP (ICDD: 00-009-0169). The XRD patterns for the $\mathrm{MgO}$ and $\mathrm{CaO}$ catalysts corresponded to their respective cubic phases with no observable defects (see Figure A.1 of Appendix A).

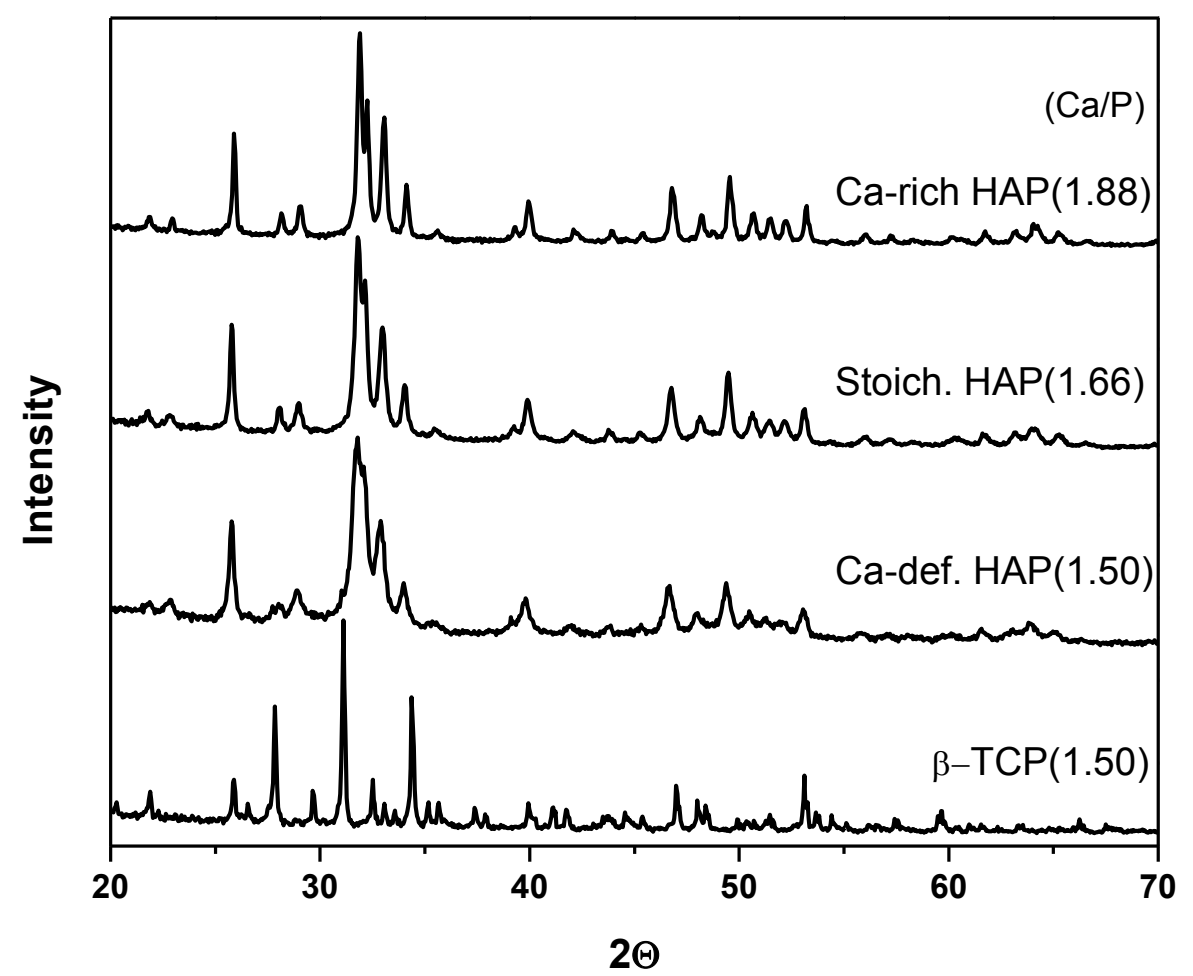

Figure 2.1. Powder $X$-ray diffraction patterns of hydroxyapatite of varying $\mathrm{Ca} / \mathrm{P}$ molar ratios and $\beta$-TCP. Patterns are offset for clarity. 
The BET surface areas of all the catalysts are listed in Table 2.1 along with the bulk and surface chemical compositions of the HAP samples, determined by ICP-OES and XPS, respectively. Surface analysis by XPS revealed that the $\mathrm{Ca} / \mathrm{P}$ surface molar ratios of all three HAP catalysts were lower than those measured in the bulk. This finding appears to be a general characteristic of the HAP material because it is consistently reported in the literature and has been attributed to the presences of excess phosphate ions in the surface layer that cover surface $\mathrm{Ca}^{2+}[4,8,13]$.

Table 2.1. Specific Surface Areas of Catalysts and Results from Elemental Analyses

\begin{tabular}{|c|c|c|c|}
\hline \multirow{2}{*}{ Catalyst } & \multirow{2}{*}{$\underset{\left(\mathbf{m}^{2} \mathbf{g}^{-1}\right)}{S_{\text {BET }}}$} & \multicolumn{2}{|c|}{ Ca/P Molar Ratio } \\
\hline & & Bulk $^{\mathbf{a}}$ & Surface $^{b}$ \\
\hline Ca-rich HAP & 72 & 1.88 & 1.62 \\
\hline Stoich. HAP & 35 & 1.66 & 1.46 \\
\hline Ca-def. HAP & 22 & 1.50 & 1.40 \\
\hline$\beta$-TCP & 5.2 & 1.46 & -- \\
\hline $\mathrm{CaO}$ & 16 & -- & -- \\
\hline $\mathrm{MgO}$ & 35 & -- & -- \\
\hline
\end{tabular}

${ }^{\mathrm{a}}$ Determined by ICP-OES

${ }^{\mathrm{b}}$ Determined by XPS

\subsubsection{Steady-State Conversion of Ethanol}

The steady-state catalytic conversion of ethanol in the gas-phase was investigated over stoichiometric calcium hydroxyapatite $(\mathrm{Ca} / \mathrm{P}=1.66)$ at various flow rates to determine its influence on ethanol conversion. Steady-state conversions of ethanol obtained over Stoich. HAP at 573,593 , and $613 \mathrm{~K}$ are plotted in Figure 2.2 as a function of inverse volumetric flow rate, which is related to reactor space time. The proportionality of the conversion to reactor space time at low conversion confirmed that the reactor could function differentially. At conversions greater than $\sim 7 \%$ at $613 \mathrm{~K}$, the reaction may have been inhibited by products such as water and other 
species. Successive coupling reactions, which are typically observed at higher ethanol conversions and elevated reaction temperatures, can lead to high molecular weight by-products that inhibit the rate of reaction.

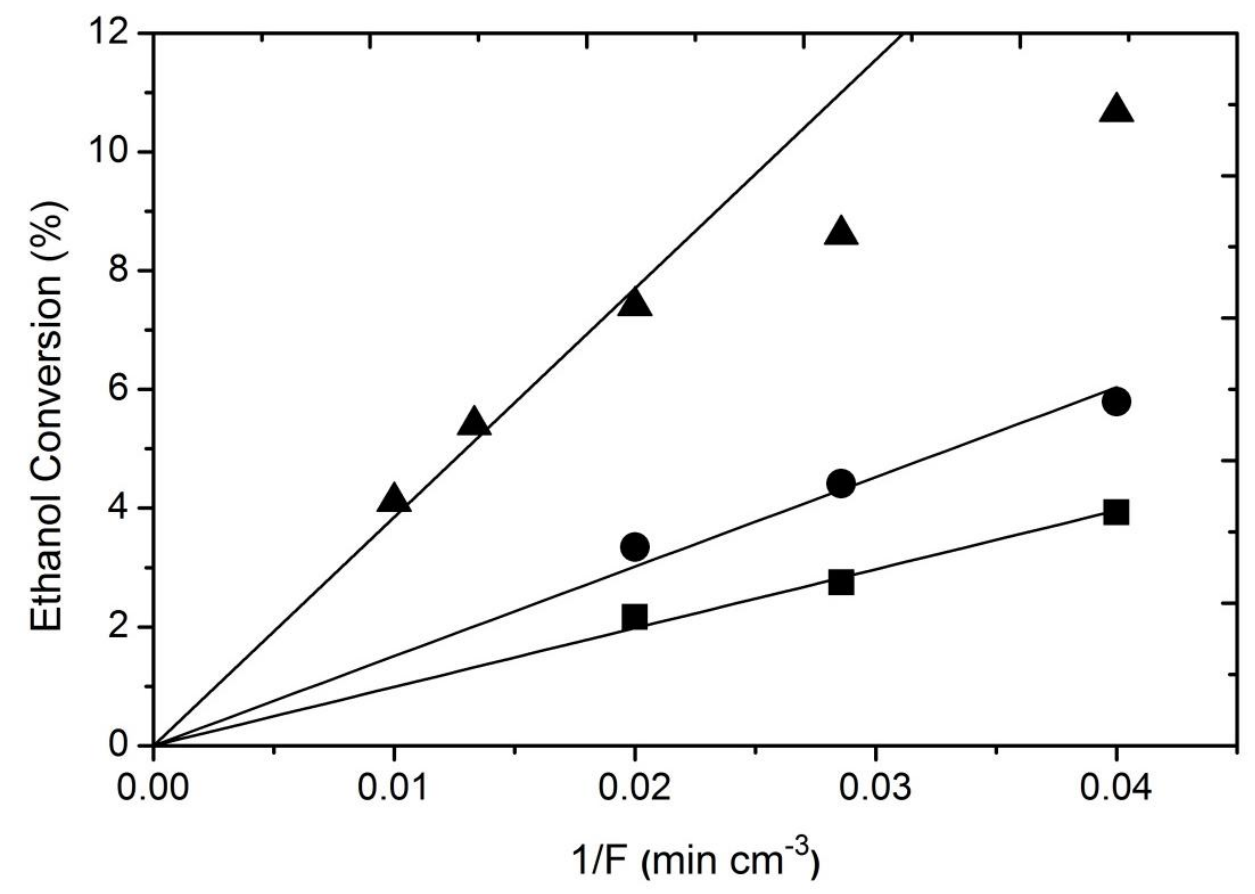

Figure 2.2. Conversion of ethanol as a function of inverse reactant flow rate during the coupling

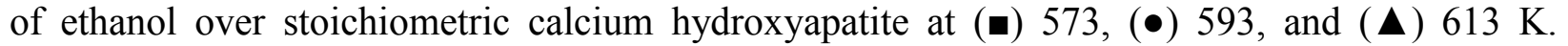
Differential conversion conditions are observed below $\sim 7 \%$ ethanol conversion.

The catalytic performance of stoichiometric $\mathrm{HAP}(\mathrm{Ca} / \mathrm{P}=1.66)$ during reactions of ethanol was compared to hydroxyapatites of varying chemical compositions $(\mathrm{Ca} / \mathrm{P}=1.50,1.88)$, $\beta$-TCP, and solid base metal oxides, $\mathrm{CaO}$ and $\mathrm{MgO}$. The product distributions observed over all the catalysts tested are presented in Table 2.2. The catalytic reactions were conducted at ethanol conversions below $7 \%$ to ensure differential reactor conditions (Fig. 2.2). The reactions over the solid base metal oxide catalysts, $\mathrm{CaO}$ and $\mathrm{MgO}$, were performed at $673 \mathrm{~K}, 40 \mathrm{~K}$ higher than the other catalysts listed in the Table, to obtain comparable levels of ethanol conversion. 
The stoichiometric HAP catalyst exhibited the highest catalytic activity and butanol selectivity (81\%) during the reaction among all of the catalysts tested, thereby confirming its exceptional catalytic performance in the ethanol coupling reaction. A strong influence of the HAP composition was observed on the product distribution and on the rate of reaction. A decrease in the $\mathrm{Ca} / \mathrm{P}$ molar ratio from Stoich. HAP (1.66) to Ca-def. HAP (1.50) resulted in a dramatic shift in the product distribution, leading to $70 \%$ selectivity towards the undesired byproduct ethene, formed via ethanol dehydration. The calcium-deficient material was not catalytically active for butanol formation and the rate of ethanol conversion was significantly lower than that over Stoich. HAP.

An increase in calcium content from Stoich. HAP (1.66) to Ca-rich HAP (1.88) appeared to hinder $\mathrm{C}-\mathrm{C}$ bond formation during ethanol coupling as the selectivity to butanol decreased from $81 \%$ to $53 \%$. The overall rate of ethanol conversion for Ca-rich HAP was similar to Ca-def. $\operatorname{HAP}\left(\sim 1 \times 10^{-8} \mathrm{~mol} \mathrm{~m}^{-2} \mathrm{~s}^{-1}\right)$, but considerably less than that measured over Stoich. HAP $(6.2 \mathrm{x}$ $\left.10^{-8} \mathrm{~mol} \mathrm{~m}^{-2} \mathrm{~s}^{-1}\right)$

The catalytic activity and product distribution observed over $\beta$-TCP during the reaction at $633 \mathrm{~K}$ was similar to that over $\mathrm{MgO}$ at $673 \mathrm{~K}$. Interestingly, compared to Ca-def. HAP, $\beta$-TCP produced much less ethene and no diethyl ether, and was active for butanol formation (22\% selectivity), despite however a similar $\mathrm{Ca} / \mathrm{P}$ molar ratio.

As shown in Table 2.2, the metal oxide catalysts $(\mathrm{CaO}$ and $\mathrm{MgO})$ were significantly less active than the HAP and $\beta$-TCP materials despite a reaction temperature $40 \mathrm{~K}$ higher. The $\mathrm{CaO}$ and $\mathrm{MgO}$ samples exhibited characteristic behavior of solid bases, i.e. catalyzing primarily ethanol dehydrogenation to acetaldehyde. The product of ethanol dehydration, ethene, was also 
observed over these materials in significant quantities (27\% selectivity). While $\mathrm{CaO}$ was inactive for coupling, $\mathrm{MgO}$ produced butanol with $14 \%$ selectivity.

Table 2.2. Catalyst Performance during the Steady-State Conversion of Ethanol

\begin{tabular}{|c|c|c|c|c|c|c|c|c|}
\hline \multirow{2}{*}{ Catalyst } & \multirow{2}{*}{$\begin{array}{c}\text { Bulk } \\
\mathrm{Ca} / \mathbf{P}^{\mathbf{b}}\end{array}$} & \multirow{2}{*}{$\begin{array}{c}\text { Temp. } \\
\text { (K) }\end{array}$} & \multirow{2}{*}{$\begin{array}{c}\text { Ethanol } \\
\text { Conversion } \\
(\%)\end{array}$} & \multirow{2}{*}{$\begin{array}{c}\text { Rate of } \\
\text { Ethanol } \\
\text { Conversion } \\
\left(\mathrm{mol} \mathrm{m}^{-2} \mathbf{s}^{-1}\right)\end{array}$} & \multicolumn{4}{|c|}{ Selectivity (C\%) } \\
\hline & & & & & Ethene & AcH & DEE & $\mathrm{BuOH}$ \\
\hline $\begin{array}{c}\text { Ca-rich } \\
\text { HAP }\end{array}$ & 1.88 & 633 & 4.4 & $1.0 \times 10^{-8}$ & 0 & 47 & 0 & 53 \\
\hline $\begin{array}{c}\text { Stoich. } \\
\text { HAP }\end{array}$ & 1.66 & 633 & 6.3 & $6.2 \times 10^{-8}$ & 0 & 19 & 0 & 81 \\
\hline $\begin{array}{c}\text { Ca-def. } \\
\text { HAP }\end{array}$ & 1.50 & 633 & 4.9 & $1.6 \times 10^{-8}$ & 70 & 23 & 7 & 0 \\
\hline$\beta-\mathrm{TCP}^{\mathrm{a}}$ & 1.46 & 633 & 4.8 & $1.2 \times 10^{-8}$ & 19 & 60 & 0 & 22 \\
\hline $\mathrm{CaO}$ & -- & 673 & 5.1 & $8.4 \times 10^{-9}$ & 27 & 73 & 0 & 0 \\
\hline $\mathrm{MgO}$ & -- & 673 & 4.2 & $1.6 \times 10^{-8}$ & 27 & 60 & 0 & 14 \\
\hline
\end{tabular}

$\mathrm{AcH}$ - Acetaldehyde; DEE - Diethyl ether; $\mathrm{BuOH}$ - Butanol

${ }^{a}$ Calcined at $1073 \mathrm{~K}$ for $2 \mathrm{~h}$ in flowing air, all other catalysts calcined at $873 \mathrm{~K}$ for $2 \mathrm{~h}$ in flowing air

${ }^{\mathrm{b}}$ Determined by ICP-OES

$7 \mathrm{~mol} \%$ initial ethanol concentration

\subsubsection{Adsorption Microcalorimetry of $\mathrm{CO}_{2}$ and TEA}

The nature, density, and strength of the surface acid and base sites on the catalytic materials were characterized using adsorption microcalorimetry of probe molecules at $303 \mathrm{~K}$. In particular, carbon dioxide $\left(\mathrm{CO}_{2}\right)$ was chosen to probe the basicity of the catalysts (Figure 2.3) and triethylamine (TEA) was used to probe the surface acid properties (Figure 2.4).

Isotherms obtained from the adsorption microcalorimetry of $\mathrm{CO}_{2}$ at $303 \mathrm{~K}$ for the materials are presented in Figure 2.3a. The stoichiometric and calcium-rich HAP samples exhibited nearly identical isotherms corresponding to a total $\mathrm{CO}_{2}$ adsorption capacity of $\sim 2.5$ 
$\mu \mathrm{mol} \mathrm{m} \mathrm{m}^{-2}$, which was calculated by extrapolating the physisorption region of the isotherm to zero pressure. The overall $\mathrm{CO}_{2}$ uptake over $\mathrm{MgO}$ was significantly lower at $1.0 \mu \mathrm{mol} \mathrm{m}^{-2}$ suggesting a much higher base site density exists on the stoichiometric and calcium-rich HAP surfaces compared with $\mathrm{MgO}$. The lower $\mathrm{Ca} / \mathrm{P}$ molar ratio materials (i.e. Ca-def. HAP and $\beta$-TCP) exposed less $\mathrm{CO}_{2}$ adsorption sites as indicated by the significantly lower adsorption isotherms, suggesting a small number of base sites present on the surfaces.
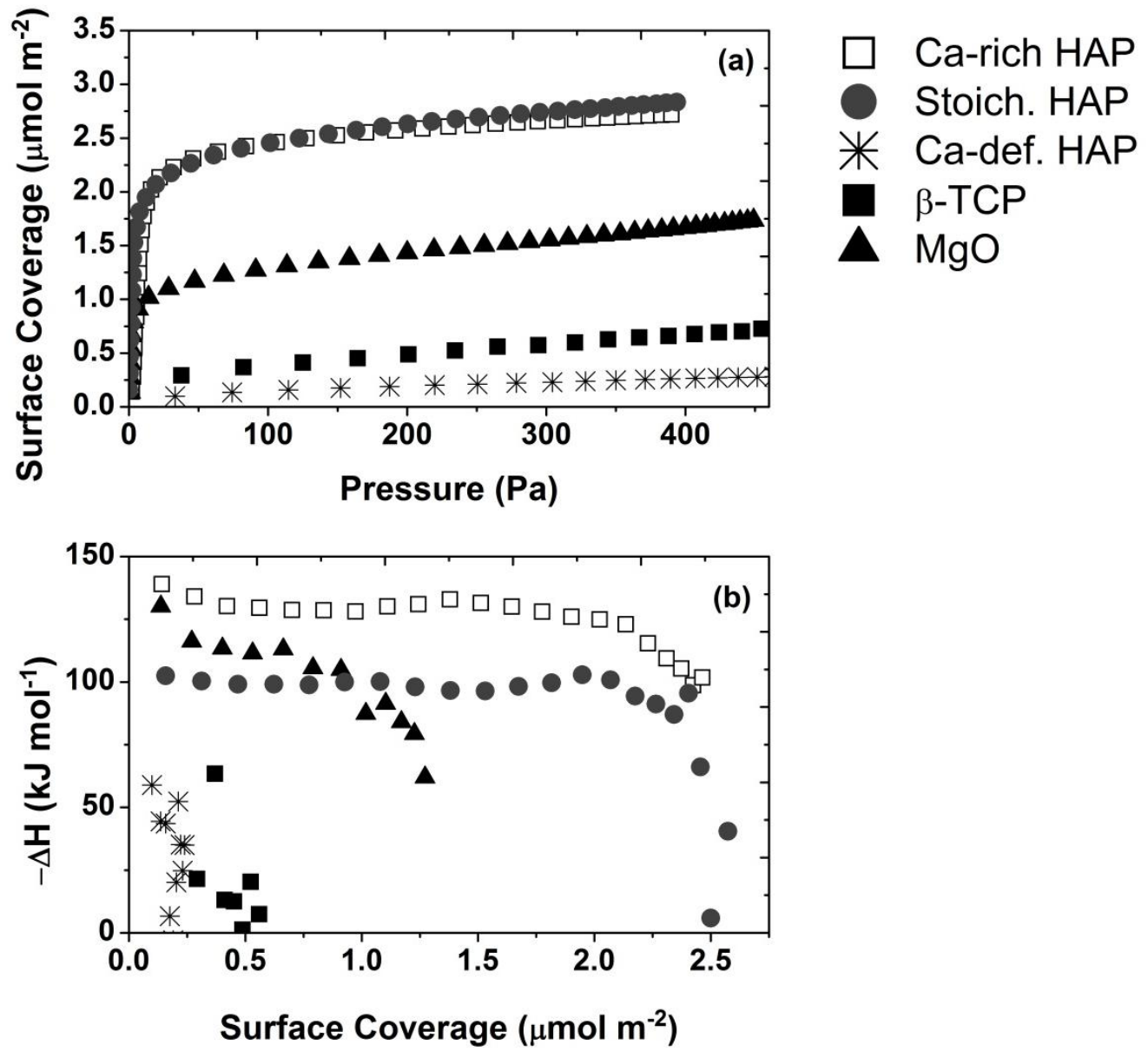

Figure 2.3. Adsorption microcalorimetry of carbon dioxide on the catalytic materials at $303 \mathrm{~K}$; (a) adsorption isotherms of carbon dioxide (b) differential heats of adsorption as a function of coverage. 
Differential heats of $\mathrm{CO}_{2}$ adsorption as a function of surface coverage are presented in Figure 2.3b. Increasing the $\mathrm{Ca} / \mathrm{P}$ molar ratio of $\mathrm{HAP}$ resulted in a corresponding increase in $\mathrm{CO}_{2}$ adsorption energy and presumably base site strength. The Ca-def. HAP and $\beta$-TCP materials exhibited similar initial heats $\left(-\Delta \mathrm{H}_{\mathrm{ads}}\right) \sim 60 \mathrm{~kJ} \mathrm{~mol}^{-1}$ characteristic of very low-strength base sites. Stoichiometric HAP possessed an intermediate-strength basicity with an initial heat of $\mathrm{CO}_{2}$ adsorption of $102 \mathrm{~kJ} \mathrm{~mol}^{-1}$. The $\mathrm{CO}_{2}$ adsorption energies measured on Ca-rich HAP and $\mathrm{MgO}$ were 139 and $130 \mathrm{~kJ} \mathrm{~mol}^{-1}$, respectively implying these surfaces exposed higher-strength base sites that interacted with $\mathrm{CO}_{2}$ relative to stoichiometric HAP.

Adsorption isotherms of TEA measured at $303 \mathrm{~K}$ are plotted in Figure 2.4a. The adsorption of TEA on the $\mathrm{MgO}$ surface resulted in a very low overall TEA uptake with a linear dependence on pressure, which is indicative of weak interactions with the surface. In contrast, the three HAP catalysts were able to chemisorb TEA, indicating the presence of stronger exposed acid sites on these surfaces that interact with TEA compared with $\mathrm{MgO}$. Interestingly, the HAP materials exhibited similar adsorption isotherms and TEA surface capacities $(\sim 1.7 \mu \mathrm{mol}$ $\mathrm{m}^{-2}$ ) despite large differences in chemical composition. The overall TEA uptake appears to be highest on $\beta$-TCP, however, the shape of the curve (i.e. increasing coverage at high pressure) suggests that the isotherm never reached saturation. This observation is also indicative of weak interactions with the surface.

Weak surface interactions between TEA and $\mathrm{MgO} / \beta$-TCP were further demonstrated by the relatively low differential heats of TEA adsorption measured on these materials $(\sim 100 \mathrm{~kJ}$ $\left.\mathrm{mol}^{-1}\right)$ compared with those observed on stoichiometric and Ca-rich HAP $\left(\sim 130 \mathrm{~kJ} \mathrm{~mol}^{-1}\right)$ (Figure 2.4b). The initial heats of TEA adsorption observed over Ca-def. HAP were also indicative of low-strength sites. Strong acid sites on the Ca-def. HAP surface that readily participated in 
ethanol dehydration reactions were likely formed in situ from by-products of the reaction and thus not measured by adsorption microcalorimetry of TEA. This concept is explored in more detail in the Discussion section.
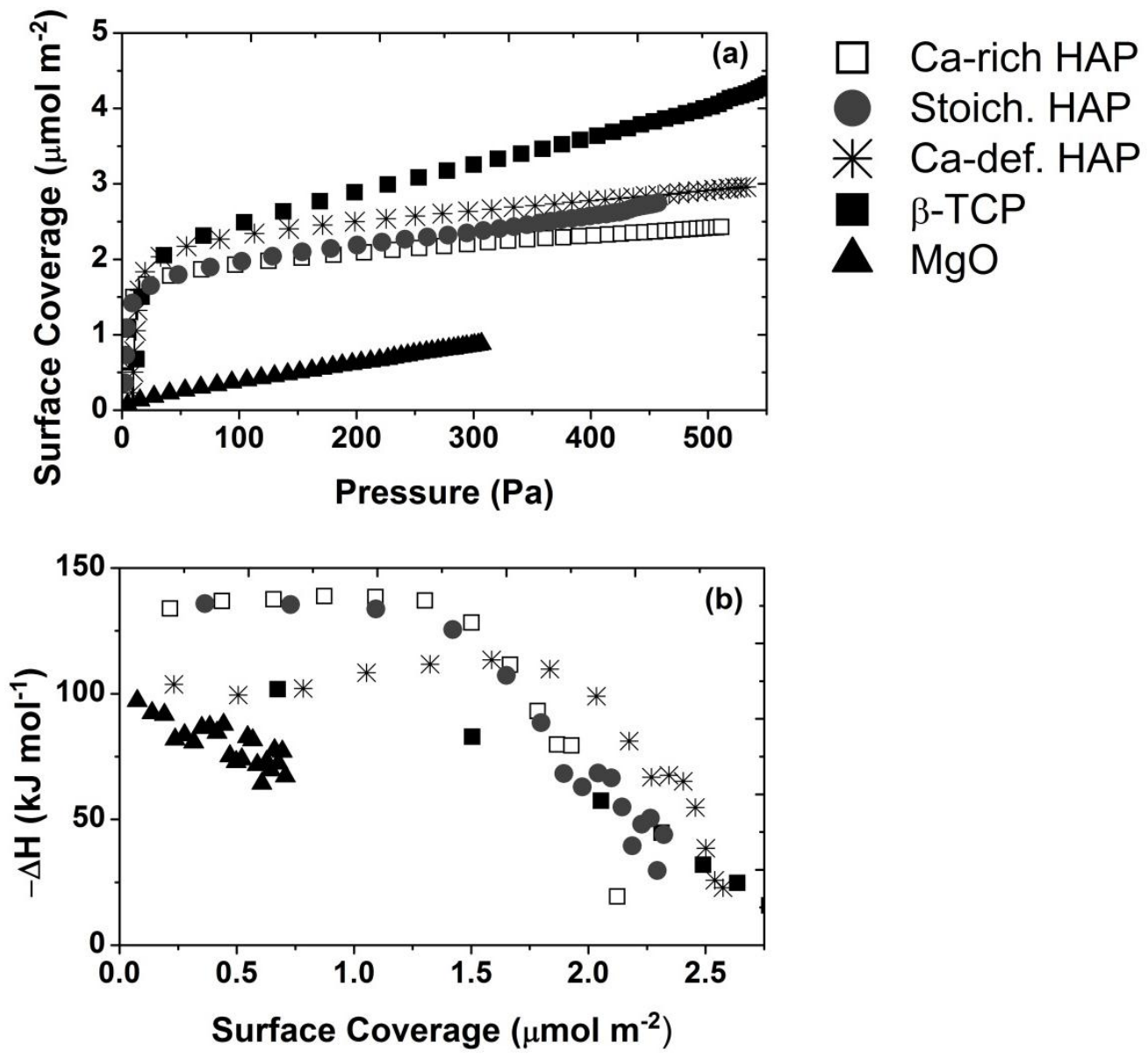

Figure 2.4. Adsorption microcalorimetry of triethylamine (TEA) on the catalytic materials at 303 $\mathrm{K}$; (a) adsorption isotherms of triethylamine (b) differential heats of adsorption as a function of coverage.

\subsection{Discussion}

\subsubsection{Surface Properties and Reactivity of Basic Sites}

Three hydroxyapatite catalysts of varying compositions $(\mathrm{Ca} / \mathrm{P}=1.50,1.66,1.88), \beta-\mathrm{TCP}$, and traditional solid base metal oxides, $\mathrm{CaO}$ and $\mathrm{MgO}$, were investigated in the catalytic 
conversion of ethanol. The nature, density, and strength of surface base sites were characterized using adsorption microcalorimetry of $\mathrm{CO}_{2}$ (Fig. 2.3). The chemical composition of HAP strongly influenced its surface base properties. In a material having high calcium content above stoichiometric (Ca-rich HAP), a high density of strong base sites was observed. Stoichiometric HAP contained intermediate-strength base sites, and HAP surfaces deficient in calcium possessed a low concentration of weak base sites.

The nature and composition of non-stoichiometric HAP, particularly calcium-deficient HAP, has been studied extensively and is of greatest biological and medical concern because the $\mathrm{Ca} / \mathrm{P}$ molar ratio in bone is closer to 1.5 . Calcium-rich hydroxyapatite surfaces, on the other hand, have not been studied in-depth and thus are not well understood. It has been postulated that these materials form a calcium oxide $(\mathrm{CaO})$ layer at the surface leading to calcium enrichment [14]. The XRD pattern of Ca-rich HAP was characteristic of phase pure hydroxyapatite with no observable $\mathrm{CaO}$ features (Fig. 2.1), however, it is possible that a $\mathrm{CaO}$ species was highly dispersed on the HAP surface. The incorporation of a highly basic $\mathrm{CaO}$ phase into HAP would presumably lead to the formation of stronger base sites on the surface relative to stoichiometric HAP, which could explain the significantly higher initial heats of $\mathrm{CO}_{2}$ adsorption observed with Ca-rich HAP compared to Stoich. HAP (Fig. 2.3b). For Sr-hydroxyapatite, an increase in base site strength by increasing the $\mathrm{Sr}$ content from stoichiometric to strontium-rich $(\mathrm{Sr} / \mathrm{P}=1.70)$ was observed by Ogo et al. [14] and was also attributed to a well-dispersed strontium oxide phase at the surface.

The low $\mathrm{Ca} / \mathrm{P}$ materials, Ca-def. HAP and $\beta$-TCP, exposed surfaces with low-strength base sites according to the $\mathrm{CO}_{2}$ adsorption microcalorimetry results (Fig. 2.3b). Infrared spectroscopy has revealed the presence of two adsorption sites on the surface of stoichiometric 
HAP for $\mathrm{CO}_{2}$ : basic $\mathrm{OH}^{-}$and $\mathrm{O}^{2-}$ of $\mathrm{PO}_{4}{ }^{3-}$ groups [15]. The phosphate groups are considerably less basic than the $\mathrm{OH}^{-}$group and thus $\mathrm{CO}_{2}$ predominantly interacts with surface hydroxyls on HAP, forming bicarbonate species [16]. The relative concentration of these sites depends on the $\mathrm{Ca} / \mathrm{P}$ ratio of HAP. Low $\mathrm{Ca} / \mathrm{P}$ ratio materials contain fewer basic $\mathrm{OH}^{-}$groups compared to the stoichiometric HAP surface to maintain charge neutrality. The $\beta$-TCP surface lacks hydroxyl groups altogether $\left(\mathrm{Ca}_{3}\left(\mathrm{PO}_{4}\right)_{2}\right)$ and only contains weakly basic phosphate groups. This accounts for the low concentration of weak base sites measured by $\mathrm{CO}_{2}$ adsorption microcalorimetry on Ca-def. HAP and $\beta$-TCP catalysts (Fig. 2.3).

The steady-state conversion of ethanol over $\mathrm{CaO}$ and $\mathrm{MgO}$ resulted in significantly lower rates than the other catalysts tested and poor selectivity towards the desired product butanol, despite a reaction temperature $40 \mathrm{~K}$ higher (Table 2.2). Adsorption microcalorimetry experiments of $\mathrm{CO}_{2}$ and TEA on $\mathrm{MgO}$ revealed the presence of high strength base sites and very few weak acid sites, respectively. The Guerbet coupling of ethanol to butanol likely proceeds by an acid-base site pair and thus, the poor catalytic performance of metal oxide catalysts in alcohol coupling reactions is likely due to strongly basic $\mathrm{O}^{2-}$ anions that are disproportionate in strength and accessibility to the surface Lewis acid sites provided by coordinately unsaturated cations (i.e. $\left.\mathrm{Ca}^{2+}, \mathrm{Mg}^{2+}\right)$. These strong base sites also catalyzed competing ethanol dehydration reactions via $\mathrm{E}_{\text {1св }}$ pathways that lead to undesired ethene formation (27\% selectivity). Iglesia and co-workers have shown that the addition of aluminum, a stronger Lewis acid than magnesium, to $\mathrm{MgO}$ created a higher density of balanced-strength acid-base site pairs that act as catalytically active sites in rate-limiting dehydrogenation steps, leading to increased ethanol conversion rates and butanol selectivities [17]. 
Like $\mathrm{CaO}$ and $\mathrm{MgO}$, high-strength base sites were also present on Ca-rich HAP indicated by the high heats of $\mathrm{CO}_{2}$ adsorption (Fig. 2.3b), likely due to a well-dispersed $\mathrm{CaO}$ surface layer. However, in contrast to the metal oxide catalysts, the Ca-rich HAP surface shows acid-base bifunctionality with a considerably higher concentration of stronger acid sites measured by TEA adsorption (Fig. 2.4). A higher number of appropriately balanced acid-base site pairs on Ca-rich HAP likely accounts for the higher observed condensation rate and lower ethene formation rate compared to $\mathrm{CaO}$ and $\mathrm{MgO}$.

When compared to stoichiometric HAP, the base sites on Ca-rich HAP were too strong, disproportionate to the strength of the surface acid sites, which lead to higher observed acetaldehyde formation, relative to butanol (Table 2.2). On the other hand, the base sites on Cadef. HAP were too weak. A decrease in the surface basicity from stoichiometric to calcium deficient HAP increased the relative strength of the surface acid sites leading to higher observed rates of acid-catalyzed dehydration. Evidently, the medium-strength base sites found on the Stoich. HAP appears to be optimal for high activity and high butanol selectivity in the ethanol coupling reaction.

\subsubsection{Surface Properties and Reactivity of Acid Sites}

The adsorption microcalorimetry of TEA showed similar surface acid properties for the three HAP catalysts, despite the large differences in product distribution observed during the reaction (Table 2.2). However, when deprived of base sites to balance the acidity as in the case of Ca-def. HAP, where few base sites were measured by $\mathrm{CO}_{2}$ adsorption, the surface acid sites dominated the catalysis leading to undesired acid-catalyzed dehydration reactions with $70 \%$ selectivity towards ethene and $7 \%$ selectivity towards diethyl ether. This observation is 
consistent with the importance of an appropriate combination of both acid and base sites required for the Guerbet coupling reaction.

Ethene formation was observed over Ca-def. HAP and $\beta$-TCP during catalytic reactions of ethanol (Table 2.2). These materials catalyze ethanol dehydration to ethene by two different reaction mechanisms ( $E_{1}$ and $E_{2}$ eliminations), which are governed by the acid-base surface properties of the catalysts (Scheme 2.1). Calcium-deficient hydroxyapatite exhibited the strongest acid-like behavior during the reaction among all of the catalysts tested, favoring the dehydration of ethanol. It is well-known in the literature that HAP catalysts with decreasing $\mathrm{Ca} / \mathrm{P}$ molar ratios correlate with increasing acidity and rates of alcohol dehydration. As calcium ions are depleted from the HAP structure in calcium-deficient materials, the charge imbalance is neutralized by the addition of acidic protons, as $\mathrm{HPO}_{4}{ }^{2-}$ groups, and the loss of basic $\mathrm{OH}^{-}$groups. These acidic phosphate groups have been shown to become deprotonated during high temperature pre-treatment steps, i.e. evacuation at $773 \mathrm{~K}$, so they may not be detectable by adsorption microcalorimetry [18]. They are regenerated in situ through hydrolysis by the water formed in the reaction [18]. The acidic protons likely catalyze ethanol dehydration reactions over calcium-deficient HAP surfaces through an $\mathrm{E}_{1}$ elimination mechanism that involves strong acid sites for carbenium ion formation by $\mathrm{OH}^{-}$abstraction from the alcohol [19].

The dehydration of primary alcohols to olefins over $\beta$-TCP has been shown to occur via $\mathrm{E}_{2}$ elimination pathways [19]. While the $\mathrm{E}_{1}$ mechanism is purely acid-catalyzed, the $\mathrm{E}_{2}$ elimination is a single-step, concerted mechanism that involves a cooperative acid-base pair of equal strength [20]. The acid site involved in the acid-base pair for the $E_{2}$ mechanism should be weaker than the one participating in the $E_{1}$ mechanism and stronger than that of the $E_{1 c B}$ mechanism [20]. 
As mentioned above, acid-base surface characterization revealed that the Ca-def. HAP surface is deprived of base sites and thus the strongly acidic protons on the surface favor the reaction towards the $\mathrm{E}_{1}$ dehydration mechanism leading to ethene as the major reaction product. Conversely, the $\mathrm{MgO}$ surface is weakly acidic and the active acid-base site pair on the surface ( $\mathrm{Mg}-\mathrm{O})$ is largely dominated by the strongly basic $\mathrm{O}^{2-}$ anion, which facilitates ethene formation via $\mathrm{E}_{1 \mathrm{cB}}$ pathways. The acid sites (coordinately unsaturated $\mathrm{Ca}^{2+}$ cations) and base sites (phosphate oxygens) on $\beta$-TCP that make up the acid-base pair are more balanced in strength compared to the Ca-def. HAP and MgO surfaces, which is consistent with the site requirements for the $\mathrm{E}_{2}$ mechanism. These active site pairs promoted $\mathrm{C}-\mathrm{C}$ bond forming steps leading to increased selectivity to butanol and decreased ethene, compared to Ca-def. HAP and MgO. Compared to $\mathrm{MgO}, \beta$-TCP contains base sites of much weaker strength and a significantly higher acid site density. An increased number of balanced-strength acid-base site pairs on the surface allows $\beta$-TCP to catalyze the ethanol conversion reaction at a similar rate as $\mathrm{MgO}$ but at a reaction temperature $40 \mathrm{~K}$ less. This observation is important for future catalyst design and optimization.

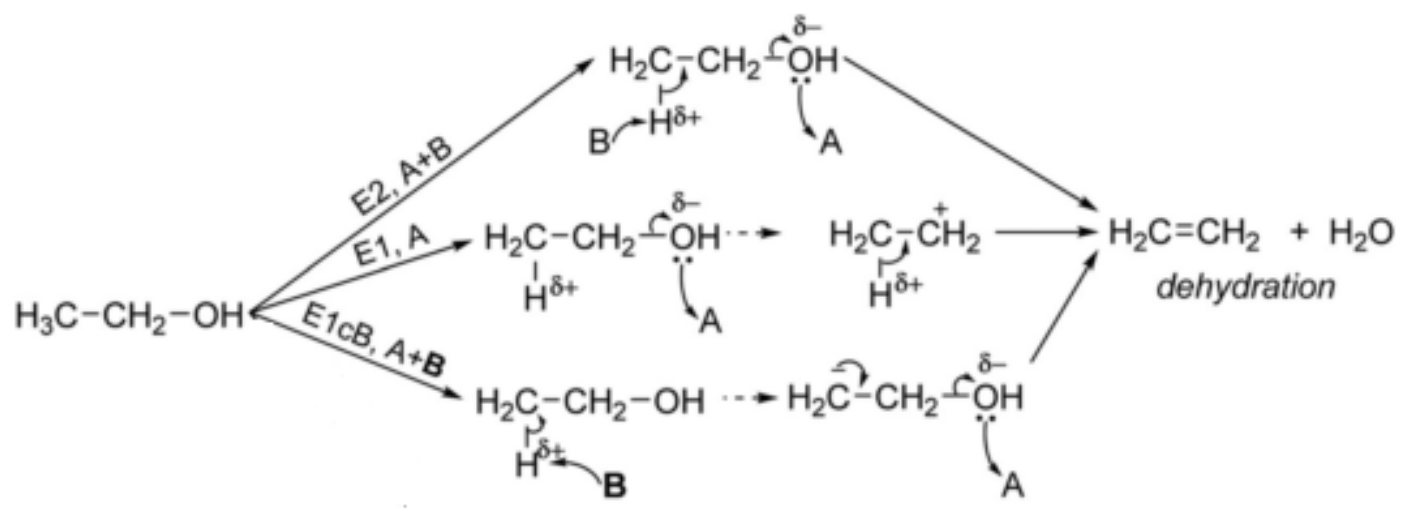

Scheme 2.1. Possible mechanisms of ethanol dehydration. A, B, and $\mathbf{B}$ represents acid, base, and strong base sites, respectively. Adapted from Angelici et al. [21]. 


\subsection{Conclusions}

The Guerbet coupling of ethanol was studied over calcium hydroxyapatite of varying chemical compositions $(\mathrm{Ca} / \mathrm{P}=1.50,1.66,1.80), \beta-\mathrm{TCP}$, and solid base metal oxides, $\mathrm{CaO}$ and $\mathrm{MgO}$. The acid-base surface properties of the catalytic materials were investigated using adsorption microcalorimetry of $\mathrm{CO}_{2}$ and TEA at $303 \mathrm{~K}$ and related to catalytic performance during the steady-state conversion of ethanol.

The distribution and strength of the acid and base sites of HAP were strongly influenced by the $\mathrm{Ca} / \mathrm{P}$ molar ratio of the material, which in turn dictated its catalytic performance during the reaction. An increase in the calcium content of HAP resulted in an increase in the base site strength, as measured by $\mathrm{CO}_{2}$ adsorption microcalorimetry. High-strength base sites on Ca-rich HAP (1.88), likely formed by a well-dispersed $\mathrm{CaO}$ phase at the surface, lead to decreased catalytic activity and butanol selectivity, relative to stoichiometric HAP. In contrast, the Ca-def. HAP surface possessed a very low concentration of weak base sites so that the strong surface acid sites (likely $\mathrm{HPO}_{4}{ }^{2-}$ ) dominated the catalytic performance and lead to undesirable acidcatalyzed ethanol dehydration. Stoichiometric HAP exhibited a high density of intermediatestrength base sites on the surface.

Strong base sites measured over $\mathrm{MgO}$ that were disproportionate in strength and number to surface acid sites, primarily catalyzed dehydrogenation of ethanol to acetaldehyde and exhibited significantly lower rates and relatively poor butanol selectivity than the stoichiometric HAP catalyst. These high-strength base sites were also active for base-catalyzed dehydration of ethanol to ethene. Compared to $\mathrm{MgO}$, stoichiometric HAP contained base sites of much weaker strength and a significantly higher acid site density which likely accounted for its higher catalytic activity and unique butanol selectivity. 
The Guerbet coupling of ethanol to butanol likely proceeds over an acid-base site pair. The relative strengths of the active acid and base sites that are involved in the pair must be carefully balanced to achieve high activity and selectivity to butanol while minimizing unwanted by-product formation. The stoichiometric HAP catalyst was the most active and selective among all of the catalysts tested with $81 \%$ selectivity towards the desired product butanol. This excellent performance is likely the result of a high density of acid-base site pairs of balanced strength that facilitate all of the steps in the Guerbet sequence.

\subsection{References}

[1] J.C. Elliott, Structure and Chemistry of the Apatites and Other Calcium Orthophosphates, ELSEVIER SCIENCE BV, 1994.

[2] T. Tsuchida, S. Sakuma, T. Takeguchi, W. Ueda, Direct Synthesis of n -Butanol from Ethanol over Nonstoichiometric Hydroxyapatite, Ind. Eng. Chem. Res. 45 (2006) 86348642.

[3] S. Sugiyama, T. Minami, T. Moriga, H. Hayashi, K. Koto, M. Tanaka, J.B. Moffatd, Surface and bulk properties, catalytic activities and selectivities in methane oxidation on near-stoichiometric calcium hydroxyapatites, J. Mater. Chem. 6 (1996) 459-464.

[4] D. Stošić, S. Bennici, S. Sirotin, C. Calais, J.-L. Couturier, J.-L. Dubois, A. Travert, A. Auroux, Glycerol dehydration over calcium phosphate catalysts: Effect of acidic-basic features on catalytic performance, Appl. Catal. A Gen. 447 (2012) 124-134.

[5] Y. Matsuura, A. Onda, K. Yanagisawa, Selective conversion of lactic acid into acrylic acid over hydroxyapatite catalysts, Catal. Commun. 48 (2014) 5-10.

[6] E.E. Berry, The Structure and Composition of Some Calcium-deficient Apatites, J. Inorg. Nucl. Chem. 29 (1967) 317-327.

[7] S.J. Joris, C.H. Amberg, The Nature of Deficiency in Nonstoichiometric Hydroxyapatites . I . Catalytic Activity of Calcium and Strontium Hydroxyapatites, 75 (1971) 3167-3171.

[8] T. Tsuchida, J. Kubo, T. Yoshioka, S. Sakuma, T. Takeguchi, W. Ueda, Reaction of ethanol over hydroxyapatite affected by $\mathrm{Ca} / \mathrm{P}$ ratio of catalyst, J. Catal. 259 (2008) 183189. 
[9] T. Tsuchida, J. Kubo, T. Yoshioka, S. Sakuma, T. Takeguchi, W. Ueda, Influence of Preparation Factors on Ca/P Ratio and Surface Basicity of Hydroxyapatite Catalyst, J. Japan Pet. Inst. 52 (2009) 51-59.

[10] I.R. Gibson, I. Rehman, S.M. Best, W. Bonfield, Characterization of the transformation from calcium-deficient apatite to $\beta$-tricalcium phosphate, J. Mater. Sci. Mater. Med. 11 (2000) 799-804.

[11] T.W. Birky, J.T. Kozlowski, R.J. Davis, Isotopic transient analysis of the ethanol coupling reaction over magnesia, J. Catal. 298 (2013) 130-137.

[12] S. Bordawekar, E. Doskocil, R. Davis, Microcalorimetric study of CO2 and NH3 adsorption on Rb-and Sr-modified catalyst supports, Langmuir. 14 (1998) 1734-1738.

[13] H. Tanaka, T. Watanabe, M. Chikazawa, FTIR and TPD studies on the adsorption of pyridine , n-butylamine and acetic acid on calcium hydroxyapatite, 93 (1997) 4377-4381.

[14] S. Ogo, A. Onda, Y. Iwasa, K. Hara, A. Fukuoka, K. Yanagisawa, 1-Butanol synthesis from ethanol over strontium phosphate hydroxyapatite catalysts with various Sr/P ratios, J. Catal. 296 (2012) 24-30.

[15] S. Diallo-garcia, M. Ben Osman, J. Kra, S. Casale, C. Thomas, J. Kubo, Identification of Surface Basic Sites and Acid-Base Pairs of Hydroxyapatite, J. Phys. Chem. C. 118 (2014) 12744-12757.

[16] I.M. Hill, S. Hanspal, Z.D. Young, R.J. Davis, DRIFTS of Probe Molecules Adsorbed on Magnesia, Zirconia, and Hydroxyapatite Catalysts, J. Phys. Chem. C. 119 (2015) 91869197.

[17] J.I. Di Cosimo, V.K. Díez, M. Xu, E. Iglesia, C.R. Apesteguía, Structure and Surface and Catalytic Properties of Mg-Al Basic Oxides, J. Catal. 178 (1998) 499-510.

[18] J.A.S. Bett, L.G. Christner, W.K. Hall, Studies of the Hydrogen Held by Solids. XII. Hydroxyapatite Catalysts, 486 (1967) 5535.

[19] K. Tanabe, M. Misono, Y. Ono, H. Hattori, New Solid Acids and Bases, ELSEVIER SCIENCE BV, 1989.

[20] J.I. Di Cosimo, V.K. Díez, M. Xu, E. Iglesia, C.R. Apesteguía, Structure and Surface and Catalytic Properties of Mg-Al Basic Oxides, J. Catal. 178 (1998) 499-510.

[21] C. Angelici, M.E.Z. Velthoen, B.M. Weckhuysen, P.C.A. Bruijnincx, Influence of acidbase properties on the Lebedev ethanol-to-butadiene process catalyzed by $\mathrm{SiO} 2-\mathrm{MgO}$ materials, Catal. Sci. Technol. 5 (2015) 2869-2879. 


\title{
Chapter 3:
}

\section{Multiproduct Steady-state Isotopic Transient Kinetic Analysis of the Ethanol Coupling Reaction over Hydroxyapatite and Magnesia}

This chapter was previously published as: S. Hanspal, Z.D. Young, H. Shou, and R.J. Davis, "Multiproduct Steady-State Isotopic Transient Kinetic Analysis of the Ethanol Coupling Reaction over Hydroxyapatite and Magnesia," ACS Catalysis 2015, 3, 1737-1746.

\begin{abstract}
The Guerbet coupling of ethanol into butanol was investigated using multiproduct steady-state isotopic transient kinetic analysis (SSITKA) in a comparative study between stoichiometric hydroxyapatite (HAP) and magnesia $(\mathrm{MgO})$ catalysts at 613 and $653 \mathrm{~K}$, respectively. The steady-state catalytic reactions were conducted in a gas-phase, fixed-bed, differential rector at 1.3 atm total system pressure. Multiproduct SSITKA results showed that the mean surface residence time of reactive intermediates leading to acetaldehyde was significantly shorter than that of intermediates leading to butanol on both HAP and $\mathrm{MgO}$. This finding may suggest that the dehydrogenation of ethanol to acetaldehyde is fast on these surfaces compared with C-C bond formation. If adsorbed acetaldehyde is a key reaction intermediate in the Guerbet coupling of ethanol into butanol, then SSITKA revealed that the majority of adsorbed acetaldehyde produced on the surface of $\mathrm{MgO}$ desorbs into the gas-phase, whereas the majority of adsorbed acetaldehyde on HAP likely undergoes sequential aldol-type reactions required for butanol formation. Adsorption microcalorimetry of triethylamine and $\mathrm{CO}_{2}$ showed a significantly higher number of acid and base sites on the surface of HAP compared with on MgO. Diffuse reflectance infrared Fourier transform spectroscopy (DRIFTS) of adsorbed ethanol followed by stepwise temperature-programmed desorption (STPD) revealed that ethoxide is more weakly bound to the
\end{abstract}


HAP surface compared with $\mathrm{MgO}$. A high surface density of acid-base site pairs along with a weak binding affinity for ethanol on HAP may provide a possible explanation for the increased activity and high butanol selectivity observed with HAP compared with $\mathrm{MgO}$ catalysts in the ethanol coupling reaction. 


\subsection{Introduction}

The use of corn-based bioethanol as a domestic and renewable transportation fuel alternative has led to a growth of ethanol production in the United States. This increased availability combined with several drawbacks posed by ethanol as a blend fuel has called attention to its catalytic transformation into a higher-value fuel or chemical such as butanol [1]. Butanol is an important industrial chemical and has recently generated interest as a potential gasoline fuel additive due to its higher energy density relative to ethanol and, thus ability to improve fuel economy for biofuel blended gasoline [1,2].

Butanol is commonly synthesized by hydroformylation via the oxo process. This method uses fossil fuel-derived feedstocks and often requires expensive catalytic materials and extreme reaction pressures, leading to high energy input and substantial operating costs [3,4]. An alternative route to butanol synthesis is the catalytic conversion of bioderived ethanol via the socalled Guerbet reaction.

The Guerbet reaction is a well-known industrial route for higher alcohol synthesis that ultimately couples two short-chain alcohols to produce a longer chain saturated alcohol. The most commonly-accepted reaction sequence for the Guerbet coupling of ethanol involves an initial dehydrogenation step to form acetaldehyde, which then undergoes an aldol condensation reaction, followed by hydrogenation of the resulting unsaturated condensation products to give butanol [5-7].

Alternative reaction pathways for ethanol coupling have been proposed by researchers in the field, primarily those involving a "direct" condensation route without the participation of gasphase acetaldehyde [3,8-11]. This "direct" bimolecular path was verified by Iglesia and coworkers through studies of ${ }^{13} \mathrm{C}$-labeled acetaldehyde reacting with ethanol over $\mathrm{K}-\mathrm{Cu} / \mathrm{MgCeO}_{\mathrm{x}}$ 
catalysts at short contact times, which resulted in a portion of the coupled products being unlabeled, suggesting that ethanol coupling can proceed without the presence of gas-phase acetaldehyde [10]. Recently, Scalbert et al. [11] investigated the role of acetaldehyde selfaldolization in the ethanol coupling reaction over a hydroxyapatite catalyst using a thermodynamic approach, and also found that the reaction primarily proceeds through a "direct" biomolecular route and that aldol condensation of acetaldehyde is a minor pathway in the sequence leading to butanol. The details regarding the "direct" condensation route, as to whether the reaction mechanism involves the direct self-coupling of two ethanol molecules and/or the condensation of ethanol and acetaldehyde, remain unclear and therefore mechanistic studies are still ongoing. For a more comprehensive discussion of Guerbet chemistry including details regarding the reaction mechanism please refer to the recent review paper by Kozlowski and Davis [12].

The ethanol coupling reaction has been extensively studied over a wide range of catalytic materials such as solid base metal oxides $[13,14]$, both unpromoted and modified by transition metal or alkaline earth metal components $[9,10]$, hydrotalcite-derived $\mathrm{Mg}$-Al mixed oxides $[15,16]$, and alkali metal ion-exchanged zeolites $[8,17]$. These catalysts typically require high reaction temperatures $(>673 \mathrm{~K}$ ) and produce butanol with poor selectivities at relatively low rates. Recent studies have demonstrated unusually high activity and high butanol selectivity for the Guerbet coupling of ethanol over hydroxyapatite catalysts $[18,19]$.

The stoichiometric form of hydroxyapatite (HAP, $\left.\mathrm{Ca}_{10}\left(\mathrm{PO}_{4}\right)_{6}(\mathrm{OH})_{2}\right)$ has a $\mathrm{Ca} / \mathrm{P}$ molar ratio equal to 1.67 , however this ratio can vary substantially in synthetic materials. The surfaces of HAP can be acidic or basic in nature depending on the $\mathrm{Ca} / \mathrm{P}$ molar ratio of the material, which in turn influences the catalytic behavior of HAP [20-22]. The active sites on these materials have 
not been identified and therefore a detailed understanding of the reaction mechanism is lacking. In this study, we used steady-state isotopic transient kinetic analysis (SSITKA) of the ethanol coupling reaction over a stoichiometric calcium hydroxyapatite catalyst and compared the results to those obtained with $\mathrm{MgO}$, a standard solid base catalyst, in an effort to gain insight into the reaction mechanism at the active site level.

The SSITKA technique is a well-established and powerful method that allows quantification of important kinetic parameters such as surface coverages of adsorbed reactant species and surface reaction intermediates, average surface lifetimes of those intermediates, and an upper bound of the turnover frequency [23-25]. For additional details regarding the SSITKA technique, see the comprehensive review by Shannon and Goodwin [26]. Recently, our group studied the gas-phase conversion of ethanol to butanol over $\mathrm{MgO}$ at $673 \mathrm{~K}$ using SSITKA; however acetaldehyde could not be followed as an intermediate with the reaction system [27]. In the present work, we have performed a comparative study between stoichiometric hydroxyapatite (HAP) and $\mathrm{MgO}$, using a modified SSITKA reactor system that allows the monitoring of multiple products formed during the reaction.

To relate reactivity results to catalyst properties, adsorption sites on the catalysts were characterized using diffuse reflectance FT-IR spectroscopy (DRIFTS) during stepwise temperature-programmed desorption (STPD) of adsorbed ethanol, as well as adsorption microcalorimetry of carbon dioxide, triethylamine, and ethanol. Results from surface characterization, reactivity testing, and isotopic transient studies were used to propose key structural and compositional properties that facilitate the Guerbet coupling reaction. 


\subsection{Experimental Methods}

\subsubsection{Catalyst Preparation}

The calcium hydroxyapatite catalyst was prepared using a controlled coprecipitation method, based on the procedure described by Tsuchida et al. [28]. First, two aqueous solutions were prepared: $200 \mathrm{~cm}^{3}$ of $0.5 \mathrm{M}$ calcium nitrate tetrahydrate $\left(\mathrm{Ca}\left(\mathrm{NO}_{3}\right)_{2} \bullet 4 \mathrm{H}_{2} \mathrm{O}\right.$, Acros Organics) and $200 \mathrm{~cm}^{3}$ of $0.3 \mathrm{M}$ diammonium phosphate $\left(\left(\mathrm{NH}_{4}\right)_{2} \mathrm{HPO}_{4}\right.$, Aldrich, $\left.>99.99 \%\right)$. These compositions corresponded to a stoichiometric molar ratio of $\mathrm{Ca} / \mathrm{P}(1.67)$ in the resulting mixed solution. Both solutions, previously adjusted with aqueous ammonia to $\mathrm{pH}=10.5$, were simultaneously added dropwise to $100 \mathrm{~cm}^{3}$ of distilled deionized water (DDI) at $353 \mathrm{~K}$. Sufficient aqueous ammonia was added continuously during precipitation to maintain a $\mathrm{pH}$ of 10.5. The resulting suspension was stirred for $24 \mathrm{~h}$ at $353 \mathrm{~K}$. The precipitate was recovered by vacuum filtration, washed 3 times with DDI water, and dried in air at $400 \mathrm{~K}$ overnight.

High-purity and ultrafine $(500 \AA) \mathrm{MgO}$ was obtained commercially (Ube Material Industries, Ltd.). The $\mathrm{MgO}$ and HAP powders were calcined at $873 \mathrm{~K}$ for $2 \mathrm{~h}$ in flowing air, using a $10 \mathrm{~K} \mathrm{~min}^{-1}$ ramp rate, then pressed, crushed and sieved into pellets between $106-180$ $\mu \mathrm{m}$.

\subsubsection{Catalyst Characterization}

Crystalline phases of the catalysts were confirmed by powder X-ray diffraction (XRD) on a PANalytical X'Pert Pro diffractometer using monochromatic $\mathrm{Cu} \operatorname{K\alpha }$ radiation $(\lambda=1.54 \AA$ ). Scans were collected at $2 \theta=20-90^{\circ}$ with a $0.05^{\circ}$ step size.

Specific surfaces areas were obtained by $\mathrm{N}_{2}$ adsorption measured at $77 \mathrm{~K}$ using the BET method on a Micromeritics ASAP 2020 automated analyzer. 
Elemental analysis of the HAP catalyst was performed by Galbraith Laboratories (Knoxville, TN) using inductively coupled plasma optical emission spectroscopy (ICP-OES) for calcium and phosphorus content in the bulk material. The chemical composition on the surface of the HAP sample was analyzed by X-ray photoelectron spectroscopy (XPS) using a ThermoFisher ESCALab 250 apparatus. The signals were referenced to adventitious carbon $(\mathrm{C}(1 \mathrm{~s}))$ at a binding energy of $285.09 \mathrm{eV}$.

\subsubsection{Ethanol Coupling Reactions}

Guerbet coupling of ethanol was performed in a downward flow, fixed-bed, stainless steel tubular reactor (ID: $0.46 \mathrm{~cm})$ at $1.3 \mathrm{~atm}$ total system pressure. The catalyst pellets $(0.2 \mathrm{~g}$ of $\mathrm{MgO}$ or $0.063 \mathrm{~g}$ of HAP) rested upon a packed region of quartz wool in the reactor tube with a thermocouple positioned at the center of the catalytic bed. Prior to reaction, the catalysts were heated in situ to $773 \mathrm{~K}$ at $10 \mathrm{~K} \mathrm{~min}^{-1}$ in flowing $\mathrm{He}\left(50 \mathrm{~cm}^{3} \mathrm{~min}^{-1}\right)$ and held at $773 \mathrm{~K}$ for $1 \mathrm{~h}$. The reactor effluent was analyzed by an online SRI 8610C gas chromatograph equipped with a flame ionization detector (FID). Reactants and products were quantified using a Restek MXT-Q-Bond column (0.53 mm I.D., 30 m length) connected to the FID.

The peak areas of reactants and products identified by GC were used to determine the ethanol conversion and selectivity of products. The conversion of ethanol was calculated as follows:

$$
\text { Conversion }(C \%)=\left(\frac{\sum n_{i} M_{i}}{2}\right) \times 100
$$

where $n_{i}$ is the number of carbon atoms in product $i$ and $M_{i}$ is the molar ratio of product $i$ detected to the initial moles of ethanol. 
The selectivity toward product $i$ was calculated on the basis of the total number of carbon atoms in the product and is therefore defined as:

$$
\text { Selectivity }(C \%)=\frac{n_{i} M_{i}}{\sum n_{i} M_{i}} \times 100
$$

\subsubsection{Multiproduct SSITKA}

A schematic of the reactor system used for the multiproduct SSITKA experiments is shown in Figure 3.1. Details regarding the system were described in previous work from our group [29] so only a brief description is provided here. After achieving steady-state conversion (minimum of $16 \mathrm{~h}$ on stream), an isotopic switch was performed using a Valco 2-postion pneumatic valve, from unlabeled ${ }^{12} \mathrm{C}$ ethanol (anhydrous, Sigma-Aldrich, 99.5\%) to doubly labeled ${ }^{13} \mathrm{C}$ ethanol (Cambridge Isotopes Laboratories, Inc.; 1,2- ${ }^{13} \mathrm{C}, \quad 99 \%$ ). The unlabeled/labeled ethanol were each contained in two identical saturators that were submerged in a heated water bath maintained at $299 \mathrm{~K}$. The ${ }^{13} \mathrm{C}$-labeled ethanol was received with a substantial amount of water (5.89 wt.\%), therefore, 3A molecular sieves (Sigma Aldrich) that were previously treated at $523 \mathrm{~K}$ for several hours in flowing $\mathrm{He}$, were added to the saturator to dehydrate the ethanol. Molecular sieves were also added to the unlabeled ethanol so that the liquid level in both saturators was the same. 


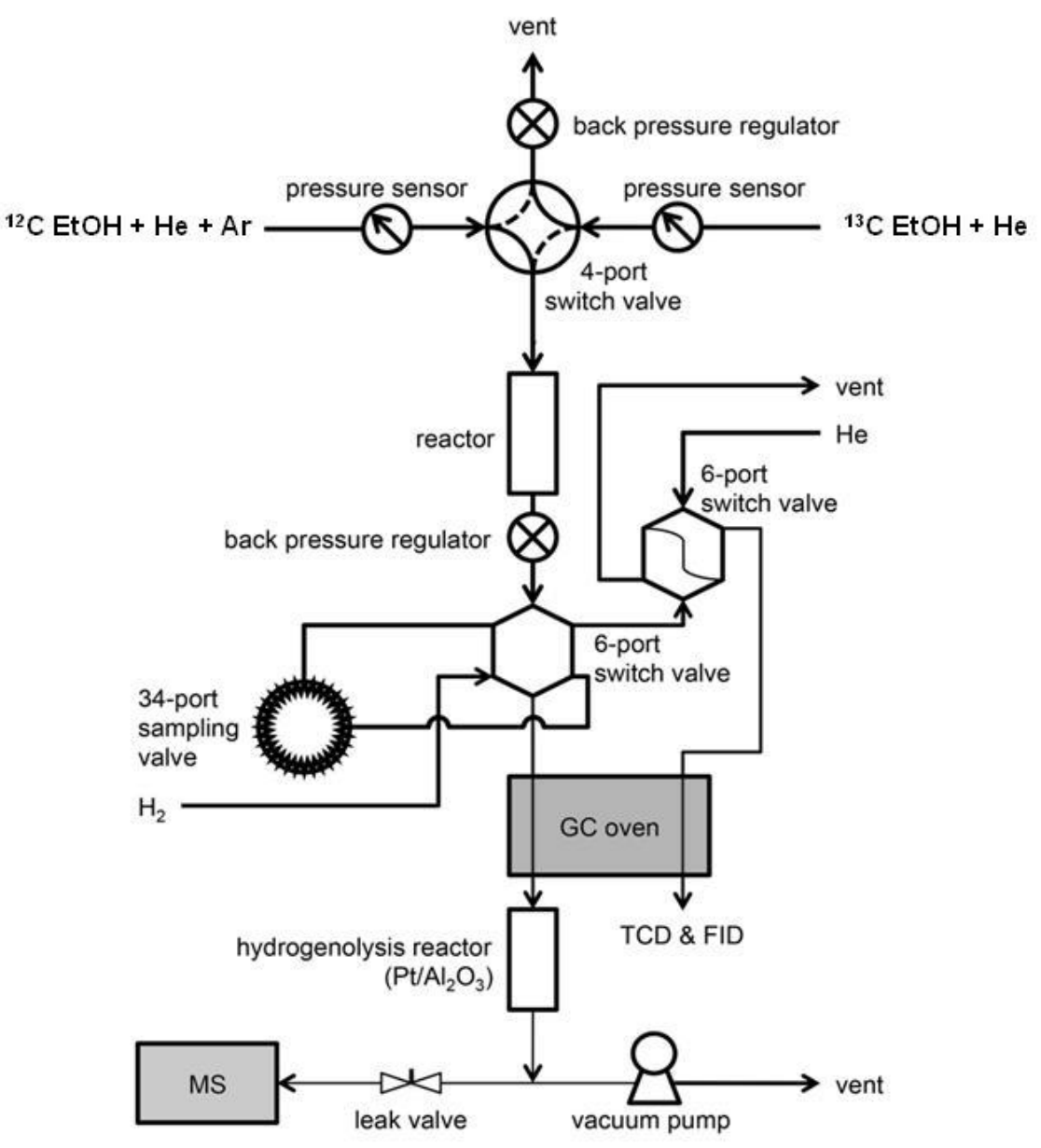

Figure 3.1. Reaction system for multiproduct SSITKA. This figure is adapted from Shou and Davis [29].

Helium (GTS-Welco, 99.999\%) was used as the carrier gas and flowed through the saturators with a mole fraction of ethanol in the gas phase equal to $6.2 \%$. The ${ }^{12} \mathrm{C}$ ethanol gas feed was mixed with an inert argon (GTS-Welco, 99.999\%) tracer (2 vol. \% of the total flow rate) that was used to correct for the gas-phase holdup in the reactor. The SSTIKA experiments were conducted at three different total gas flow rates $\left(30,50\right.$, and $\left.75 \mathrm{~cm}^{3} \mathrm{~min}^{-1}\right)$ to investigate reactant and product readsorption effects. 
The ${ }^{12} \mathrm{C} /{ }^{13} \mathrm{C}$ ethanol switch was achieved without disrupting the steady-state of the reaction by maintaining the reaction temperature as well as the total system pressure at 1.3 atm, with the use of two back pressure regulators positioned at the end of the reactor and the vent line. Following the isotope switch, 16 gas samples of the reactor effluent were collected at various time intervals throughout the transient, using an automated Valco 34-port sampling valve. The samples were injected and separated by gas chromatography (GC). To avoid fragmentation and overlapping issues that are often associated with mass spectrometric (MS) analysis of higher alcohols, the gas samples were passed to a hydrogenolysis reactor held at $673 \mathrm{~K}$ and converted into methane over 5 wt.\% $\mathrm{Pt} / \mathrm{Al}_{2} \mathrm{O}_{3}$ (Sigma Aldrich) after separation by GC and prior to entering the MS (Pfeiffer Vacuum). In the MS, the ion signals for $\mathrm{m} / \mathrm{z}=15\left({ }^{12} \mathrm{CH}_{4}\right)$ and $17\left({ }^{13} \mathrm{CH}_{4}\right)$ were continuously monitored to determine the isotope content of the original gas sample. On the basis of the fragmentation pattern for methane, a portion of the ${ }^{12} \mathrm{CH}_{4}$ signal is attributed to ${ }^{13} \mathrm{CH}_{4}$, therefore, the MS ${ }^{12} \mathrm{CH}_{4}$ responses were all corrected by subtracting the ${ }^{13} \mathrm{CH}_{4}$ contribution.

Figure 3.2 shows an example set of normalized transient response curves for Ar, acetaldehyde, butanol, and ethanol that were obtained following the isotopic switch from ${ }^{12} \mathrm{C}$ ethanol to ${ }^{13} \mathrm{C}$ ethanol during the steady-state reaction of ethanol over HAP at $613 \mathrm{~K}$ at a total flow rate of $50 \mathrm{~cm}^{3} \mathrm{~min}^{-1}$. Transient responses were normalized by the difference between the initial and final ion signals. The argon decay curve was used to determine the gas-phase holdup of the reactor system since we assumed that the inert gas did not adsorb or react on the surface of the catalyst. Therefore, the difference in area under the normalized transient response of each species $\left(F_{i}\right)$ from that of the inert $\operatorname{Ar}$ tracer $\left(F_{A r}\right)$ is equal to the overall mean surface residence time associated with that species $\left(\tau_{i}\right)$ :

$$
\tau_{i}=\int_{0}^{\infty}\left(F_{i}-F_{A r}\right) d t
$$


The surface coverage of reactant or reactive intermediates that lead to a specific product $\left(N_{i}\right)$ can then be determined as follows:

$$
N_{i}=R_{i} \times \tau_{i}
$$

where $R_{i}$ refers to the steady-state flow rate of reactant or the reaction rate to form product $i$.

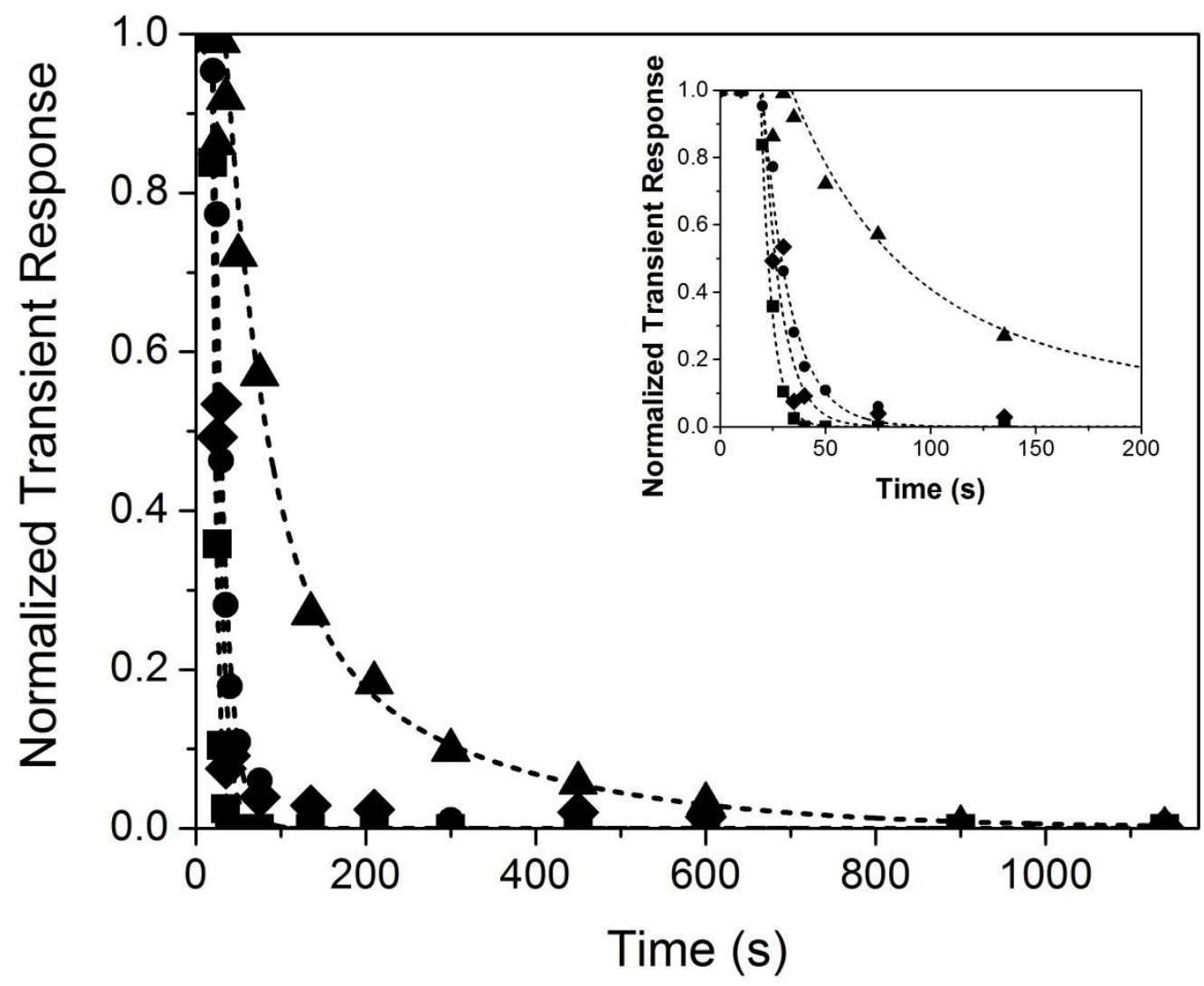

Figure 3.2. Normalized isotopic transient response curves following the switch from unlabeled ethanol to doubly labeled ${ }^{13} \mathrm{C}$-labeled ethanol with a total flow of $50 \mathrm{~cm}^{3} \mathrm{~min}^{-1}$ at $613 \mathrm{~K}$ during the coupling of ethanol over HAP. ( $\boldsymbol{\square})$ argon, ( $)$ acetaldehyde, $(\bullet)$ ethanol, $(\boldsymbol{\Delta})$ butanol. 


\subsubsection{Adsorption Microcalorimetry}

Adsorption sites on HAP and $\mathrm{MgO}$ were characterized using adsorption microcalorimetry of carbon dioxide, triethylamine (TEA), and ethanol. The experiments were conducted at $303 \mathrm{~K}$ using a heat-flow microcalorimeter. Experimental procedures [27] as well as a detailed description of the apparatus [30], used for the calorimetry measurements have been reported in previous work.

In summary, samples were first outgassed at $773 \mathrm{~K}$ for $16 \mathrm{~h}$ under vacuum to a pressure below $10^{-3}$ Torr then cooled to room temperature. Prior to adsorption, the pretreated sample cell was inserted into an isothermal heat block (maintained at $303 \mathrm{~K}$ ) for $2 \mathrm{~h}$ and allowed to thermally equilibrate with the system. Incremental doses of the gas probe molecule (carbon dioxide, triethylamine, ethanol) were introduced to the catalyst via a volumetric dosing system. Liquid TEA and ethanol were purified by several freeze-pump-thaw cycles prior to use. Adsorption isotherms and differential enthalpies of adsorption were obtained by measuring the amount of adsorbed species on the catalytic surface and the heats evolved for each dose.

\subsubsection{Diffuse Reflectance Infrared Fourier Transform Spectroscopy (DRIFTS)}

Stepwise temperature-programmed desorption (STPD) of adsorbed ethanol was investigated in the diffuse reflectance mode on a Bio-Rad (FTS-60A) FTIR spectrometer, equipped with a liquid nitrogen cooled MCT detector. The DRIFTS experiments were conducted using a high-temperature gas reaction chamber (Harrick Scientific) positioned onto a Praying Mantis diffuse reflectance sample accessory. All spectra were obtained by coadding and averaging 100 scans at a spectral resolution of $4 \mathrm{~cm}^{-1}$. 
The STPD measurements were carried out according to the experimental procedure described in detail in previous work by Birky et al. [27] Catalyst samples, diluted in $\mathrm{KBr}$ powder at $1 \mathrm{wt} . \%$ HAP and $5 \mathrm{wt} . \% \mathrm{MgO}$, were loaded into the DRIFTS cell and pretreated in situ at 773 $\mathrm{K}$ for $1 \mathrm{~h}$ in flowing $\mathrm{He}\left(30 \mathrm{~cm}^{3} \mathrm{~min}^{-1}\right)$. The DRIFTS cell was exposed to anhydrous ethanol (Sigma Aldrich) at $303 \mathrm{~K}$ for $15 \mathrm{~min}$ by passing $\mathrm{He}\left(30 \mathrm{~cm}^{3} \mathrm{~min}^{-1}\right)$ through an ethanol saturator followed by purging under He flow $\left(30 \mathrm{~cm}^{3} \mathrm{~min}^{-1}\right)$ for $15 \mathrm{~min}$. The catalyst sample was then heated stepwise to $673 \mathrm{~K}$ at $10 \mathrm{~K} \mathrm{~min}^{-1}$ with IR spectra collected after waiting 15 min at each temperature. The DRIFTS spectrum of the catalyst sample taken at each temperature prior to ethanol adsorption was used as background for each measurement.

\subsection{Results}

\subsubsection{Catalyst Characterization}

Powder X-ray diffraction patterns of the investigated materials are shown in Figure 3.3. The magnesia catalyst (Figure 3.3a) had an XRD pattern that is characteristic of periclase MgO, the cubic form of magnesium oxide. The XRD pattern of the stoichiometric HAP material, prepared via coprecipitation (Figure 3.3b), confirmed that the sample was composed of crystalline hydroxyapatite and that no other phases were present.

The BET surface areas of the HAP and MgO catalysts used for this work are summarized in Table 3.1. Surface analysis by XPS revealed that the HAP material had a lower Ca/P surface molar ratio (1.46) than that measured in the bulk by ICP-OES (1.66). The surface deficiency in calcium is consistent with prior works and is likely due to its susceptibility to lattice substitutions and an ability to assemble in non-stoichiometric forms [18,31,32]. 


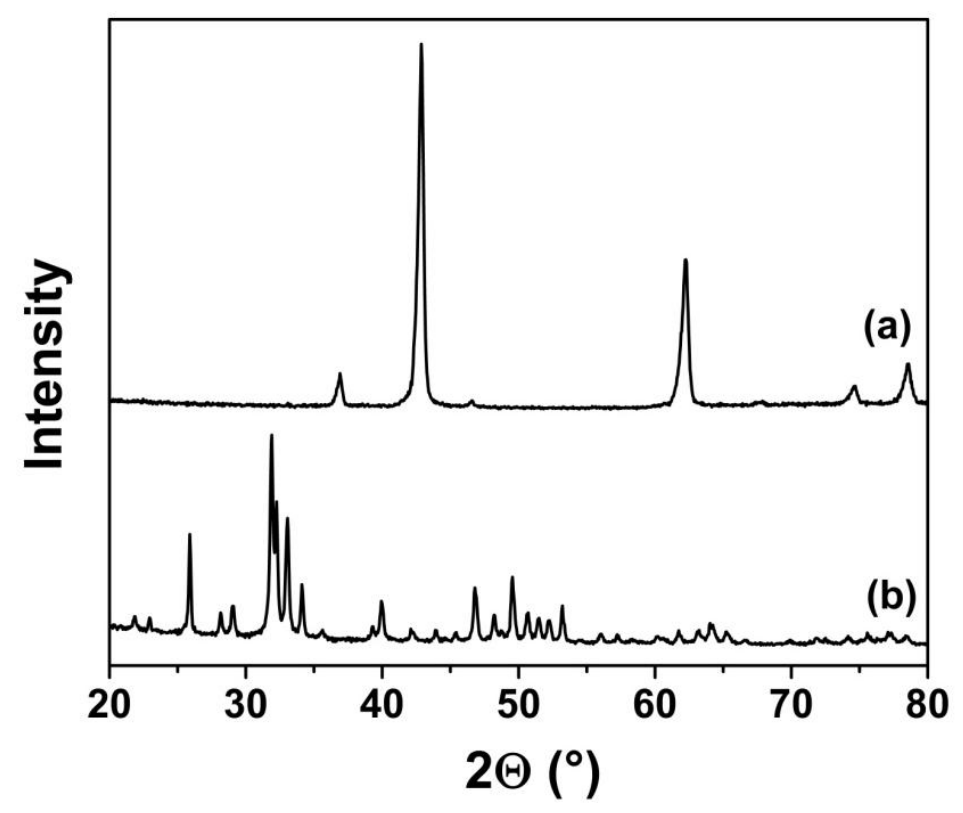

Figure 3.3. X-ray diffraction patterns of (a) $\mathrm{MgO}$ and (b) stoichiometric HAP (catalysts were calcined at $873 \mathrm{~K}$ for $2 \mathrm{~h}$ in air). Patterns are offset for clarity.

Table 3.1. Specific surface areas of stoichiometric hydroxyapatite and magnesia catalysts.

\begin{tabular}{c|c}
\hline Catalyst & $\begin{array}{c}\text { BET Surface Area } \\
\left(\mathbf{m}^{\mathbf{2}} \mathbf{g}^{\mathbf{- 1}}\right)\end{array}$ \\
\hline $\mathrm{HAP}$ & 35 \\
$\mathrm{MgO}$ & 35 \\
\hline
\end{tabular}

\subsubsection{Steady-state Conversion of Ethanol}

The reactivity results obtained during the steady-state conversion of ethanol over $\mathrm{MgO}$ at $653 \mathrm{~K}$ at three different total gas flow rates are presented in Table 3.2. Acetaldehyde, formed via dehydrogenation of ethanol, was the primary product at low ethanol conversion $(<5 \%)$. As conversion increased, the product distribution shifted towards the coupled product, butanol, as expected for a sequential reaction network in which acetaldehyde is a reaction intermediate in the conversion of ethanol into butanol. The dehydration reaction of ethanol to ethene, which is an 
undesired side reaction, was also observed over $\mathrm{MgO}$ at $653 \mathrm{~K}$. The ethene selectivity remained constant $(\sim 10 \%)$ at the reaction conditions tested. Constant ethene selectivity was also observed in previous work by Birky et al. over $\mathrm{MgO}$ at $673 \mathrm{~K}$ over a wide range of ethanol conversions (7$23 \%$ ) [27].

Table 3.2. Product distribution during the catalytic conversion of ethanol over $\mathrm{MgO}$ at $653 \mathrm{~K}$.

\begin{tabular}{|c|c|c|c|c|c|}
\hline \multirow{2}{*}{$\begin{array}{c}\text { Total } \\
\text { flow rate } \\
\left(\mathrm{cm}^{3} \text { min }^{-1}\right)\end{array}$} & \multirow{2}{*}{$\begin{array}{c}\text { Ethanol } \\
\text { conversion } \\
(\%)\end{array}$} & \multirow{2}{*}{$\begin{array}{c}\text { Rate of } \\
\text { ethanol } \\
\text { conversion } \\
\left(\mathrm{mol} \mathrm{m}^{-2} \mathrm{~s}^{-1}\right)\end{array}$} & \multicolumn{3}{|c|}{ Selectivity (C\%) } \\
\hline & & & Ethene & Acetaldehyde & Butanol \\
\hline 30 & 7.9 & $1.5 \times 10^{-8}$ & 11 & 49 & 40 \\
\hline 50 & 4.5 & $1.4 \times 10^{-8}$ & 12 & 67 & 21 \\
\hline 75 & 3.7 & $1.7 \times 10^{-8}$ & 13 & 67 & 20 \\
\hline
\end{tabular}

Catalyst loading: $0.2 \mathrm{~g} ; \mathrm{T}=653 \mathrm{~K}$; total system pressure $=1.3 \mathrm{~atm}$.

Table 3.3 presents the analogous results obtained from the steady-state reaction of ethanol over stoichiometric hydroxyapatite at $613 \mathrm{~K}$ at three different total flow rates. Butanol was the major product observed at all three conditions with selectivities towards the coupled product greater than $60 \%$ even at conversions as low as $3.2 \%$. The dehydrated side product ethene was a minor product observed during the coupling of ethanol over HAP with a selectivity of only $1 \%$ at the reaction conditions investigated. It should also be noted that the temperature of the reaction over HAP $(613 \mathrm{~K})$ was $40 \mathrm{~K}$ lower than that over $\mathrm{MgO}$ and even at the lower temperature, the HAP catalyst was about $300 \%$ more active in the ethanol coupling reaction than $\mathrm{MgO}$ on a surface area basis (Tables 3.2, 3.3). 
Table 3.3. Product distribution during the catalytic conversion of ethanol over stoichiometric HAP at $613 \mathrm{~K}$.

\begin{tabular}{|c|c|c|c|c|c|}
\hline \multirow{2}{*}{$\begin{array}{c}\text { Total } \\
\text { flow rate } \\
\left(\mathrm{cm}^{3} \mathrm{~min}^{-1}\right)\end{array}$} & \multirow{2}{*}{$\begin{array}{c}\text { Ethanol } \\
\text { conversion } \\
(\%)\end{array}$} & \multirow{2}{*}{$\begin{array}{c}\begin{array}{c}\text { Rate of } \\
\text { ethanol }\end{array} \\
\text { conversion } \\
\left(\mathrm{mol} \mathrm{m}^{-2} \mathbf{s}^{-1}\right)\end{array}$} & \multicolumn{3}{|c|}{ Selectivity (C\%) } \\
\hline & & & Ethene & Acetaldehyde & Butanol \\
\hline 30 & 6.6 & $4.1 \times 10^{-8}$ & 1 & 24 & 75 \\
\hline 50 & 4.3 & $4.4 \times 10^{-8}$ & 1 & 32 & 67 \\
\hline 75 & 3.2 & $5.0 \times 10^{-8}$ & 1 & 36 & 63 \\
\hline
\end{tabular}

Catalyst loading: $0.06 \mathrm{~g} ; \mathrm{T}=613 \mathrm{~K}$; total system pressure $=1.3 \mathrm{~atm}$.

Ethanol conversions obtained during the steady-state Guerbet coupling of ethanol over $\mathrm{HAP}$ and $\mathrm{MgO}$ are plotted in Figure 3.4 as a function of inverse volumetric flow rate, which is proportional to reactor space time. Linearity of the results confirms that the reactor was operated differentially with respect to ethanol conversion.

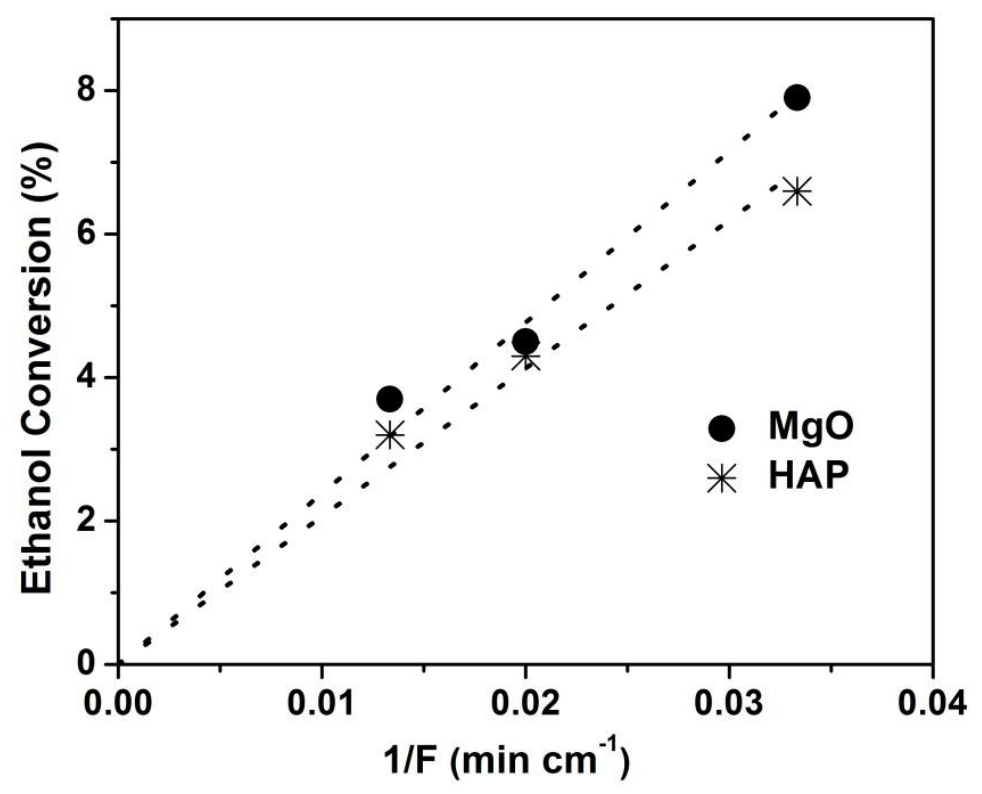

Figure 3.4. The conversion of ethanol as a function of inverse reactant flow rate during the coupling of ethanol over $\mathrm{MgO}$ and stoichiometric HAP at $653 \mathrm{~K}$ and $613 \mathrm{~K}$, respectively. The observed linear dependence confirms differential reactor conditions. 


\subsubsection{Multiproduct SSITKA}

Multiproduct SSITKA measurements during the Guerbet coupling of ethanol over $\mathrm{MgO}$ and HAP allowed for the quantification of important kinetic parameters of the reaction such as surface concentrations of reaction intermediates $\left(\mathrm{N}_{\mathrm{i}}\right)$, mean surface residence times of adsorbed species $(\tau)$, and an approximation for the intrinsic turnover frequencies of the catalyic cycle.

The average surface residence time and surface coverage of ethanol on $\mathrm{MgO}$ and $\mathrm{HAP}$ with varying flow rate are summarized in Table 3.4. The surface coverage of ethanol on $\mathrm{MgO}$ was about $5.0 \times 10^{-6} \mathrm{~mol} \mathrm{~m}^{-2}$ (between 4.5 and $5.7 \times 10^{-6} \mathrm{~mol} \mathrm{~m}^{-2}$ ) regardless of total flow rate, which agrees well with results obtained previously in our lab on $\mathrm{MgO}$ at $673 \mathrm{~K}$ [27]. Significantly higher surface coverages of ethanol were observed on HAP at $613 \mathrm{~K}$. Since a lower temperature and a smaller HAP sample mass loading relative to $\mathrm{MgO}$ were required to maintain low conversion, the interaction of ethanol with the reactor system walls and quartz wool plug would be relatively more important in the HAP experiments. A blank SSITKA experiment was thus performed at the two highest flowrates (50 and $75 \mathrm{~cm}^{3} \mathrm{~min}^{-1}$ ) to determine the surface residence time of the ethanol in the system. The time associated with the blank reactor was then subtracted from $\tau_{\text {ethanol }}$ to give a "corrected" $\tau$ at each flow rate $\left(50\right.$ and $\left.75 \mathrm{~cm}^{3} \mathrm{~min}^{-1}\right)$ which was used to calculate a "corrected" value of ethanol surface coverage that accounts for ethanol adsorption in the reactor system (Table 3.4). Evidently, the surface coverage of ethanol was similar on both $\mathrm{MgO}$ and $\mathrm{HAP}$, at $\sim 5.0 \times 10^{-6} \mathrm{~mol} \mathrm{~m}^{-2}$.

Figure 3.5 compares the normalized transient decays for ${ }^{12} \mathrm{C}$-unlabeled butanol obtained over HAP to that obtained over $\mathrm{MgO}$, during the steady-state reaction of ethanol following a switch from ${ }^{12} \mathrm{C}$-labeled ethanol to ${ }^{13} \mathrm{C}$-labeled ethanol. The butanol response curves presented in Figure 3.5 were fit with a two-term exponential decay function. The ${ }^{12} \mathrm{C}$ butanol signal observed 
with the HAP catalyst exhibited a slow decay which did not fully reach background level until after $900 \mathrm{~s}$. The butanol transient over $\mathrm{MgO}$, on the other hand, was completed after only $300 \mathrm{~s}$.

Table 3.4. Time constants and surface coverages of ethanol $\left(\mathrm{N}_{\text {ethanol }}\right)$ during the steady-state Guerbet coupling of ethanol over $\mathrm{MgO}$ and HAP at 653 and $613 \mathrm{~K}$, respectively.

\begin{tabular}{|c|c|c|c|c|c|}
\hline \multirow{2}{*}{$\begin{array}{l}\text { Total Flow Rate } \\
\qquad\left(\mathrm{cm}^{3} \mathrm{~min}^{-1}\right)\end{array}$} & \multicolumn{2}{|c|}{$\begin{array}{c}\tau_{\text {ethanol }} \\
(\mathbf{s})\end{array}$} & \multicolumn{3}{|c|}{$\begin{array}{c}\text { Coverage of Ethanol } \\
\mathrm{N}_{\text {ethanol }}\left(\mathrm{mol} \mathrm{m}^{-2}\right)\end{array}$} \\
\hline & $\begin{array}{l}\mathrm{MgO} \\
(653 \mathrm{~K})\end{array}$ & $\begin{array}{l}\text { HAP } \\
(613 \mathrm{~K})\end{array}$ & $\begin{array}{c}\mathrm{MgO} \\
(653 \mathrm{~K})\end{array}$ & $\begin{array}{l}\text { HAP } \\
(613 \mathrm{~K})\end{array}$ & $\begin{array}{c}\text { HAP (corrected) } \\
(613 \mathrm{~K})\end{array}$ \\
\hline 30 & 25 & 43 & $4.8 \times 10^{-6}$ & $2.7 \times 10^{-5}$ & 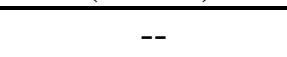 \\
\hline 50 & 18 & 8.8 & $5.7 \times 10^{-6}$ & $9.1 \times 10^{-6}$ & $3.9 \times 10^{-6}$ \\
\hline 75 & 10 & 7.1 & $4.5 \times 10^{-6}$ & $1.1 \times 10^{-5}$ & $5.0 \times 10^{-6}$ \\
\hline
\end{tabular}

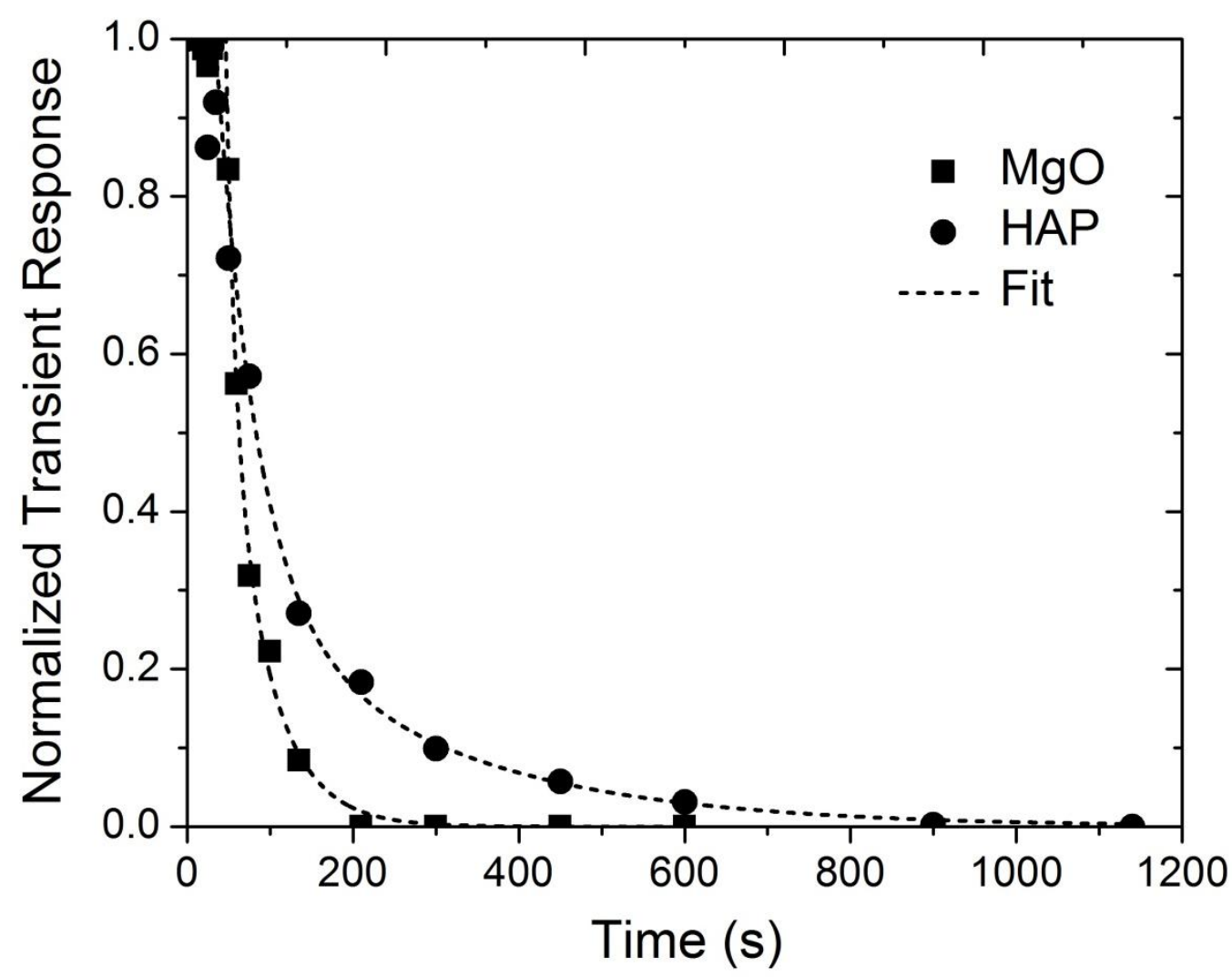

Figure 3.5. Normalized isotopic transient response curves for butanol following the switch from unlabeled ethanol to doubly labeled ${ }^{13} \mathrm{C}$-labeled ethanol with a total flow of $50 \mathrm{~cm}^{3} \mathrm{~min}^{-1}$ during the coupling of ethanol over $\mathrm{MgO}$ at $653 \mathrm{~K}$ and HAP at $613 \mathrm{~K}$. Curves have been fit using a twoterm exponential decay function. 
Mean surface residence times as well as coverages of surface intermediates that led to acetaldehyde and butanol are summarized in Tables 3.5 and 3.6, respectively. For both $\mathrm{MgO}$ and HAP, the average surface lifetime of reactive intermediates leading to acetaldehyde was much shorter than that leading to butanol. Stated another way, it took a significantly longer time for butanol to exit the reactor compared to acetaldehyde. The surface coverage of reaction intermediates leading to acetaldehyde relative to butanol on the two catalysts also provides valuable information. On $\mathrm{MgO}$, there was a higher number of intermediates that led to acetaldehyde compared to those that lead to butanol $\left(\mathrm{N}_{\mathrm{AcH}}>\mathrm{N}_{\mathrm{BuOH}}\right)$, whereas the opposite trend was observed over HAP $\left(\mathrm{N}_{\mathrm{BuOH}} \gg>\mathrm{N}_{\mathrm{AcH}}\right)$. Moreover, Table 3.6 indicates the surface density of adsorbed intermediates leading to butanol was orders of magnitude greater on HAP than on $\mathrm{MgO}$ at all three flowrates investigated.

Table 3.5. Time constants and surface coverages of reactive intermediates leading to acetaldehyde $\left(\mathrm{N}_{\mathrm{AcH}}\right)$ during the steay-state Guerbet coupling of ethanol over $\mathrm{MgO}$ and $\mathrm{HAP}$ at 653 and $613 \mathrm{~K}$, respectively.

\begin{tabular}{c|cc|cc}
\hline \multirow{2}{*}{$\begin{array}{c}\text { Total Flow Rate } \\
\left(\mathbf{c m}^{\mathbf{3}} \mathbf{~ m i n}^{-1}\right)\end{array}$} & \multicolumn{2}{|c|}{$\begin{array}{c}\boldsymbol{\tau}_{\mathbf{A c H}} \\
(\mathbf{s})\end{array}$} & \multicolumn{2}{c}{$\begin{array}{c}\text { Coverage of intermediates } \\
\text { to acetaldehyde } \mathbf{N}_{\text {AcH }} \\
\left(\mathbf{m o l ~ m}^{-2}\right)\end{array}$} \\
\cline { 2 - 6 } & \multicolumn{2}{|c|}{$\begin{array}{c}\mathrm{MgO} \\
(653 \mathrm{~K})\end{array}$} & $\begin{array}{c}\mathrm{HAP} \\
(613 \mathrm{~K})\end{array}$ & $\begin{array}{c}\mathrm{HAP} \\
(653 \mathrm{~K})\end{array}$ \\
\hline 30 & 15 & 4.4 & $1.1 \times 10^{-7}$ & $4.3 \times 10^{-8}$ \\
50 & 13 & 4.6 & $1.2 \times 10^{-7}$ & $6.5 \times 10^{-8}$ \\
75 & 11 & 4.6 & $1.2 \times 10^{-7}$ & $8.2 \times 10^{-8}$ \\
\hline
\end{tabular}


Table 3.6. Time constants and surface coverages of reactive intermediates leading to butanol $\left(\mathrm{N}_{\text {butanol }}\right)$ during the steady-state Guerbet coupling of ethanol over $\mathrm{MgO}$ and HAP at 653 and 613 $\mathrm{K}$, respectively.

\begin{tabular}{c|cc|cc}
\hline \multirow{2}{*}{$\begin{array}{c}\text { Total Flow } \\
\text { Rate } \\
\left(\mathbf{c m}^{3} \mathbf{~ m i n}^{-1}\right)\end{array}$} & \multicolumn{2}{|c|}{$\begin{array}{c}\boldsymbol{\tau}_{\text {butanol }} \\
(\mathbf{s})\end{array}$} & $\begin{array}{c}\text { Coverage of intermediates } \\
\text { to butanol } \mathbf{~}_{\text {butanol }} \\
\left(\mathbf{m o l ~ m}^{-2}\right)\end{array}$ \\
\cline { 2 - 6 } & $\mathrm{MgO}$ & $\mathrm{HAP}$ & $\mathrm{MgO}$ & $\mathrm{HAP}$ \\
$(653 \mathrm{~K})$ & $(613 \mathrm{~K})$ & $(653 \mathrm{~K})$ & $(613 \mathrm{~K})$ \\
\hline 30 & 93 & 310 & $2.8 \times 10^{-7}$ & $4.8 \times 10^{-6}$ \\
50 & 53 & 117 & $8.1 \times 10^{-8}$ & $1.7 \times 10^{-6}$ \\
75 & 27 & 69 & $4.6 \times 10^{-8}$ & $1.1 \times 10^{-6}$ \\
\hline
\end{tabular}

The re-adsorption of reactants or products in the reaction can have a significant influence on the time constant measured by SSITKA. The possible effect of re-adsorption can be seen in the variation of $\tau$ for ethanol and butanol with respect to flowrate listed in Tables 3.4 and 3.6, respectively. The mean surface residence times of adsorbed intermediates to acetaldehyde $\left(\tau_{\mathrm{AcH}}\right)$ (Table 3.5), however were relatively independent of total flow rate, which suggests acetaldehyde re-adsorption was negligible. Because butanol is the product of a sequential surface reaction, the contribution of re-adsorption to the butanol formation time constant cannot be determined by simply varying the flow rate. This concept will be explored in the Discussion section.

\subsubsection{STPD of Adsorbed Ethanol Monitored by DRIFTS}

To probe the interaction of ethanol on the catalytic surfaces, DRIFTS of pre-adsorbed ethanol on $\mathrm{MgO}$ and HAP followed by STPD was performed. The spectra obtained from these experiments are presented in Figure 3.6.

The left plot in Figure 3.6 shows IR bands observed in the 3200-2600 and 1300-1000 $\mathrm{cm}^{-1}$ regions after ethanol adsorption on $\mathrm{MgO}$ at $303 \mathrm{~K}$ at various temperatures. The bands are characteristic of adsorbed ethoxide species formed on the surface of the catalyst. The peaks at 
$2954\left(\mathrm{vCH}_{3}\right), 2917\left(\mathrm{vCH}_{3}\right)$, and $2847\left(\mathrm{vCH}_{2}\right) \mathrm{cm}^{-1}$ are attributed to $\mathrm{C}-\mathrm{H}$ stretches of ethoxide and the bands observed at 1125 and $1063 \mathrm{~cm}^{-1}$ correspond to the two $\mathrm{C}-\mathrm{C}-\mathrm{O}$ stretching modes of the adsorbed ethoxide species [27]. Features of the surface ethoxide intermediate in the C-H stretching region remain evident on the $\mathrm{MgO}$ surface up to $673 \mathrm{~K}$.
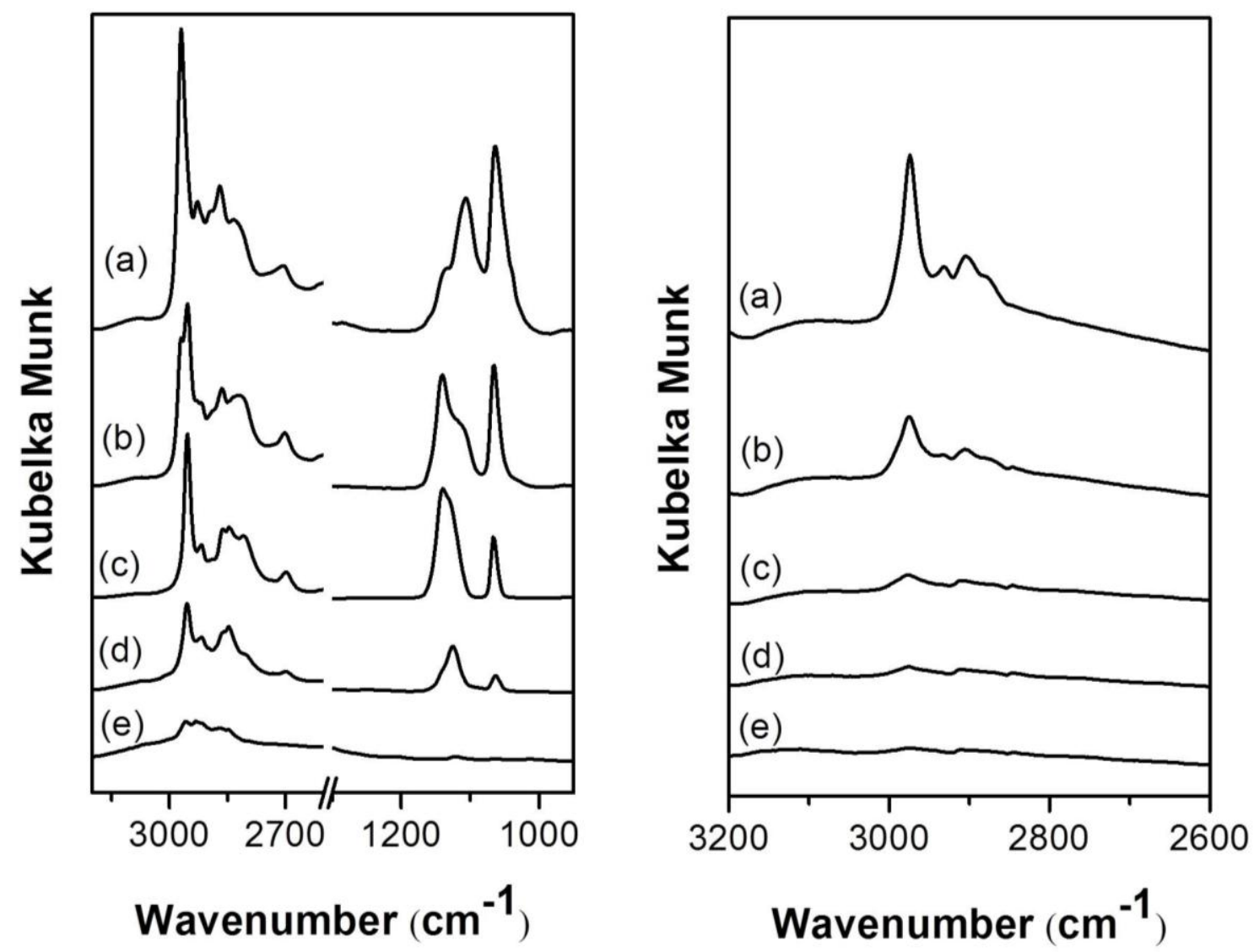

Figure 3.6. DRIFTS spectra of adsorbed ethanol at $303 \mathrm{~K}$ on $\mathrm{MgO}$ (left) and HAP (right) collected after heating to various temperatures: (a) $303 \mathrm{~K}$, (b) $373 \mathrm{~K}$, (c) $473 \mathrm{~K}$, (d) $573 \mathrm{~K}$, (e) 673 K. Spectra are offset for clarity. 
The DRIFTS spectra collected of adsorbed ethanol on HAP at $303 \mathrm{~K}$ followed by stepwise heating to $673 \mathrm{~K}$ are displayed in Figure 3.6 (right). The adsorption of ethanol revealed 3 peaks in the $3100-2800 \mathrm{~cm}^{-1}$ region that can be assigned to the $\mathrm{C}-\mathrm{H}$ stretches of a surface ethoxide species: $2975\left(v \mathrm{CH}_{3}\right), 2932\left(\mathrm{vCH}_{2}\right)$, and $2904 \mathrm{~cm}^{-1}\left(\mathrm{vCH}_{3}\right)$. Lower wavenumber bands associated with ethoxide could not be detected because of strong absorption by the HAP material in this region. The intensity of the $\mathrm{C}-\mathrm{H}$ bands attributed to ethoxide significantly decreased after heating the sample to just $373 \mathrm{~K}$. Upon further heating to $573 \mathrm{~K}$ the bands were not observed, indicating ethoxide had completely desorbed from HAP at this temperature. This result is consistent with previous reports on hydroxyapatite materials that also showed the disappearance of C-H ethoxide bands by $573 \mathrm{~K}$ [33].

\subsubsection{Adsorption Microcalorimetry of Carbon Dioxide, Triethylamine and Ethanol}

Adsorption sites on the catalytic materials were also characterized by adsorption microcalorimetry at $303 \mathrm{~K}$. The experimental results, obtained from the adsorption of carbon dioxide, triethylamine, and ethanol, are summarized in Figures 3.7, 3.8, and 3.9, respectively.

Carbon dioxide was used to probe the surface base properties of the catalysts. Isotherms obtained from the adsorption microcalorimetry of $\mathrm{CO}_{2}$ on $\mathrm{MgO}$ and $\mathrm{HAP}$ are given in Figure 3.7. The total adsorption capacity or uptake of each probe molecule on the catalytic surface, was determined by extrapolating the high pressure, horizontal portion of the isotherm (corresponds to saturation) to zero pressure. For $\mathrm{CO}_{2}$ on $\mathrm{MgO}$ and $\mathrm{HAP}$ the capacity was 1.0 and $2.5 \mu \mathrm{mol} \mathrm{m}{ }^{-2}$, respectively, suggesting a significantly higher base site density on the surface of stoichiometric hydroxyapatite compared to that observed on $\mathrm{MgO}$. 

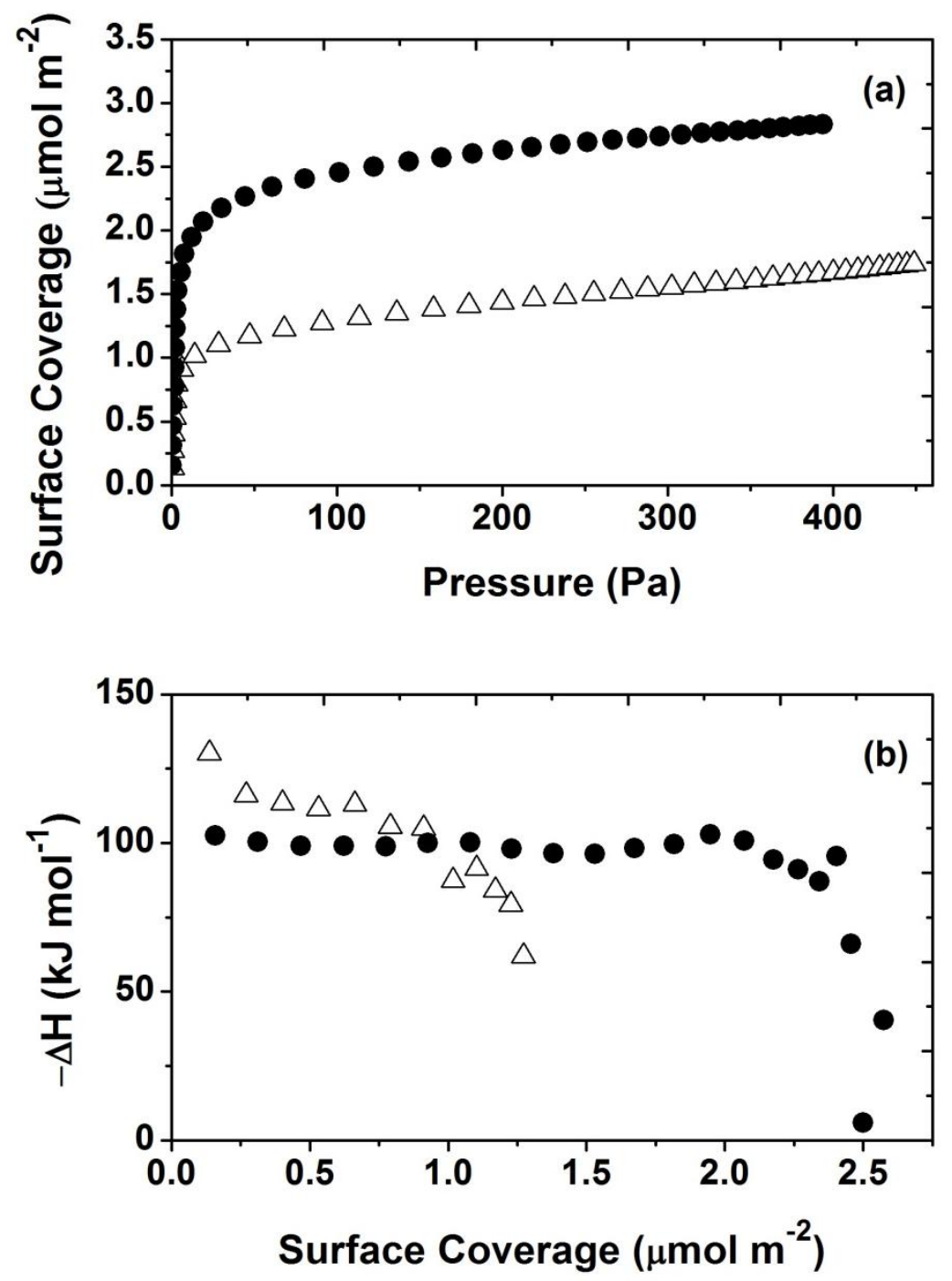

Figure 3.7. Adsorption microcalorimetry of carbon dioxide on $(\Delta) \mathrm{MgO}$ and $(\bullet)$ stoichiometric hydroxyapatite (HAP) catalysts at $303 \mathrm{~K}$; (a) adsorption isotherms of carbon dioxide (b) differential heats of adsorption as a function of coverage.

Figure $3.7 \mathrm{~b}$ presents the differential heats of $\mathrm{CO}_{2}$ adsorption on $\mathrm{MgO}$ and $\mathrm{HAP}$ as a function of surface coverage. The initial differential heat of $\mathrm{CO}_{2}$ adsorption on $\mathrm{MgO}$ was $\sim 20 \mathrm{~kJ}$ mol $^{-1}$ higher than that on HAP, which implies $\mathrm{MgO}$ exposes stronger base sites that interact with $\mathrm{CO}_{2}$ compared to those on HAP. 
Adsorption microcalorimetry of ammonia has been employed extensively as a probe of surface acidity, however there can be multiple interactions with ammonia and solid surfaces. These additional adsorption states include weak hydrogen bonding interactions with the surface as well as deprotonation of ammonia by strong base sites to form surface $\mathrm{NH}_{2}$ species [34].

Triethylamine (TEA) is harder to deprotonate and is therefore less susceptible to dissociation on the surface. It also has a stronger proton affinity than ammonia suggesting it is a stronger gas-phase base and should therefore be more selective in probing surface acid sites [35].

Adsorption isotherms of TEA obtained on $\mathrm{MgO}$ and $\mathrm{HAP}$ at $303 \mathrm{~K}$ are presented in Figure 3.8a. The low observed uptake and linear variation of TEA surface coverage with pressure on $\mathrm{MgO}$ indicate a very weak interaction with the surface. In contrast, TEA was chemisorbed onto the HAP catalytic surface with an overall uptake of $1.7 \mu \mathrm{mol} \mathrm{m}{ }^{-2}$, which is illustrated by its Langmuirian adsorption isotherm. A weak surface interaction between TEA and $\mathrm{MgO}$ is confirmed by the relatively low differential heats of TEA adsorption on $\mathrm{MgO}$ compared to those observed on HAP (Figure 3.8b). Evidently, HAP exposes a considerably higher acid site density than $\mathrm{MgO}$.

Figure 3.9 shows the results from adsorption microcalorimetry of ethanol on $\mathrm{MgO}$ and HAP at $303 \mathrm{~K}$. The adsorption isotherms for the two catalysts in Figure 3.9a were nearly identical, resulting in an overall ethanol uptake of $5.1 \mu \mathrm{mol} \mathrm{m} \mathrm{m}^{-2}$ on $\mathrm{MgO}$ and $5.2 \mu \mathrm{mol} \mathrm{m} \mathrm{m}^{-2}$ on HAP. These results are consistent with the surface coverages of ethanol on $\mathrm{MgO}$ and HAP determined by SSITKA (Table 3.4). 

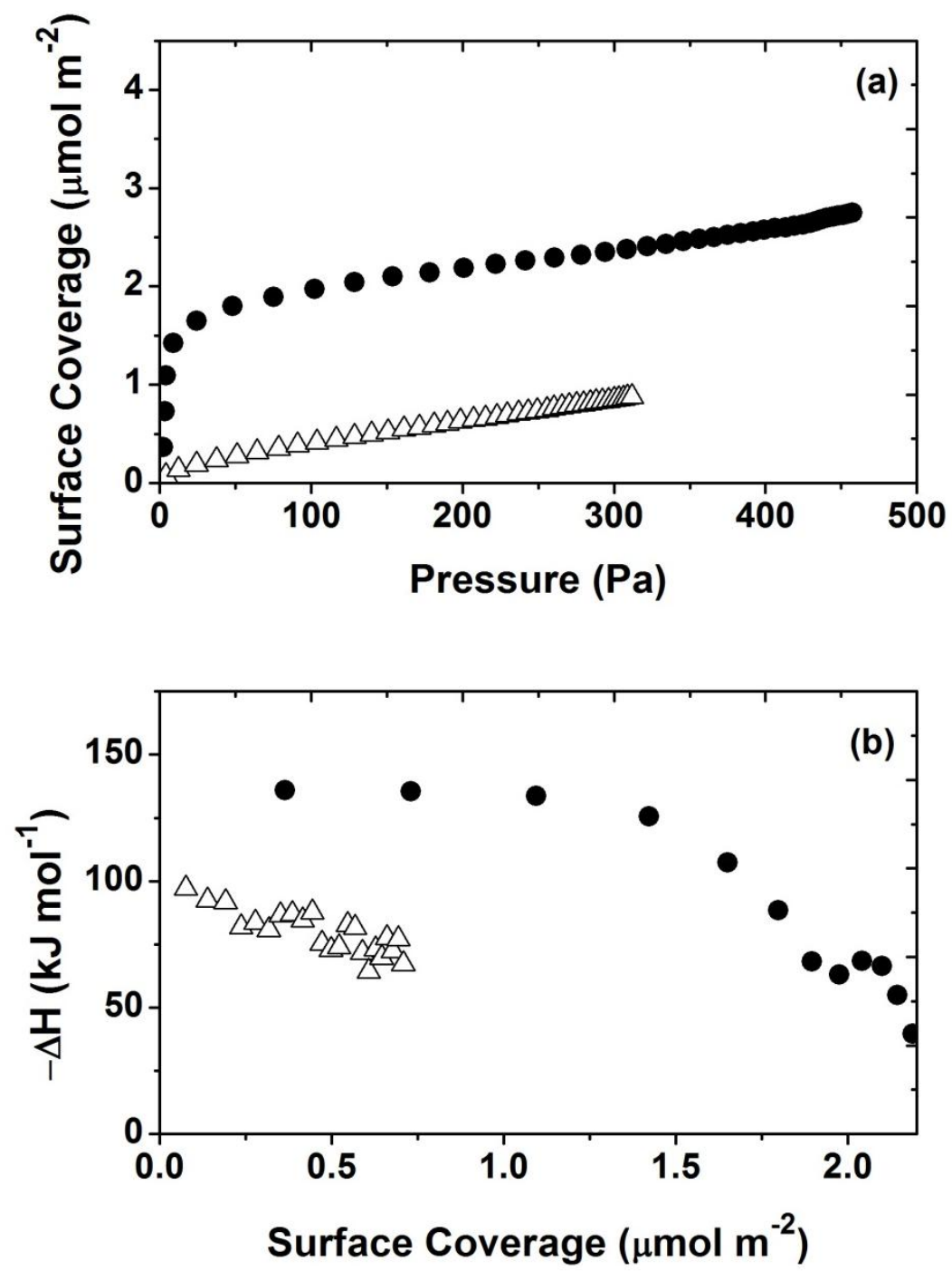

Figure 3.8. Adsorption microcalorimetry of triethylamine (TEA) on $(\Delta) \mathrm{MgO}$ and $(\bullet)$ stoichiometric hydroxyapatite (HAP) catalysts at $303 \mathrm{~K}$; (a) adsorption isotherms of triethylamine (b) differential heats of adsorption as a function of coverage.

Differential heats of ethanol adsorption as a function of surface coverage for the catalysts are provided in Figure 3.9b. The initial differential heats observed on MgO and HAP were $\sim 118$ and $\sim 90 \mathrm{~kJ} \mathrm{~mol}^{-1}$, respectively. This $\sim 30 \mathrm{~kJ} \mathrm{~mol}^{-1}$ difference in adsorption energy suggests that the ethanol interacts more weakly with HAP compared to $\mathrm{MgO}$, which is consistent with the results obtained from STPD of pre-adsorbed ethanol (Figure 3.6) that reveal desorption of 
ethanol from HAP at a significantly lower temperature than from $\mathrm{MgO}$. It is also worth mentioning that the ethanol adsorption sites on both $\mathrm{MgO}$ and HAP appear to be fairly uniform in strength, indicated by the invariance in $\Delta \mathrm{H}_{\mathrm{ads}}$ as a function of coverage up to about $4 \mu \mathrm{mol} \mathrm{m}{ }^{-2}$ (Figure 3.9b).
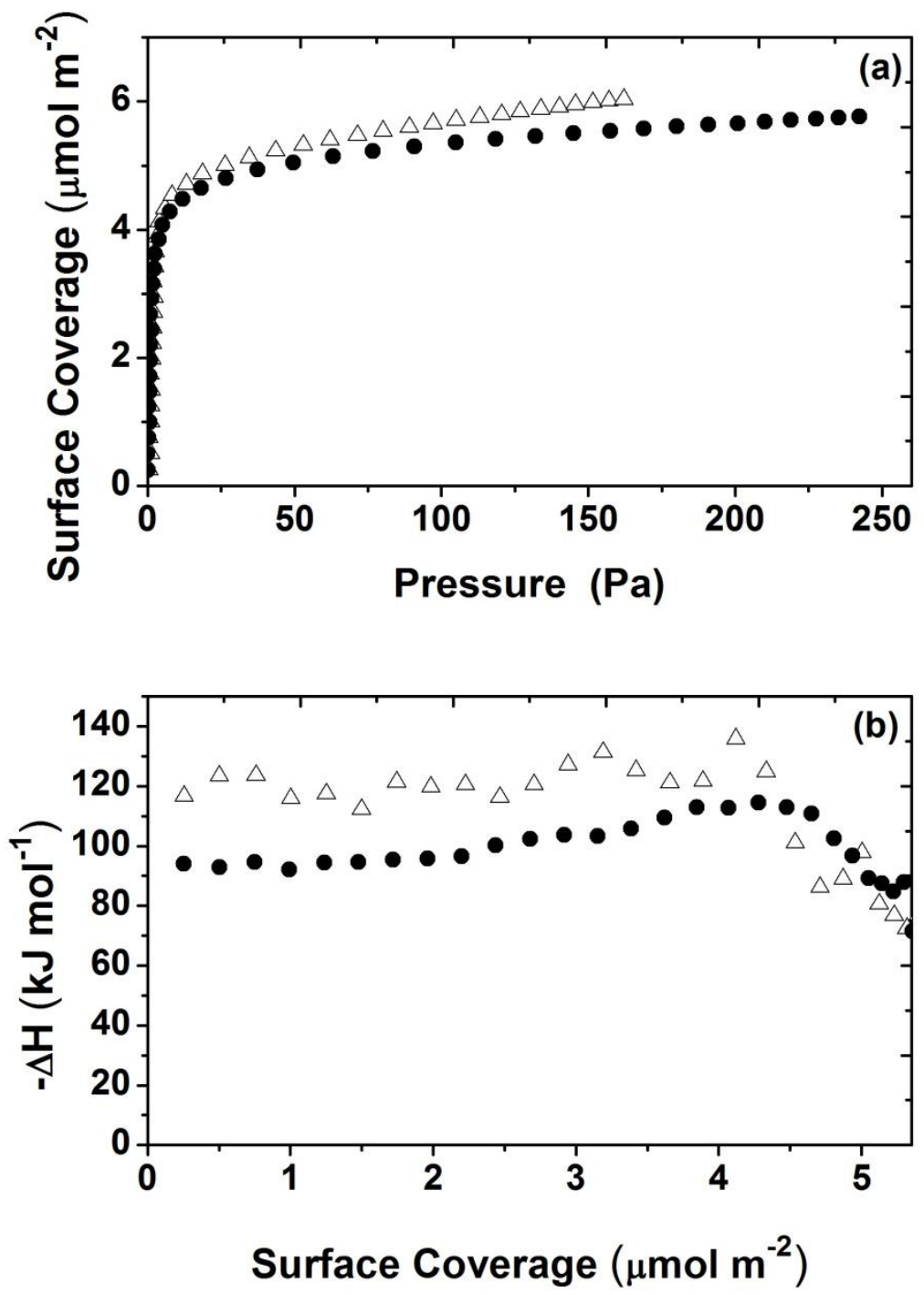

Figure 3.9. Adsorption microcalorimetry of ethanol on $(\Delta) \mathrm{MgO}$ and $(\bullet)$ stoichiometric hydroxyapatite (HAP) catalysts at $303 \mathrm{~K}$; (a) adsorption isotherms of ethanol (b) differential heats of adsorption as a function of coverage. 


\subsection{Discussion}

The SSITKA measurements allowed for the direct quantification of critical kinetic parameters such as mean surface residence times as well as surface coverages of intermediates leading to products formed in the reaction. Transient results revealed that, for both $\mathrm{MgO}$ and $\mathrm{HAP}$, the residence time for intermediates leading to acetaldehyde $\left(\tau_{\mathrm{AcH}}\right)$ was much shorter than the residence time of reaction intermediates leading to butanol $\left(\tau_{\mathrm{BuOH}}\right)$ at all three flowrates investigated. Moreover, the residence times of ethanol and butanol depended strongly on flow rate, which suggests that the alcohols re-adsorbed and desorbed as they passed through the reactor. It is tempting to extrapolate the SSITKA results to infinite flow rate in an attempt to remove the effects of re-adsorption on the calculated time constants. Unfortunately, the selectivity to butanol during Guerbet coupling can depend on ethanol conversion because of the sequential nature of the reaction network to produce butanol. Therefore, the discussion of SSITKA results will be focused on those determined at the highest flow rate, $75 \mathrm{~cm}^{3} \mathrm{~min}^{-1}$, which is a compromise between achieving a measurable conversion level and minimizing readsorption effects. From Table 3.4, the values of $\tau_{\text {ethanol }}$ for $\mathrm{MgO}$ and HAP were 10 and $7.1 \mathrm{~s}$, respectively, and provide a reasonable estimation of the time constant for an alcohol to desorb from the catalyst bed and exit the reactor. The values of $\tau_{\text {butanol }}$ reported in Table 3.6 for $\mathrm{MgO}$ and HAP were 27 and $69 \mathrm{~s}$, respectively, at $75 \mathrm{~cm}^{3} \mathrm{~min}^{-1}$ total flow rate. The substantially longer time constants associated with butanol formation compared to ethanol desorption over both materials suggests that the butanol time constants are determined primarily by reaction kinetics instead of adsorption/desorption artifacts. Moreover, since the ratio of ethanol to butanol in the gas phase at the reactor exit is greater than 50:1 over both catalysts, the competitive adsorption 
of ethanol over butanol should also help to minimize re-adsorption effects in the time constant associated with butanol formation.

A commonly-hypothesized reaction path for the Guerbet coupling of ethanol involves the aldol condensation of intermediate acetaldehyde which likely proceeds through a surface enolate species that produces coupled products that desorb as butanol. In this coupling path, surface acetaldehyde produced from ethanol dehydrogenation may desorb or undergo base-catalyzed abstraction of the $\alpha-\mathrm{H}$ to form an adsorbed enolate species. The isotopic transient results obtained during the steady-state conversion of ethanol over $\mathrm{MgO}$ revealed a significantly higher surface coverage of reactive intermediates leading to acetaldehyde than to butanol (Tables 3.5, 3.6: $\mathrm{N}_{\mathrm{AcH}}>\mathrm{N}_{\mathrm{BuoH}}$ ) at all flow rates. These results suggest a higher fraction of surface acetaldehyde produced during the reaction of ethanol on $\mathrm{MgO}$ desorbed rather than coupled form butanol. The coverages $\mathrm{N}_{\mathrm{AcH}}$ and $\mathrm{N}_{\mathrm{BuOH}}$ are consistent with the higher selectivity to acetaldehyde compared to butanol observed over $\mathrm{MgO}$.

In contrast, the coverage of intermediates that led to butanol on HAP was higher than that leading to acetaldehyde by roughly 1-2 orders of magnitude $\left(\mathrm{N}_{\mathrm{BuOH}} \gg \mathrm{N}_{\mathrm{AcH}}\right)$, regardless of flowrate (Tables 3.5, 3.6). Evidently, the majority of acetaldehyde formed from ethanol dehydrogenation on HAP remained on the surface to undergo sequential reactions leading to butanol formation.

A previous study from our group on ethanol coupling over $\mathrm{MgO}$, investigated the relationship between butanol rate and acetaldehyde concentration over a broad range of ethanol conversions (7-23\%) and observed a first-order dependence of butanol formation on gas-phase acetaldehyde concentration [27]. In the current work on $\mathrm{MgO}$, a $36 \%$ decrease in gas-phase acetaldehyde concentration at the reactor exit (from $57.8 \mu \mathrm{mol} \mathrm{L}{ }^{-1}$ to $37.2 \mu \mathrm{mol} \mathrm{L}^{-1}$ at $7.9 \%$ and 
$3.7 \%$ ethanol conversion, respectively) corresponded with a $44 \%$ decrease in butanol production rate $\left(3.0 \times 10^{-9}\right.$ to $\left.1.7 \times 10^{-9} \mathrm{~mol} \mathrm{~s}^{-1} \mathrm{~m}^{-2}\right)$, which is consistent with earlier work and confirms a strong dependence of butanol formation on acetaldehyde concentration. Interestingly, a $28 \%$ decrease in gas-phase acetaldehyde concentration at the reactor exit during ethanol coupling over HAP was not accompanied by a significant change in the production rate of butanol. These results suggest that most of the butanol formed over HAP did not involve the participation of gas-phase acetaldehyde whereas the butanol formation over $\mathrm{MgO}$ might involve a surface that is closer to equilibrated with gas-phase acetaldehyde.

Adsorption microcalorimetry of $\mathrm{CO}_{2}$ was performed to investigate the number and nature of base sites on the catalytic surfaces. Microcalorimetry results revealed that the coverage of $\mathrm{CO}_{2}$ on the HAP surface was 2.5 times that of $\mathrm{MgO}$. However, differential heats of $\mathrm{CO}_{2}$ adsorption on HAP were lower than on MgO. Recent IR studies on HAP have shown that $\mathrm{CO}_{2}$ interacts with the $\mathrm{OH}^{-}$groups and the $\mathrm{O}^{2-}$ atoms of surface $\mathrm{PO}_{4}{ }^{3-}$ groups [36]. Adsorption microcalorimetry suggests that relative to MgO, HAP exposed a higher number density of base sites but that the sites were weaker in adsorption binding energy. Adsorption microcalorimetry of TEA also revealed a higher acid site density on the surface of HAP compared to $\mathrm{MgO}$. Since the Guerbet coupling of ethanol likely occurs on acid-base site pairs, the high reactivity of ethanol on HAP compared to $\mathrm{MgO}$ appears to be related to high number of acid-base site pairs with appropriate binding affinity on HAP. The higher density of these preferred site pairs may also explain why a significantly higher surface coverage of intermediates leading to butanol was observed on HAP relative to $\mathrm{MgO}$.

Stepwise temperature-programmed desorption of pre-adsorbed ethanol at $303 \mathrm{~K}$ on $\mathrm{MgO}$ and HAP was studied using DRIFTS. The IR spectra revealed the formation of a surface 
ethoxide intermediate on both of the catalytic materials. Ethanol dissociatively adsorbs on the surface forming ethoxide coordinated to a Lewis acid site $\left(\mathrm{Ca}^{2+}\right.$ on $\mathrm{HAP}, \mathrm{Mg}^{2+}$ for $\left.\mathrm{MgO}\right)$ and proton-like hydrogen coordinated to a Brønsted base site. The STPD results show that the ethoxide species on HAP completely desorbed from the surface by $473 \mathrm{~K}$, whereas a temperature of $673 \mathrm{~K}$ was required on $\mathrm{MgO}$. This $200 \mathrm{~K}$ difference in desorption temperature indicates that the dissociated ethanol is much more weakly held to $\mathrm{HAP}$ relative to $\mathrm{MgO}$, which is consistent with the results obtained from adsorption microcalorimetry of ethanol where the initial differential heat of ethanol adsorption on HAP was $\sim 30 \mathrm{~kJ} \mathrm{~mol}^{-1}$ lower than that on $\mathrm{MgO}$.

The TOF based on ethanol adsorption is a lower bound because not all of the adsorbed ethanol proceeds to product. A better estimate of the TOF can be derived from the isotopic transient results as the reciprocal of the mean surface residence time (TOF $\left.=\tau^{-1}\right)$. Unfortunately, the re-adsorption of alcohols during the transient increased the measured surface residence time. If we try to minimize the effects of re-adsorption by using the surface residence time of intermediates to butanol at the highest flow rate in the study $\left(75 \mathrm{~cm}^{3} \mathrm{~min}^{-1}\right)$, we have $\tau_{\mathrm{BuOH}}=27$ and $69 \mathrm{~s}$ for $\mathrm{MgO}(653 \mathrm{~K})$ and HAP $(613 \mathrm{~K})$. Moreover, if we assume that the $\tau_{\mathrm{EtOH}}$ at high flow rate is a reasonable approximation of the effect of re-adsorption then we can simply subtract the value for $\tau_{\mathrm{EtOH}}$ (Table 3.4) from $\tau_{\mathrm{BuOH}}($ Table 3.6) as reported by Birky et al. to get a "corrected" $\tau_{\mathrm{BuOH}}$. The inverse of the "corrected" $\tau_{\mathrm{BuOH}}$ provides a better estimate of the TOF associated with

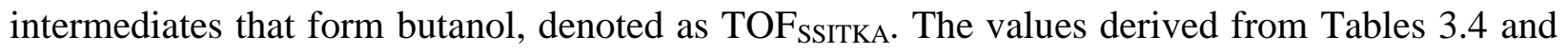
3.6 are $0.059 \mathrm{~s}^{-1}$ for $\mathrm{MgO}(653 \mathrm{~K})$ and $0.016 \mathrm{~s}^{-1}$ for HAP $(613 \mathrm{~K})$. The values of TOF $\mathrm{SSITKA}_{\text {for }}$ acetaldehyde production can be estimated as the inverse of the $\tau_{\mathrm{AcH}}$ at the highest flow rate because re-adsorption appears to be insignificant. Thus the TOF SSITKA for AcH is $0.091 \mathrm{~s}^{-1}$ for $\mathrm{MgO}$ at $653 \mathrm{~K}$ and $0.22 \mathrm{~s}^{-1}$ for HAP at $613 \mathrm{~K}$. The higher selectivity to butanol over HAP 
compared to $\mathrm{MgO}$ is apparently the consequence of a much higher coverage of surface intermediates leading to butanol during the steady state reaction.

Ogo et al. [37] used isotopic exchange reactions to show that ethanol dehydrogenation occurs rapidly on strontium-substituted hydroxyapatite catalysts and that aldol condensation is the rate determining step. The very short residence time of intermediates leading to acetaldehyde ( $\left.\tau_{\mathrm{AcH}}\right)$ relative to $\tau_{\mathrm{BuOH}}$ observed here by SSITKA, would support their kinetic mechanism. It is possible that the kinetically-relevant step of the reaction is related to enolate formation via $\alpha-\mathrm{H}$ abstraction of adsorbed acetaldehyde. Results from adsorption microcalorimetry of $\mathrm{CO}_{2}$ (a general probe of base sites) and STPD of adsorbed ethanol suggest HAP has a weaker surface affinity than $\mathrm{MgO}$ for those probe molecules. Furthermore, adsorption of triethylamine revealed the presence of weak Lewis acid sites on HAP that were not found on MgO. Thus, under steady state reaction conditions, more surface acid-base pairs on HAP may be available for enolate formation compared to $\mathrm{MgO}$, which would lead to a higher formation rate of coupled products.

\subsection{Conclusions}

Isotopic transient studies were performed during the steady-state Guerbet coupling of ethanol to butanol over stoichiometric hydroxyapatite and $\mathrm{MgO}$ at $613 \mathrm{~K}$ and $653 \mathrm{~K}$, respectively. The HAP catalyst was about 3 times more active in the reaction than $\mathrm{MgO}$ on a surface area basis even at the lower TOF. The selectivity over HAP was as high as $75 \%$ to butanol.

The surface coverage of reactive intermediates leading to butanol $\left(\mathrm{N}_{\mathrm{BuOH}}\right)$ relative to that leading to acetaldehyde $\left(\mathrm{N}_{\mathrm{AcH}}\right)$ was very high on $\mathrm{HAP}\left(\mathrm{N}_{\mathrm{BuOH}}>>\mathrm{N}_{\mathrm{AcH}}\right)$ whereas on $\mathrm{MgO}, \mathrm{N}_{\mathrm{AcH}}$ $>\mathrm{N}_{\mathrm{BuOH}}$. Given the generally-accepted mechanism for Guerbet coupling that involves aldol 
condensation of acetaldehyde, it appears that a greater fraction of the acetaldehyde produced during the reaction proceeds toward coupling products on HAP relative to $\mathrm{MgO}$.

Adsorption microcalorimetry of $\mathrm{CO}_{2}$ showed a higher surface density of base sites on HAP compared to that on $\mathrm{MgO}$, but the $\mathrm{CO}_{2}$ adsorption binding energy was weaker on HAP. Moreover, adsorption of triethylamine revealed significant Lewis acidity on HAP and negligible acidity on $\mathrm{MgO}$.

It is likely that the high activity and selectivity observed during the Guerbet coupling of ethanol over HAP involves the proper balance of acid-base site pairs to facilitate all of the steps in the sequence, including alcohol dehydrogenation, aldol condensation and aldehyde hydrogenation. The relatively strong basicity of $\mathrm{MgO}$ retains adsorbed ethanol at higher temperatures compared to HAP, which is consistent with the idea that Guerbet coupling is facilitated by weak acid-base bifunctional catalysts.

\subsection{Acknowledgements}

This work was supported by the Chemical Sciences, Geosciences and Biosciences Division, Office of Basic Energy Sciences, Office of Science, U.S. Department of Energy, grant no. DEFG02-95ER14549. The authors would like to thank Dmitry Pestov at Virginia Commonwealth University for assistance with XPS. 


\subsection{References}

[1] G.R.M. Dowson, M.F. Haddow, J. Lee, R.L. Wingad, D.F. Wass, Catalytic Conversion of Ethanol into an Advanced Biofuel: Unprecedented Selectivity for n-Butanol, Angew. Chem. Int. Ed. Engl. 52 (2013) 9005-9008.

[2] N. Savage, Fuel options: the ideal biofuel, Nature. 474 (2011) S9-S11.

[3] T. Tsuchida, S. Sakuma, T. Takeguchi, W. Ueda, Direct Synthesis of $\mathrm{n}$-Butanol from Ethanol over Nonstoichiometric Hydroxyapatite, Ind. Eng. Chem. 45 (2006) 8634-8642.

[4] K. Koda, T. Matsu-ura, Y. Obora, Y. Ishii, Guerbet Reaction of Ethanol to n-Butanol Catalyzed by Iridium Complexes, Chem. Lett. 38 (2009) 838-839.

[5] A.J. O’Lenick, Guerbet chemistry, J. Surfactants Deterg. 4 (2001) 311-315.

[6] C. Carlini, M. Di Girolamo, A. Macinai, M. Marchionna, M. Noviello, A.M. Raspolli Galletti, G. Sbrana, Selective synthesis of isobutanol by means of the Guerbet reaction:: Part 2. Reaction of methanol/ethanol and methanol/ethanol/n-propanol mixtures over copper based/MeONa catalytic systems, J. Mol. Catal. A Chem. 200 (2003) 137-146.

[7] S. Veibel, J. Nielsen, On the mechanism of the Guerbet reaction, Tetrahedron. 23 (1967) 1723-1733.

[8] C. Yang, Z.Y. Meng, Bimolecular condensation of ethanol to 1-butanol catalyzed by alkali cation zeolites, J. Catal. 142 (1993) 37-44.

[9] A.S. Ndou, N. Plint, N.J. Coville, Dimerisation of ethanol to butanol over solid-base catalysts, Appl. Catal. A Gen. 251 (2003) 337-345.

[10] M.J.L. Gines, E. Iglesia, Bifunctional condensation reactions of alcohols on basic oxides modified by copper and potassium, J. Catal. 176 (1998) 155-172.

[11] J. Scalbert, F. Thibault-Starzyk, R. Jacquot, D. Morvan, F. Meunier, Ethanol condensation to butanol at high temperatures over a basic heterogeneous catalyst: How relevant is acetaldehyde self-aldolization?, J. Catal. 311 (2014) 28-32.

[12] J.T. Kozlowski, R.J. Davis, Heterogeneous Catalysts for the Guerbet Coupling of Alcohols, ACS Catal. 3 (2013) 1588-1600.

[13] W. Ueda, T. Kuwabara, T. Ohshida, Y. Morikawa, A low-pressure guerbet reaction over magnesium oxide catalyst, J. Chem. Soc., Chem. Commun. (1990) 1558-1559.

[14] W. Ueda, T. Ohshida, T. Kuwabara, Y. Morikawa, Condensation of alcohol over solidbase catalyst to form higher alcohols, Catal. Letters. 12 (1992) 97-104. 
[15] J. Di Cosimo, C. Apesteguía, M. Ginés, E. Iglesia, Structural requirements and reaction pathways in condensation reactions of alcohols on MgyAlOx catalysts, J. Catal. 190 (2000) 261-275.

[16] M. León, E. Díaz, S. Ordóñez, Ethanol catalytic condensation over Mg-Al mixed oxides derived from hydrotalcites, Catal. Today. 164 (2011) 436-442.

[17] K. Gotoh, S. Nakamura, T. Mori, Y. Morikawa, Supported Alkali Salt Catalysts Active for the Guerbet Reaction between Methanol and Ethanol, Stud. Surf. Sci. Catal. 130 (2000) 2669-2674.

[18] T. Tsuchida, J. Kubo, T. Yoshioka, S. Sakuma, T. Takeguchi, W. Ueda, Reaction of ethanol over hydroxyapatite affected by $\mathrm{Ca} / \mathrm{P}$ ratio of catalyst, J. Catal. 259 (2008) 183189.

[19] S. Ogo, A. Onda, K. Yanagisawa, Selective synthesis of 1-butanol from ethanol over strontium phosphate hydroxyapatite catalysts, Appl. Catal. A-Gen. 402 (2011) 188-195..

[20] C.L. Kibby, W.K. Hall, Studies of acid catalyzed reactions XII. Alcohol decomposition over hydroxyapatite catalysts, J. Catal. 29 (1973) 144-159.

[21] S.J. Joris, C.H. Amberg, The Nature of Deficiency in Nonstoichiometric Hydroxyapatites . I . Catalytic Activity of Calcium and Strontium Hydroxyapatites, 75 (1971) 3167-3171.

[22] J.A.S. Bett, L.G. Christner, W.K. Hall, Studies of the Hydrogen Held by Solids. XII. Hydroxyapatite Catalysts, 486 (1967) 5535.

[23] B.C. McClaine, R.J. Davis, Importance of Product Readsorption during Isotopic Transient Analysis of Ammonia Synthesis on Ba-Promoted Ru/BaX Catalyst, J. Catal. 211 (2002) 379-386.

[24] J. Gao, X. Mo, J.G. Goodwin, Relationships between oxygenate and hydrocarbon formation during $\mathrm{CO}$ hydrogenation on $\mathrm{Rh} / \mathrm{SiO} 2$ : Use of multiproduct SSITKA, J. Catal. 275 (2010) 211-217.

[25] C. Ledesma, J. Yang, D. Chen, A. Holmen, Recent Approaches in Mechanistic and Kinetic Studies of Catalytic Reactions Using SSITKA Technique, ACS Catal. 4 (2014) $4527-4547$.

[26] S.L. Shannon, J.G. Goodwin, Characterization of Catalytic Surfaces, Chem. Rev. 95 (1995) 677-695.

[27] T.W. Birky, J.T. Kozlowski, R.J. Davis, Isotopic transient analysis of the ethanol coupling reaction over magnesia, J. Catal. 298 (2013) 130-137. 
[28] T. Tsuchida, J. Kubo, T. Yoshioka, S. Sakuma, T. Takeguchi, W. Ueda, Influence of Preparation Factors on $\mathrm{Ca} / \mathrm{P}$ Ratio and Surface Basicity of Hydroxyapatite Catalyst, J. Japan Pet. Inst. 52 (2009) 51-59.

[29] H. Shou, R.J. Davis, Multi-product steady-state isotopic transient kinetic analysis of CO hydrogenation over supported molybdenum carbide, J. Catal. 306 (2013) 91-99.

[30] S. Bordawekar, E. Doskocil, R. Davis, Microcalorimetric study of CO2 and NH3 adsorption on Rb-and Sr-modified catalyst supports, Langmuir. 14 (1998) 1734-1738.

[31] D. Stošić, S. Bennici, S. Sirotin, C. Calais, J.-L. Couturier, J.-L. Dubois, A. Travert, A. Auroux, Glycerol dehydration over calcium phosphate catalysts: Effect of acidic-basic features on catalytic performance, Appl. Catal. A Gen. 447 (2012) 124-134.

[32] H. Tanaka, T. Watanabe, M. Chikazawa, FTIR and TPD studies on the adsorption of pyridine , n-butylamine and acetic acid on calcium hydroxyapatite, 93 (1997) 4377-4381.

[33] R.M.B. Faria, D. V. Cesar, V.M.M. Salim, Surface reactivity of zinc-modified hydroxyapatite, Catal. Today. 133-135 (2008) 168-173.

[34] A. Auroux, A. Gervasini, Microcalorimetric study of the acidity and basicity of metal oxide surfaces, J. Phys. Chem. 94 (1990) 6371-6379.

[35] N.C. Cardona-Martinez, J.A. Dumesic, Applications of Adsorption Microcalorimetry to the Study of Heterogeneous Catalysis, Adv. Catal. 38 (1992) 149-244.

[36] S. Diallo-garcia, M. Ben Osman, J. Kra, S. Casale, C. Thomas, J. Kubo, Identification of Surface Basic Sites and Acid-Base Pairs of Hydroxyapatite, J. Phys. Chem. C. 118 (2014) 12744-12757.

[37] S. Ogo, A. Onda, Y. Iwasa, K. Hara, A. Fukuoka, K. Yanagisawa, 1-Butanol synthesis from ethanol over strontium phosphate hydroxyapatite catalysts with various Sr/P ratios, J. Catal. 296 (2012) 24-30. 


\title{
Chapter 4:
}

\section{Mechanistic Insights into the Ethanol Coupling Reaction over Metal Phosphate Catalysts}

\begin{abstract}
The catalytic coupling of ethanol to butanol was investigated at $633 \mathrm{~K}$ over beta tricalcium phosphate $\left(\beta\right.$-TCP; $\left.\beta-\mathrm{Ca}_{3}\left(\mathrm{PO}_{4}\right)_{2}\right)$ and fluorine-substituted hydroxyapatite $\left(\mathrm{FAP} ; \mathrm{Ca}_{10}\left(\mathrm{PO}_{4}\right)_{6} \mathrm{~F}_{2}\right)$ catalysts to gain insight into the catalytic role of the $\mathrm{OH}^{-}$anion of calcium hydroxyapatite (HAP; $\left.\mathrm{Ca}_{10}\left(\mathrm{PO}_{4}\right)_{6}(\mathrm{OH})_{2}\right)$ in the reaction. Steady-state catalytic reactions of ethanol were conducted in a gas-phase, fixed-bed, differential reactor at atmospheric total system pressure. Both $\beta$-TCP and FAP catalysts were catalytically active for $\mathrm{C}-\mathrm{C}$ bond formation, leading to $\sim 35 \%$ selectivity towards butanol, suggesting that the $\mathrm{PO}_{4}{ }^{3-}$ group is critical for butanol production over these materials and is likely the base site in the active acid-base site pair for butanol formation during ethanol coupling over HAP. These results are consistent with water co-feeding experiments performed over HAP where the inhibiting effect of water on butanol formation was likely the result of water interactions with adjacent $\mathrm{Ca}-\mathrm{PO}_{4}{ }^{3-}$ site pairs on the surface. Water co-feeeding experiments over $\mathrm{MgO}$ revealed that water irreversibly adsorbed onto Lewis acid-strong base site pairs that were catalytically active for butanol formation and thus inhibited $\mathrm{C}-\mathrm{C}$ bond formation. In contrast, weaker base sites on the surface of $\mathrm{HAP}$ relative to $\mathrm{MgO}$, measured by $\mathrm{CO}_{2}$ adsorption microcalorimetry, likely accounted for weak and reversible surface interactions observed between water and the HAP surface. Catalytic reactions of ethanol over $\mathrm{Mg}_{3}\left(\mathrm{PO}_{4}\right)_{2}$, $\mathrm{Ca}_{3}\left(\mathrm{PO}_{4}\right)_{2}$, and $\mathrm{Sr}_{3}\left(\mathrm{PO}_{4}\right)_{2}$ catalysts demonstrated the importance of Lewis acidity of the metal phosphates on the reaction. Strong Lewis acid sites on the $\mathrm{Mg}_{3}\left(\mathrm{PO}_{4}\right)_{2}$ surface $\left(\mathrm{Mg}^{2+}\right.$ cations $)$
\end{abstract}


favored undesired ethanol dehydration to ethene (36\% selectivity) and diethyl ether (52\% selectivity) whereas the $\mathrm{Sr}_{3}\left(\mathrm{PO}_{4}\right)_{2}$ catalyst predominantly catalyzed ethanol dehydrogenation to acetaldehyde (91\% selectivity) at a rate significantly higher than those observed over the other catalytic materials. The poor selectivity to butanol observed during the reaction over the $\mathrm{Sr}_{3}\left(\mathrm{PO}_{4}\right)_{2}$ catalyst was likely a result of weak Lewis acid interactions between reaction intermediates and surface $\mathrm{Sr}^{2+}$ cations. Evidently, the $\beta-\mathrm{Ca}_{3}\left(\mathrm{PO}_{4}\right)_{2}$ possesses an intermediatestrength Lewis acidity provided by surface $\mathrm{Ca}^{2+}$ cations that allow the material to effectively convert ethanol to butanol with $35 \%$ selectivity. 


\subsection{Introduction}

The catalytic upgrading of bioethanol into value-added fuels and chemicals, such as butanol, has attracted increased interest in recent years due to the many drawbacks posed by ethanol as a gasoline fuel additive. Butanol is a more desirable transportation blend fuel because, compared to ethanol, it has a lower vapor pressure, lower solubility in water, and is less corrosive [1]. These properties allow butanol to be easily transported using the existing fuel distribution infrastructure and to be blended with gasoline at higher concentrations than ethanol. Additionally, the energy content of butanol is closer to that of conventional petroleum, which allows for improved gas mileage for biofuel blended gasoline [1,2].

The catalytic transformation of ethanol into butanol occurs via the Guerbet coupling reaction - a well-known industrial route for higher alcohol synthesis. The Guerbet coupling reaction is a multi-step, sequence of reactions that likely involves an initial dehydrogenation step to form acetaldehyde, which then undergoes an aldol self-condensation reaction to crotonaldehyde, followed by hydrogenation of the condensation product to give butanol $[3,4]$. A variety of catalytic materials have been studied for this reaction including solid base metal oxides (e.g. $\mathrm{MgO}$ ) [5-7], Mg-Al mixed metal oxides [8-10], basic zeolites [11,12], and more recently hydroxyapatite [13-15].

Calcium hydroxyapatite (HAP; $\left.\mathrm{Ca}_{10}\left(\mathrm{PO}_{4}\right)_{6}(\mathrm{OH})_{2}\right)$ has demonstrated exceptional catalytic performance in the Guerbet coupling of ethanol into butanol exhibiting unusually high activity and high butanol selectivity $(70 \%)$ at significantly lower reaction temperatures than what has been previously reported in the literature for this reaction $[16,17]$. Recent work from our group has shown that the HAP surface exposes a high surface density of acid and base sites of moderate-strength that likely facilitate the reaction and account for its high catalytic activity and 
unique selectivity observed during the reaction $[18,19]$. However, the nature and composition of the active acid-base site pair on the HAP surface responsible for butanol formation has not been clearly assigned which continues to complicate future catalyst design and optimization.

In a recent study by Ho et al. [20] in situ titration experiments combined with IR spectroscopy revealed the presence of two different active sites on the surface of HAP: surface $\mathrm{Ca}-\mathrm{O}$ sites responsible for ethanol dehydrogenation to acetaldehyde and $\mathrm{CaO} / \mathrm{PO}_{4}{ }^{3-}$ site pairs required for butanol formation. Diallo Garcia et al. [21] also investigated acid-base site pairs on the HAP surface and concluded that strongly basic surface $\mathrm{OH}^{-}$groups are likely the active base site involved in catalytic reactions, because $\mathrm{O}^{2-}$ anions of surface $\mathrm{PO}_{4}{ }^{3-}$ groups were weakly basic and unperturbed during acetylene adsorption studies. From the brief discussion presented here it is evident that a clear consensus regarding the active acid-base site pairs on the HAP surface, responsible for butanol formation, is lacking and therefore investigations are needed.

In this work, the catalytic conversion of ethanol was investigated over beta-tricalcium phosphate $\left(\beta\right.$-TCP; $\left.\beta-\mathrm{Ca}_{3}\left(\mathrm{PO}_{4}\right)_{2}\right)$ and fluorine-substituted hydroxyapatite $\left(\mathrm{FAP} ; \mathrm{Ca}_{10}\left(\mathrm{PO}_{4}\right)_{6} \mathrm{~F}_{2}\right)$, compared with stoichiometric HAP, to gain insight into the role or function of the $\mathrm{OH}^{-}$anion of HAP and whether it participates as the active base site required for butanol formation. Cationic effects of the metal phosphate catalysts were also explored by investigating the catalytic behavior of $\mathrm{Mg}$ - and Sr- phosphate during the reaction. Additionally, to help elucidate the role of the dihydrogen and water that is evolved throughout the Guerbet sequence, the by-products were co-fed with ethanol during the steady-state gas-phase conversion of ethanol over stoichiometric HAP. Catalytic reactions of ethanol combined with surface characterization were used to identify key composition-reactivity relationships of the catalytic materials in the Guerbet coupling reaction of ethanol into butanol. 


\subsection{Experimental Methods}

\subsubsection{Catalyst Preparation}

Stoichiometric calcium hydroxyapatite $\left(\mathrm{Ca}_{10}\left(\mathrm{PO}_{4}\right)_{6}(\mathrm{OH})_{2}\right)$ was prepared using a controlled co-precipitation method based on the procedure reported by Tsuchida et al. [22], as described in detail in previous work [18]. Briefly, aqueous solutions of $0.5 \mathrm{M}$ calcium nitrate tetrahydrate $\left(\mathrm{Ca}\left(\mathrm{NO}_{3}\right)_{2} 4 \mathrm{H}_{2} \mathrm{O}\right.$, Acros Organics) and $0.3 \mathrm{M}$ diammonium phosphate $\left(\left(\mathrm{NH}_{4}\right)_{2} \mathrm{HPO}_{4}\right.$, Aldrich, >99.99\%), previously adjusted to $\mathrm{pH}=10.5$ using aqueous ammonia, were simultaneously added dropwise to $100 \mathrm{~cm}^{3}$ of distilled deionized water (DDI) held at $353 \mathrm{~K}$. The resulting suspension was stirred for $24 \mathrm{~h}$ at $353 \mathrm{~K}$ under reflux. The precipitate was recovered by vacuum filtration, washed 3 times with DDI water, and dried in stagnant air at $400 \mathrm{~K}$ overnight. The final HAP powder was calcined at $873 \mathrm{~K}$ for $2 \mathrm{~h}$ in flowing air using a $10 \mathrm{~K} \mathrm{~min}^{-1}$ heating rate from room temperature and sized to $106-180 \mu \mathrm{m}$ pellets prior to characterization and reactivity measurements.

Beta-tricalcium phosphate $\left(\beta-\mathrm{TCP}, \mathrm{Ca}_{3}\left(\mathrm{PO}_{4}\right)_{2}\right)$ was obtained by heating calcium-deficient hydroxyapatite (Sigma-Aldrich, CAS \#7758-87-4, $\geq 98 \%$ ) in flowing air to $1073 \mathrm{~K}$ using a thermal ramp rate of $2.5 \mathrm{~K} \mathrm{~min}^{-1}$ from room temperature and holding at $1073 \mathrm{~K}$ for $2 \mathrm{~h}$. The phase transformation from calcium-deficient hydroxyapatite to $\beta$-TCP upon heating occurs according to the following formula [23,24]: $\mathrm{Ca}_{9}\left(\mathrm{HPO}_{4}\right)\left(\mathrm{PO}_{4}\right)_{5}(\mathrm{OH}) \rightarrow 3 \mathrm{Ca}_{3}\left(\mathrm{PO}_{4}\right)_{2}+\mathrm{H}_{2} \mathrm{O}$. The resulting powder was sized to $106-180 \mu \mathrm{m}$ pellets prior to characterization and reactivity measurements.

Fluorine-substituted hydroxyapatite, or fluorapatite, (FAP; $\left.\mathrm{Ca}_{10}\left(\mathrm{PO}_{4}\right)_{6} \mathrm{~F}_{2}\right)$ was prepared by solid-state reaction [25]. A stoichiometric mixture (3:1 molar ratio) of $\beta$-TCP (described above) and calcium fluoride $\left(\mathrm{CaF}_{2}\right.$, Sigma-Aldrich) was heated using an electrical tube furnace 
in flowing argon (UHP, 99.999\%) to $1373 \mathrm{~K}$ with a $4.5 \mathrm{~K} \mathrm{~min}^{-1}$ thermal ramp rate and holding at $1373 \mathrm{~K}$ for $4 \mathrm{~h}$. Pure $\mathrm{CaF}_{2}$ was placed in the furnace upstream of the reaction mixture to reduce the volatilization of fluorine $\left(\mathrm{as}_{\mathrm{CaF}}\right)[25,26]$.

Magnesium phosphate $\left(\mathrm{Mg}_{3}\left(\mathrm{PO}_{4}\right)_{2}\right)$ was obtained by heating magnesium phosphate hydrate $\left(\mathrm{Mg}_{3}\left(\mathrm{PO}_{4}\right)_{2} \times \mathrm{H}_{2} \mathrm{O}\right.$, Sigma-Aldrich) in flowing air to $873 \mathrm{~K}$ using a thermal ramp rate of $10 \mathrm{~K} \mathrm{~min}^{-1}$ from room temperature and holding at $873 \mathrm{~K}$ for $2 \mathrm{~h}$. The resulting $\mathrm{Mg}_{3}\left(\mathrm{PO}_{4}\right)_{2}$ powder was sized to $106-180 \mu \mathrm{m}$ pellets prior to characterization and reactivity measurements. Strontium phosphate $\left(\mathrm{Sr}_{3}\left(\mathrm{PO}_{4}\right)_{2}\right.$, Sigma-Aldrich) and magnesium oxide $(\mathrm{MgO}$, Ube Material Industries, Ltd) were obtained commercially. The strontium phosphate and magnesium oxide powders were calcined at $873 \mathrm{~K}$ for $2 \mathrm{~h}$ in flowing air with a $10 \mathrm{~K} \mathrm{~min}^{-1}$ ramp rate prior to characterization and reactivity measurements. The resulting $\mathrm{MgO}$ powder was sized to $106-180$ $\mu \mathrm{m}$ pellets prior to characterization and reactivity measurements.

\subsubsection{Catalyst Characterization}

Crystalline phases of the catalytic materials were confirmed by powder X-ray diffraction (XRD) on a PANalytical X'Pert Pro Multi-Purpose Diffractometer using monochromatic $\mathrm{Cu} \mathrm{K} \alpha$ radiation $(\lambda=1.54 \AA)$. Scans were collected at $2 \theta=10-100^{\circ}$ with a $0.05^{\circ}$ step size. Specific surface areas were obtained by $\mathrm{N}_{2}$ adsorption at $77 \mathrm{~K}$ on a Micromeritics ASAP 2020 automated analyzer using the BET method after evacuation at $723 \mathrm{~K}$ for $4 \mathrm{~h}$. Thermogravimetric analysis (TGA) experiments were conducted using a TA Instruments SDT Q600. Each sample was heated

to $1273 \mathrm{~K}$ from room temperature with a $10 \mathrm{~K} \mathrm{~min}^{-1}$ thermal ramp rate under $100 \mathrm{~cm}^{3} \mathrm{~min}^{-1}$ of flowing He. 
Elemental analyses of the catalytic materials were performed by Galbraith Laboratories, Inc. (Knoxville, TN). The metal and phosphorous content of the catalysts were measured using inductively coupled plasma optical emission spectroscopy (ICP-OES) and the fluorine content of the fluorapatite sample was determined using a fluoride ion specific electrode. The surface composition of the hydroxyapatite sample was analyzed by X-ray photoelectron spectroscopy (XPS) using a ThermoFisher ESCALab 250 apparatus. The signals were corrected using adventitious carbon $(\mathrm{C}(1) \mathrm{s})$ set to a binding energy of $284.6 \mathrm{eV}$.

The diffuse reflectance infrared Fourier transform spectroscopy (DRIFTS) of adsorbed pyridine was investigated using a Bio-Rad (FTS-60A) FTIR spectrometer equipped with a liquid-nitrogen-cooled MCT detector. The DRIFTS experiments were conducted using a hightemperature gas reaction chamber (Harrick Scientific) positioned onto a Praying Mantis diffuse reflectance sample accessory. All spectra were obtained by coadding and averaging 100 scans at a spectral resolution of $4 \mathrm{~cm}^{-1}$. The magnesium phosphate sample, diluted in KBr by $50 \mathrm{wt} \%$, was loaded into the DRIFTS cell and thermally treated in situ at $773 \mathrm{~K}$ for $1 \mathrm{~h}$ in flowing He (30 $\mathrm{cm}^{3} \mathrm{~min}^{-1}$ ) prior to pyridine exposure. Spectral backgrounds were then collected at 373 and 303 $\mathrm{K}$ as the sample cooled in flowing He. Pyridine (Sigma-Aldrich) was introduced to the DRIFTS cell at $303 \mathrm{~K}$ for $1 \mathrm{~min}$ by passing $\mathrm{He}\left(30 \mathrm{~cm}^{3} \mathrm{~min}^{-1}\right)$ through a pyridine saturator maintained at $273 \mathrm{~K}$ followed by purging under He flow $\left(30 \mathrm{~cm}^{3} \mathrm{~min}^{-1}\right)$ for $20 \mathrm{~min}$. The catalyst sample was then heated to $373 \mathrm{~K}$ and IR spectra were collected after 15 minutes of holding at $373 \mathrm{~K}$.

The nature, density, and strength of surface base sites were characterized using adsorption microcalorimetry of carbon dioxide $\left(\mathrm{CO}_{2}\right)$. The experiments were conducted at $303 \mathrm{~K}$ using a heat-flow microcalorimeter. Experimental procedures [7] as well as a detailed description of the apparatus [27] used for the calorimetry measurements have been reported in previous 
work. The samples were first outgassed at $773 \mathrm{~K}$ for $16 \mathrm{~h}$ under vacuum to a pressure below $10^{-3}$ Torr then cooled to room temperature. Incremental doses of the gas probe molecule were introduced to the catalyst via a volumetric dosing system and each dose was allowed to equilibrate with the sample for $15 \mathrm{~min}$. Adsorption isotherms and differential enthalpies of adsorption were obtained by measuring the amount of adsorbed species on the catalytic surface and the heats evolved for each dose.

\subsubsection{Catalytic Reactions}

Catalytic reactions of gas-phase ethanol were conducted using a fixed-bed, stainless steel, tubular reactor (ID: $0.46 \mathrm{~cm}$ ). The catalyst pellets were supported on a quartz wool plug in the reactor tube with a K-type thermocouple positioned at the center of the catalyst bed. Prior to reaction the catalysts were thermally treated in situ at $773 \mathrm{~K}$ for $1 \mathrm{~h}$ in flowing $\mathrm{N}_{2}\left(100 \mathrm{~cm}^{3} \mathrm{~min}^{-1}\right)$ after a $10 \mathrm{~K} \mathrm{~min}^{-1}$ thermal ramp. All catalytic experiments were performed at atmospheric total pressure. Anhydrous ethanol (Aldrich, 99.99\%) was introduced to the reactor system by passing a $\mathrm{N}_{2}$ carrier gas stream through a room temperature ethanol saturator. The reactor effluent streams were analyzed using an online Agilent 7890A gas chromatograph equipped with a Varian CP-PoraPLOT Q-HT column (25 m x $0.32 \mathrm{~mm}$ x $10 \mu \mathrm{m})$ and a flame ionization detector.

Water co-feeding experiments were conducted in the same manner described above with liquid water fed with a syringe pump to a vaporizer connected to the reactor system. In kinetic studies where the amount of ethanol in the gas stream was varied, ethanol was fed to the vaporizer with a syringe pump. 
The peak areas of reactants and products identified by GC were used to determine the ethanol conversion and selectivity of products. The conversion of ethanol was calculated as follows:

$$
\text { conversion }(C \%)=\left(\frac{\sum n_{i} M_{i}}{2 M_{0}}\right) \times 100
$$

where $n_{i}$ is the number of carbon atoms in product $i, M_{i}$ is the molar flow rate of product $i$, and $M_{0}$ is the initial molar flow rate of ethanol. The selectivity towards product $i$ was calculated on the basis of the total number of carbon atoms in the product and is therefore defined as:

$$
\text { selectivity }(C \%)=\left(\frac{n_{i} M_{i}}{\sum n_{i} M_{i}}\right) \times 100
$$

Aldol condensation reactions of acetaldehyde at $553 \mathrm{~K}$ were conducted using the same gas-phase reactor system described above. Acetaldehyde was introduced to the reactor system by passing a $\mathrm{N}_{2}$ carrier gas stream through an acetaldehyde saturator maintained at $273 \mathrm{~K}$ with an ice-water bath. Reactions were carried out at $220 \mathrm{kPa}$ total system pressure and $5 \mathrm{kPa}$ acetaldehyde partial pressure. Severe catalyst deactivation was observed therefore, initial rates were found by fitting results to an empirical hyperbolic function and extrapolating to zero time on stream. 


\subsection{Results and Discussion}

\subsubsection{Catalyst Characterization}

The BET surface areas of the catalytic materials studied in this work are listed in Table 4.1 along with the bulk metal and phosophorous content as determined by ICP-OES. As shown in the Table, the metal/phosphorus bulk molar ratio for all catalyst samples was close to the theoretical (stoichiometric) value. The fluorine content of the fluorapatite catalyst was measured to be $3.96 \mathrm{wt} \%$, slightly in exccess of the theoretical value $3.77 \mathrm{wt} \%$. The measured chemical composition of the FAP sample (Ca:P:F = 10:6.1:2.2) was in good agreement with the theoretical stoichiometric composition for FAP (Ca:P:F = 10:6:2). Surface analysis of the stoichiometric HAP catalyst by XPS revealed a lower $\mathrm{Ca} / \mathrm{P}$ surface molar ratio (1.46) than that of the bulk material (1.66). This finding appears to be a general characteristic of the HAP material that is often reported in the literature [17,28,29].

Table 4.1. Specific Surface Areas of Catalysts and Results from Elemental Analyses

\begin{tabular}{|c|c|c|}
\hline \multirow{2}{*}{ Catalyst } & $\mathbf{S}_{\text {BET }}$ & M/P Ratio \\
\cline { 3 - 3 } & $\left(\mathbf{m}^{\mathbf{2}} \mathbf{g}^{-\mathbf{1}}\right)$ & $\mathbf{B u l k}^{\mathbf{a}}$ \\
\hline $\mathrm{MgO}$ & 35 & -- \\
\hline $\mathrm{Mg}_{3}\left(\mathrm{PO}_{4}\right)_{2}$ & 21 & 1.51 \\
\hline$\beta-\mathrm{Ca}_{3}\left(\mathrm{PO}_{4}\right)_{2}$ & 5.2 & 1.46 \\
\hline $\mathrm{Ca}_{10}\left(\mathrm{PO}_{4}\right) \mathrm{F}_{2}$ & 0.5 & 1.64 \\
\hline $\mathrm{Ca}_{10}\left(\mathrm{PO}_{4}\right)_{6}(\mathrm{OH})_{2}$ & 35 & 1.66 \\
\hline $\mathrm{Sr}_{3}\left(\mathrm{PO}_{4}\right)_{2}$ & 1.5 & 1.47 \\
\hline
\end{tabular}

${ }^{\mathrm{a} D e t e r m i n e d ~ b y ~ I C P-O E S}$ 
Crystal structures of the catalytic materials were confirmed by powder X-ray diffraction. The XRD patterns of the stoichiometric calcium hydroxyapatite, fluorine-substituted hydroxyapatite, $\mathrm{MgO}$, and $\mathrm{Sr}_{3}\left(\mathrm{PO}_{4}\right)_{2}$ materials are presented in Figure 4.1. The diffraction patterns of the synthesized hydroxyapatite (Figure 4.1a) and fluorapatite (Figure 4.1b) powders are consistent with the known hexagonal dipyramidal crystal structure of the apatite framework (ICDD: 01-074-9780) and no additional crystalline phases were detected. The magnesia catalyst (Figure 4.1c) had an XRD pattern that is characteristic of periclase $\mathrm{MgO}$, the cubic form of magnesium oxide with no observable defects (ICDD: 00-004-0829). The diffraction pattern for the strontium phosphate catalyst (Figure 4.1d) is in agreement with the rhombohedral crystal stucture of phase pure $\mathrm{Sr}_{3}\left(\mathrm{PO}_{4}\right)_{2}$ (ICDD: 00-024-1008).

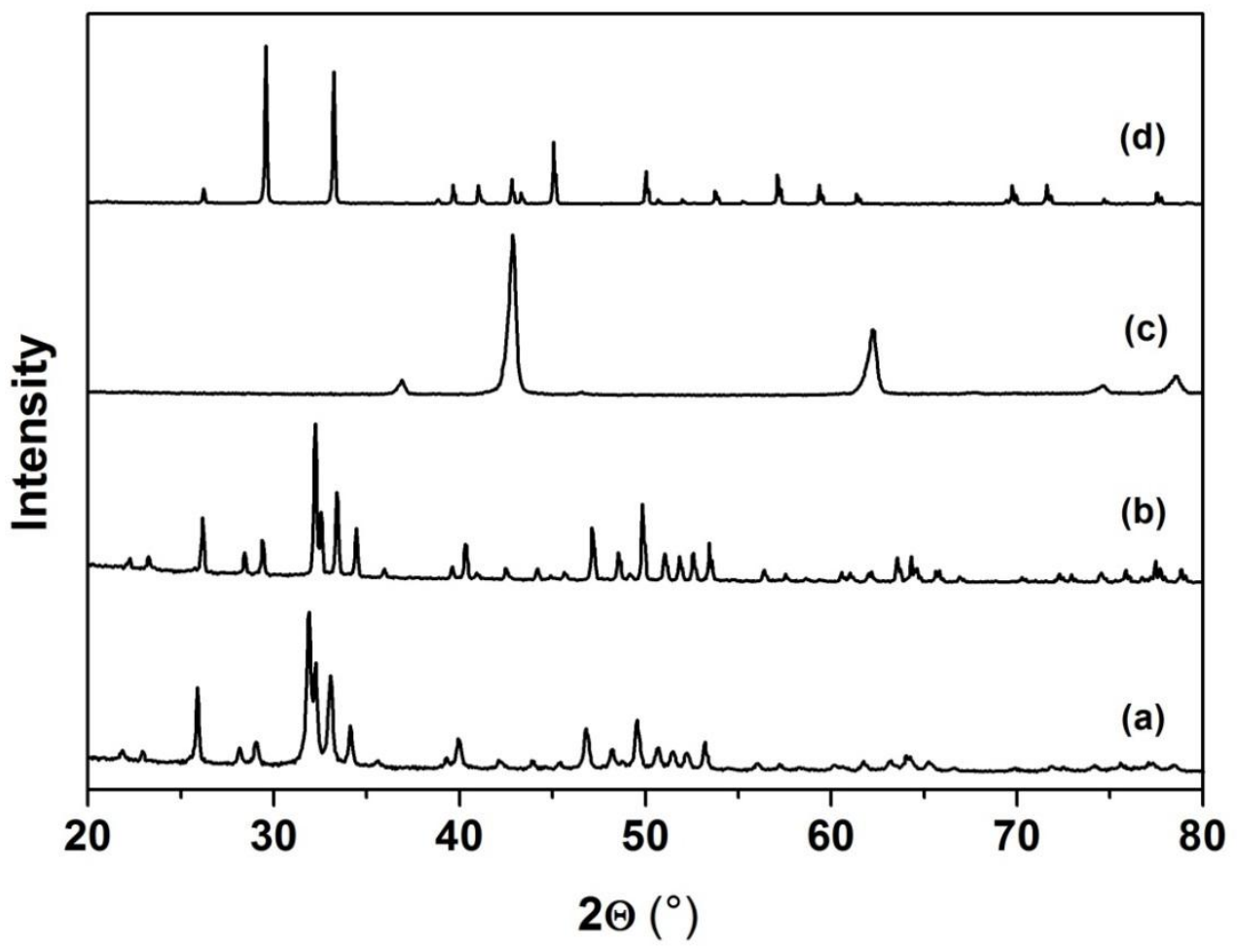

Figure 4.1. X-ray diffraction patterns of (a) stoichiometric hydroxyapatite (HAP; $\left.\mathrm{Ca}_{10}\left(\mathrm{PO}_{4}\right)_{6}(\mathrm{OH})_{2}\right)$, (b) fluorine-substitued hydroxyapatite (FAP; $\left.\mathrm{Ca}_{10}\left(\mathrm{PO}_{4}\right) \mathrm{F}_{2}\right)$, (c) periclase $\mathrm{MgO}$, and (d) strontium phosphate $\left(\mathrm{Sr}_{3}\left(\mathrm{PO}_{4}\right)_{2}\right)$. Patterns are offset for clarity. 
The powder X-ray diffraction patterns of calcium-deficient hydroxyapatite as received at room temperature and after calcination at $1073 \mathrm{~K}$ are shown in Figure $4.2 \mathrm{a}$ and $4.2 \mathrm{~b}$, respectively. The XRD pattern of calcium-deficient HAP after calcination (Figure 4.2b) is consistent with the reference pattern for the rhombohedral form of $\beta$-TCP (ICDD: 00-009-0169) and confirms that the HAP material transformed to phase pure $\beta$-TCP upon heating to $1073 \mathrm{~K}$.

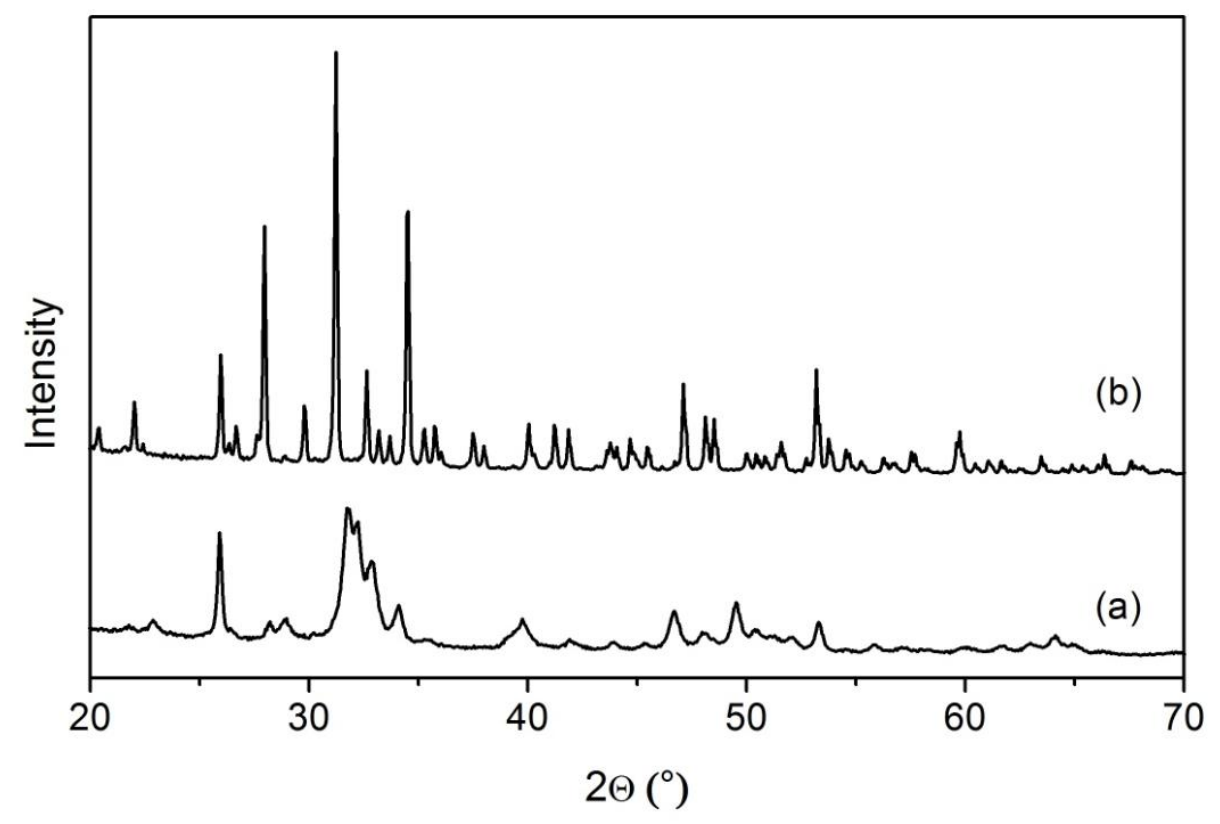

Figure 4.2. Powder X-ray diffraction pattern of calcium-deficient hydroxyapatite at (a) room temperature and (b) after calcination at $1073 \mathrm{~K}$ for $2 \mathrm{~h}$. in flowing air. Patterns are offset for clarity. 
Figure 4.3 displays the X-ray diffraction patterns of the $\mathrm{Mg}_{3}\left(\mathrm{PO}_{4}\right)_{2}$ sample after calcination at $873 \mathrm{~K}$ (Fig 4.3b) and the magnesium phosphate hydrate precursor as received at room temperature (Fig. 4.3a). The $\mathrm{Mg}_{3}\left(\mathrm{PO}_{4}\right)_{2}$ pattern is in agreement with the monoclininc crystal structure of $\mathrm{Mg}_{3}\left(\mathrm{PO}_{4}\right)_{2}$ (ICDD: 00-025-1373). Additionally, the inherently different XRD patterns of the two materials, confirms that a structural transformation from magnesium phosphate hydrate to magnesium phosphate occurred upon heating, related to the loss of stucutral water from the crystal lattice.

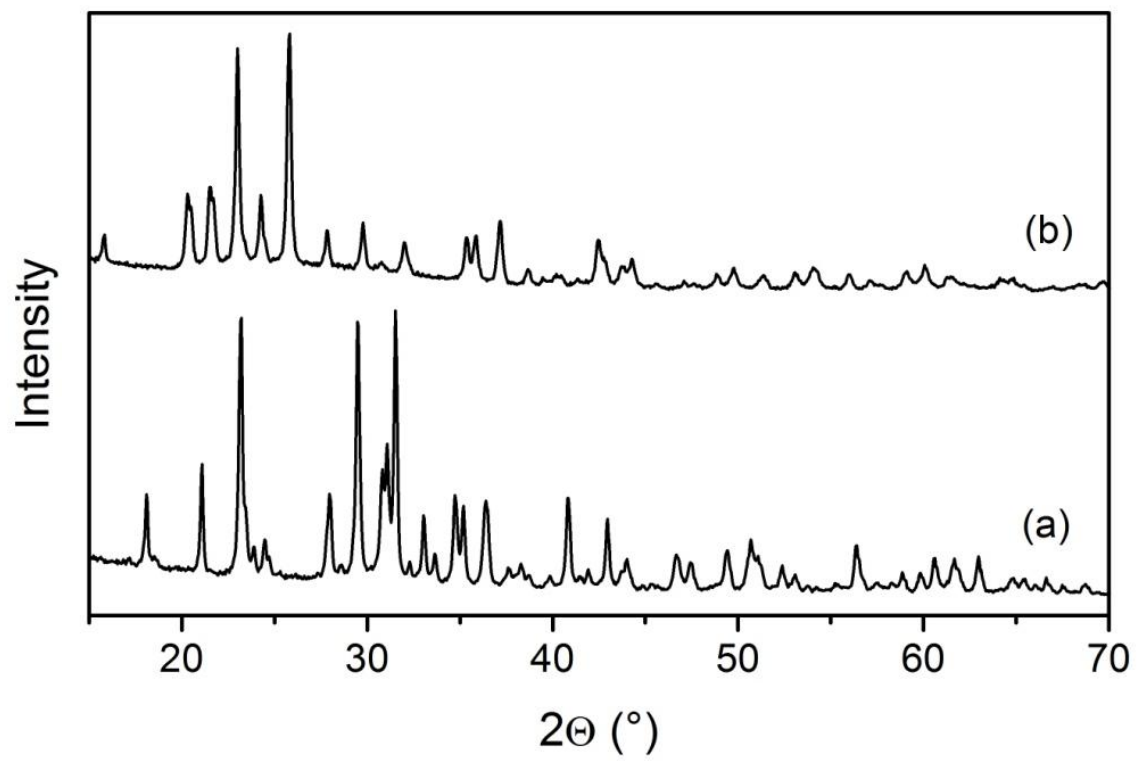

Figure 4.3. Powder $\mathrm{X}$-ray diffraction pattern of $\mathrm{Mg}_{3}\left(\mathrm{PO}_{4}\right)_{2} \mathrm{xH}_{2} \mathrm{O}$ at (a) room temperature and (b) after calcination at $873 \mathrm{~K}$ for $2 \mathrm{~h}$. in flowing air. Patterns are offset for clarity. 
To further verify that the magnesium phosphate hydrate $\left(\mathrm{Mg}_{3}\left(\mathrm{PO}_{4}\right)_{2} \mathrm{xH}_{2} \mathrm{O}\right)$ material fully transformed to magnesium phosphate after calcination at $873 \mathrm{~K}$, thermogravimetric analysis (TGA) was performed. The (TGA) profile of $\mathrm{Mg}_{3}\left(\mathrm{PO}_{4}\right)_{2} \mathrm{xH}_{2} \mathrm{O}$ is presented in Figure 4.4. Three major regions of weight loss were observed corresponding to derivative weight loss peaks at 472 , 625 , and $706 \mathrm{~K}$. These peaks are likely attributed to the loss of physisorbed and structural water. Negligible weight loss was observed from $800 \mathrm{~K}$ to the final program temperature at $1273 \mathrm{~K}$, implying that the final magnesium phosphate phase was fully dehydrated after calcination at 873 K.

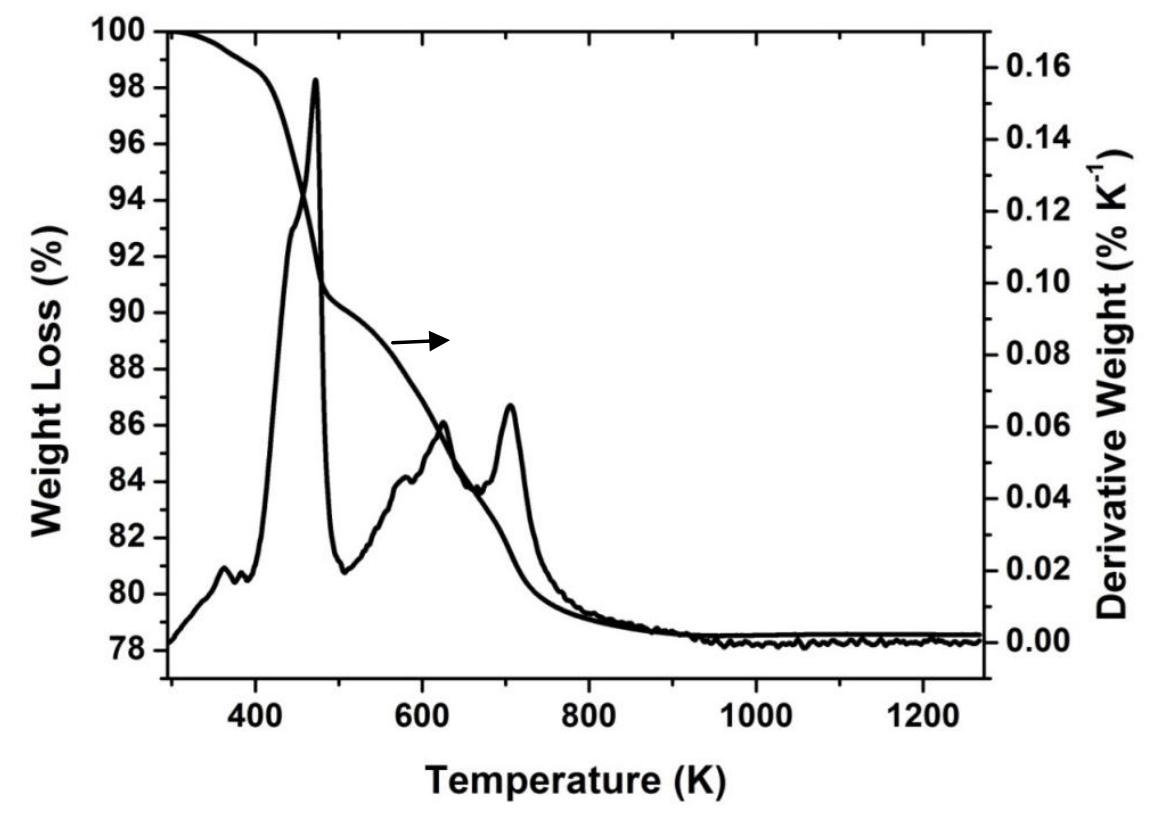

Figure 4.4. Thermogravimetric analysis (TGA) profile of magnesium phosphate hydrate $\left(\mathrm{Mg}_{3}\left(\mathrm{PO}_{4}\right)_{2} \times \mathrm{H}_{2} \mathrm{O}\right)$. 
The nature, density, and strength of surface base sites of the catalytic materials were characterized using adsorption microcalorimetry of carbon dioxide at $303 \mathrm{~K}$. Adsorption isotherms of $\mathrm{CO}_{2}$ on $\mathrm{HAP}, \mathrm{MgO}$, strontium phosphate, and $\beta$-TCP are presented in Figure 4.5a Stoichiometric HAP exhibited the highest overall $\mathrm{CO}_{2}$ uptake of $\sim 2.5 \mu \mathrm{mol} \mathrm{m}{ }^{-2}$, which was calculated by extrapolating the physisorption region of the isotherm to zero pressure. The measured $\mathrm{CO}_{2}$ adsorption capacities of the other catalysts were significantly lower, suggesting a much higher base site density exists on the surface of HAP compared to $\mathrm{MgO}, \mathrm{Sr}_{3}\left(\mathrm{PO}_{4}\right)_{2}$, and $\beta$ TCP. The $\beta$-TCP catalyst exposed the least amount of $\mathrm{CO}_{2}$ adsorption sites indicated by the significantly lower adsorption isotherm, suggesting a small number of base sites present on this surface. The $\mathrm{MgO}$ and $\mathrm{Sr}_{3}\left(\mathrm{PO}_{4}\right)_{2}$ surfaces exhibited an intermediate base site density of $\sim 1.0$ $\mu \mathrm{mol} \mathrm{m} \mathrm{m}^{-2}$. The $\mathrm{CO}_{2}$ adsorption isotherm measured for strontium phosphate is a result of a considerably smaller total $\mathrm{CO}_{2}$ dosing pressure due to the very low surface area of this material (Table 4.1).

Differential heats of $\mathrm{CO}_{2}$ adsorption as a function of surface coverage are presented in Figure 4.5b. The highest initial heat of $\mathrm{CO}_{2}$ adsorption was measured on the $\mathrm{MgO}$ surface ($\Delta \mathrm{H}_{\mathrm{ads}}=130 \mathrm{~kJ} \mathrm{~mol}^{-1}$ ) suggesting $\mathrm{MgO}$ exposed stronger base sites that interact with $\mathrm{CO}_{2}$, relative to the other materials. Stoichiometric HAP possessed an intermediate-strength basicity with an initial heat of $\mathrm{CO}_{2}$ adsorption of $102 \mathrm{~kJ} \mathrm{~mol}^{-1}$. Low $\mathrm{CO}_{2}$ adsorption enthalpies were measured on the metal phosphate catalysts, $\mathrm{Sr}_{3}\left(\mathrm{PO}_{4}\right)_{2}$, and $\beta$-TCP, which are indicative of low-strength base sites.

Infrared spectroscopy has revealed the presence of two adsorption sites on the surface of stoichiometric HAP for $\mathrm{CO}_{2}$ : basic $\mathrm{OH}^{-}$and $\mathrm{O}^{2-}$ of $\mathrm{PO}_{4}{ }^{3-}$ groups [21]. These reports have shown that the phosphate groups are considerably less basic than the $\mathrm{OH}^{-}$group and thus $\mathrm{CO}_{2}$ 
predominantly interacts with surface hydroxyls on HAP, forming bicarbonate species [19]. These findings account for the lower $\mathrm{CO}_{2}$ adsorption capacity and weaker base site strength measured on the metal phosphate catalysts, which lack structural hydroxyl groups, compared with HAP.
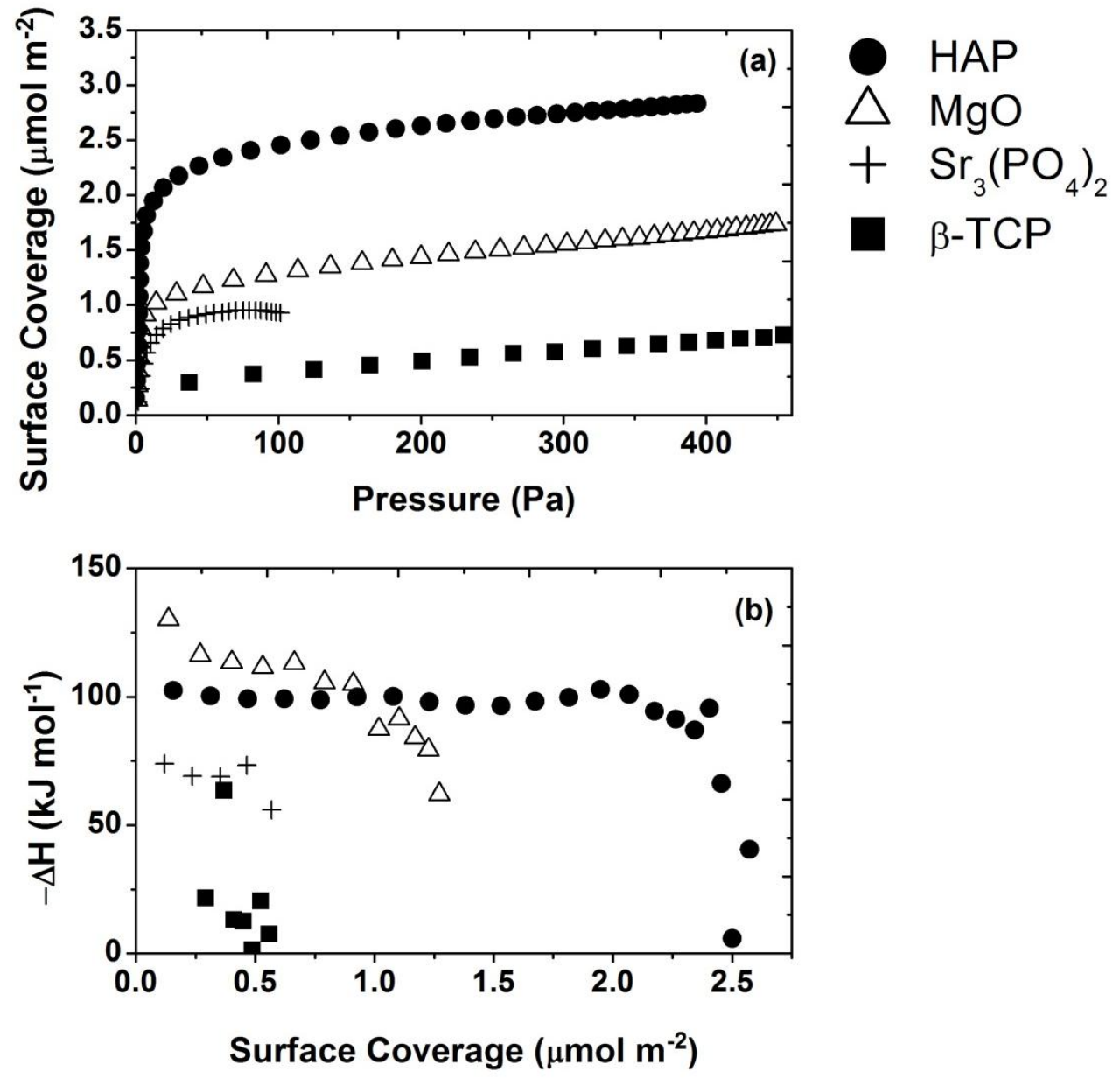

Figure 4.5. Adsorption microcalorimetry of carbon dioxide on the catalytic materials at $303 \mathrm{~K}$; (a) adsorption isotherms of carbon dioxide (b) differential heats of adsorption as a function of coverage. 


\subsubsection{Catalytic Reactions of Ethanol}

The total rate of ethanol conversion and product formation rates as a function of the initial ethanol concentration over stoichiometric calcium hydroxyapatite at $613 \mathrm{~K}$ are presented in Figure 4.6. All of the rates displayed in the Figure were evaluated at similar ethanol conversions $(\sim 5 \%)$. The total rate of ethanol conversion, which was calculated as the sum of the product formation rates, appears to be approximately first-order at low initial ethanol concentrations and zero-order at higher concentrations of ethanol. This observation is consistent with results reported recently by Ho et al. [30].

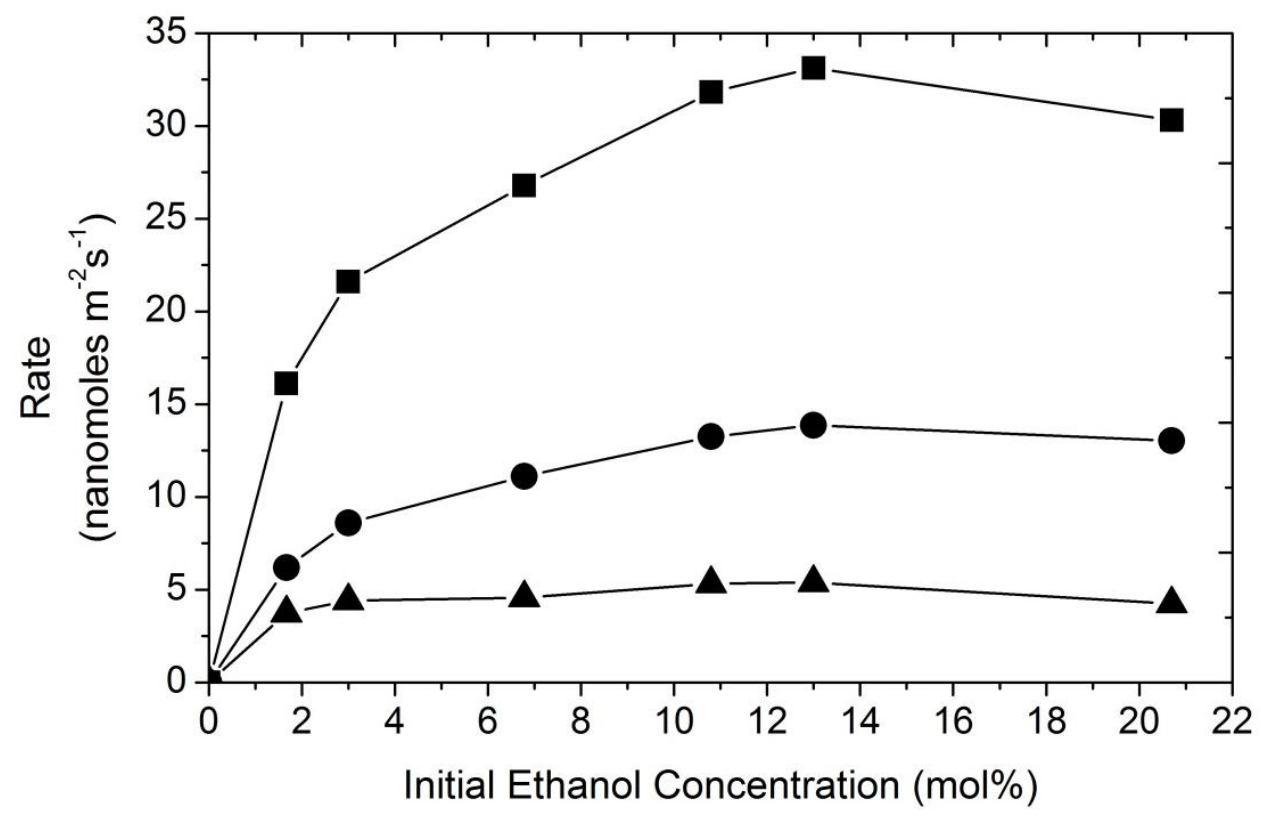

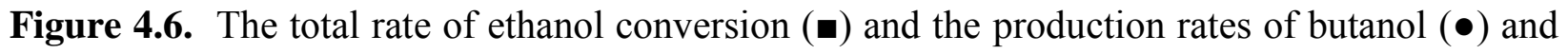
acetaldehyde $(\boldsymbol{\Delta})$ as a function of the initial ethanol concentration during the steady-state conversion of ethanol over stoichiometric calcium hydroxyapatite at $613 \mathrm{~K}$. 


\section{Dihydrogen co-feeding Experiments}

One aspect of the Guerbet coupling of ethanol into butanol that remains unclear is the role and chemical state of the dihydrogen that is produced in the reaction from alcohol dehydrogenation. There are several possible scenarios for the dihydrogen evolved via dehydrogenation of ethanol: desorption into the gas-phase as dihydrogen gas, surface migration followed by recombination and desorption as dihydrogen, or surface $\mathrm{H}$-adatoms used for successive hydrogenation reactions of C-C coupling intermediates [31]. To gain insight into the effect of dihydrogen on the Guerbet coupling of ethanol, dihydrogen was co-fed with ethanol during the steady-state reaction over stoichiometric hydroxyapatite at $613 \mathrm{~K}$. The results obtained during the co-feed of dihydrogen to the reaction are presented in Figure 4.7.

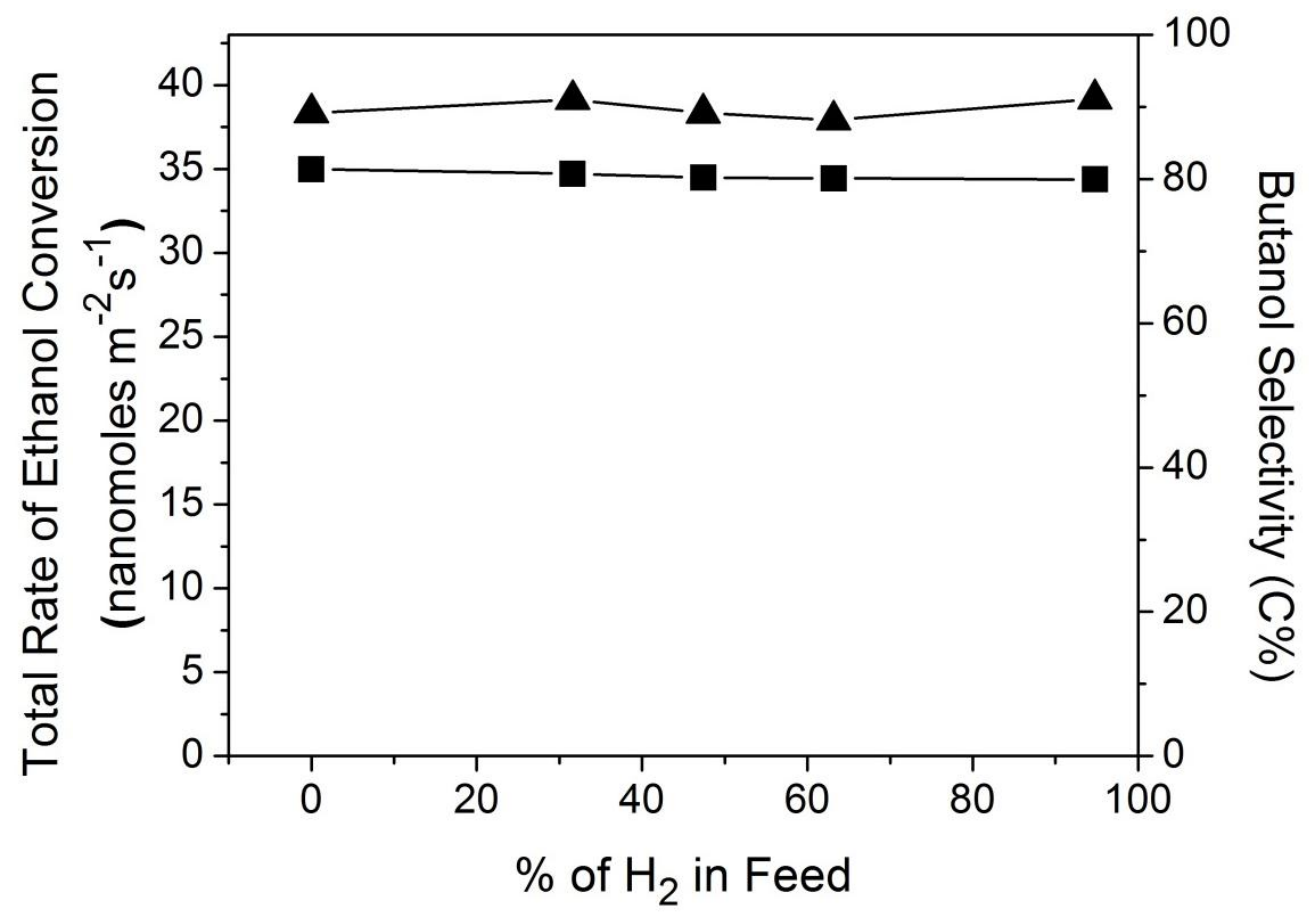

Figure 4.7. The effect of increasing gas-phase dihydrogen on the total rate of ethanol conversion $(\boldsymbol{\Delta})$ and the butanol selectivity $(\bullet)$ during the steady-state coupling of ethanol over stoichiometric hydroxyapatite at $613 \mathrm{~K}$. 
Increasing the concentration of dihydrogen in the feed, even to $>90 \%$ of the feed, had no observable effect on the total rate of ethanol conversion or the butanol selectivity. Evidently, atmospheric dihydrogen does not play a role in the catalysis during Guerbet coupling of ethanol to butanol over hydroxyapatite catalysts. This observation suggests that gas-phase dihydrogen is not the source for hydrogenation steps in the Guerbet coupling reaction sequence over HAP and that ethanol is the likely source of hydrogen. These results are consistent with those reported by Ogo et al. [13] who observed no hydrogenation products when croty alcohol was co-fed with $\mathrm{H}_{2}$ over Sr-hydroxyapatite at $573 \mathrm{~K}$.

\section{Water Co-feeding Experiments}

Water is a by-product in the coupling of ethanol to butanol and therefore its effect on the overall reaction is of interest. The detrimental effect of water in liquid-phase systems has been reported and is generally ascribed to water accumulation in the reaction vessel that can lead to catalyst deactivation and/or undesirable side reactions (i.e. via base-catalyzed Tishchenko or Cannizzaro reactions) [32,33]. However, to the best of our knowledge, the role of water in the conversion of ethanol into butanol in the gas-phase has not been reported. Thus, the introduction and removal of water during the steady-state, vapor-phase conversion of ethanol was investigated over stoichiometric HAP at $613 \mathrm{~K}$ (Figure 4.8) and $\mathrm{MgO}$ at $673 \mathrm{~K}$ (Figure 4.9).

The introduction of water to the reaction over stoichiometric HAP rapidly inhibited production of butanol (Figure 4.8). In contrast, the production rate of acetaldehyde was decreased by half of the steady-state rate prior to the addition of water. The removal of water from the feed to the reactor restored butanol and acetaldehyde formation rates to greater than 
$70 \%$ of their original steady-state values, suggesting weak and reversible interactions of water with the HAP surface.

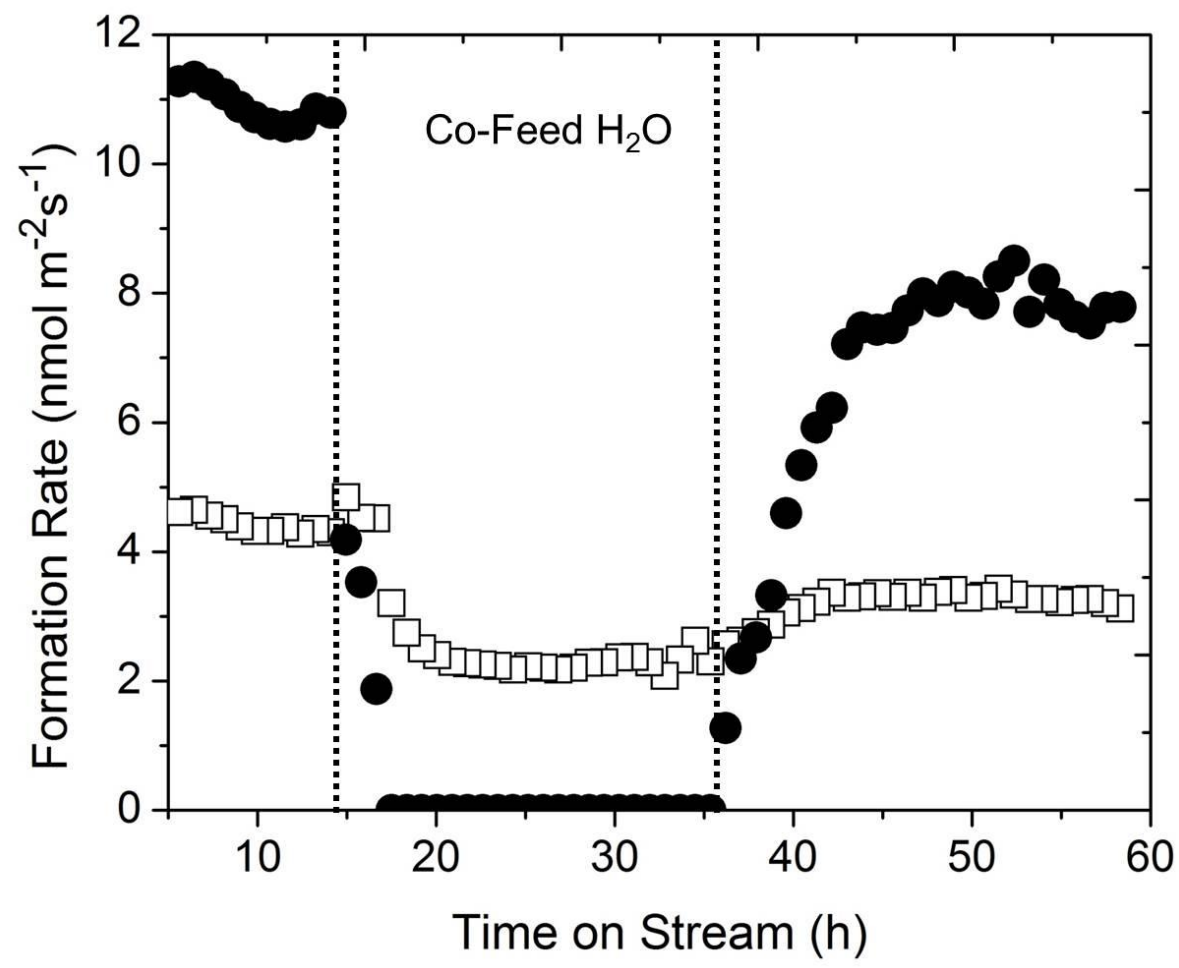

Figure 4.8. Production rates of $(\bullet)$ butanol and $(\square)$ acetaldehyde obtained during the steady-state conversion of ethanol over stoichiometric hydroxyapatite at $613 \mathrm{~K}$ with the addition and removal of water.

Bolis and co-workers [34] investigated the hydrophilicity of HAP materials using adsorption microcalorimetry and IR spectroscopy measurements and found that water adsorption sites on the surface of HAP were composed of coordinatively unsaturated $\mathrm{Ca}^{2+}$ and nearby hydrophilic $\mathrm{PO}_{4}^{-3}$ species. The findings in that work are consistent with those reported recently by Diallo-Garcia et al. [21] who observed a decrease in the IR bands ascribed to $\mathrm{O}^{2-}$ of surface $\mathrm{PO}_{4}{ }^{3-}$ groups upon water adsorption onto the HAP surface. The reported interaction of water with phosphate groups on the HAP surface together with the observed poisoning effect of water on 
butanol formation during the reaction (Figure 4.8), suggests that the $\mathrm{PO}_{4}{ }^{3-}$ group is likely involved in the active site for $\mathrm{C}-\mathrm{C}$ bond formation during ethanol coupling over HAP. This finding is consistent with the reactivity results obtained during the ethanol coupling reaction over FAP and $\beta$-TCP discussed later in the chapter (Table 4.2).

The effect of water co-fed with ethanol during the reaction over $\mathrm{MgO}$ at $673 \mathrm{~K}$ is presented in Figure 4.9. The introduction of water decreased acetaldehyde formation rates by a factor of 3, whereas ethene and butanol production was eliminated after water addition. Similar to the results observed over stoichiometric HAP (Fig. 4.8), the presence of water during the reaction over $\mathrm{MgO}$ appears to have a greater inhibiting effect on $\mathrm{C}-\mathrm{C}$ bond forming steps compared to ethanol dehydrogenation.

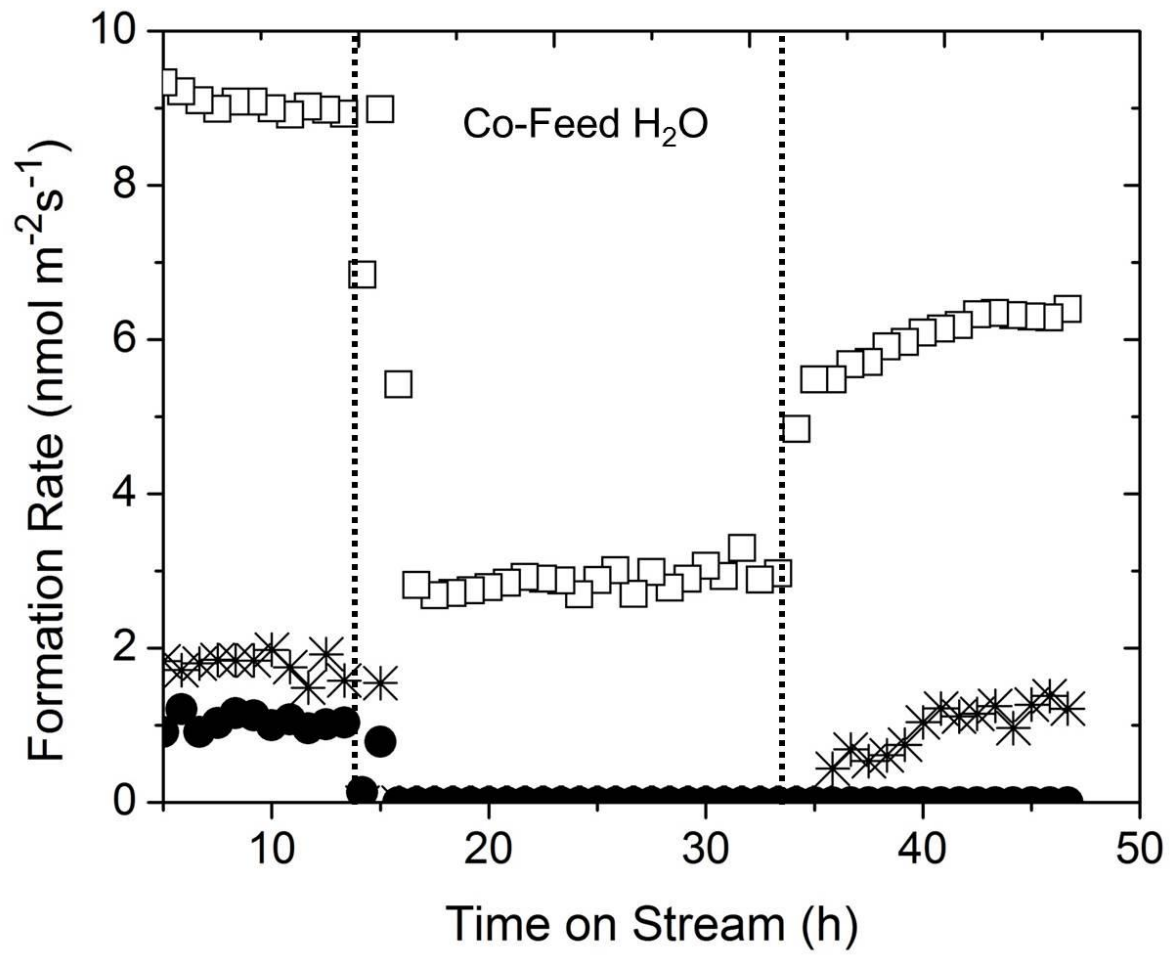

Figure 4.9. Production rates of $(\bullet)$ butanol, $(\square)$ acetaldehyde, and $(*)$ ethene obtained during the steady-state conversion of ethanol over $\mathrm{MgO}$ at $673 \mathrm{~K}$ with the addition and removal of water. 
In contrast to the HAP surface, however, the active sites on $\mathrm{MgO}$ that participated in the production of butanol were not regenerated after stopping the addition of water. The sites on $\mathrm{MgO}$ responsible for ethene and acetaldehyde formation rates were nearly restored when water was removed from the feed. These observations suggest that water irreversibly adsorbed onto $\mathrm{MgO}$ surface sites that were catalytically active for butanol formation, most likely by dissociative adsorption. The dissociative adsorption of water on the $\mathrm{MgO}$ surface is well-studied and occurs on an acid-base site pair that contains strong base sites. The $\mathrm{OH}^{-}$from water coordinates to a Lewis acid site (coordinatively unsaturated $\mathrm{Mg}^{2+}$ cation) and $\mathrm{H}^{+}$from water coordinates to a Brønsted base site provided by the $\mathrm{O}^{2-}$ anion $[35,36]$. Thus, based on these results it can be inferred that cofed water dissociatively adsorbs onto Lewis acid-strong base site pairs $\left(\mathrm{Mg}^{2+}-\mathrm{O}^{2-}\right)$ on $\mathrm{MgO}$ during the ethanol coupling reaction, which inhibits $\mathrm{C}-\mathrm{C}$ bond formation. Interestingly, the irreversible adsorption of water onto these sites did not inhibit the production of acetaldehyde or ethene.

Compared to the $\mathrm{MgO}$ surface, the base sites exposed on HAP are significantly weaker in strength, as measured by $\mathrm{CO}_{2}$ adsorption microcalorimetry (Figure 4.5b) and likely accounts for the weak and reversible surface interactions observed between water and the HAP surface during Guerbet coupling of ethanol. This observation has important implications in reactions where water is formed in situ as a product such as Guerbet coupling and aldol condensation and may account for the significantly higher catalytic activity of HAP for these reactions compared to $\operatorname{MgO}[18,37]$. 


\section{Catalyst Performance during Steady-state Conversion of Ethanol}

The observed inhibitory influence of water on butanol formation over stoichiometric HAP during the steady-state conversion of ethanol (Figure 4.8) and prior observations that water adsorption on HAP occurs on $\mathrm{PO}_{4}^{3-}[21,34]$, motivated us to investigate the $\mathrm{PO}_{4}^{3-}$ group of HAP further to gain insight as to whether it is involved in the active site for $\mathrm{C}-\mathrm{C}$ bond formation during the ethanol coupling reaction. In an effort to study the potential roles of cations $\left(\mathrm{Ca}^{2+}\right.$, $\left.\mathrm{Mg}^{2+}, \mathrm{Sr}^{2+}\right)$ and anions $\left(\mathrm{OH}^{-}, \mathrm{F}^{-}\right)$on the reactivity of phosphate based catalysts, a variety of catalysts such as $\beta$-TCP $\left(\mathrm{Ca}_{3}\left(\mathrm{PO}_{4}\right)_{2}\right), \mathrm{Sr}_{3}\left(\mathrm{PO}_{4}\right)_{2}, \mathrm{Mg}_{3}\left(\mathrm{PO}_{4}\right)_{2}$, and fluorapatite (FAP; $\mathrm{Ca}_{10}\left(\mathrm{PO}_{4}\right)$ $\left.{ }_{6} \mathrm{~F}_{2}\right)$ were tested in Guerbet coupling and compared to hydroxyapatite $\left(\mathrm{HAP} ; \mathrm{Ca}_{10}\left(\mathrm{PO}_{4}\right)_{6}(\mathrm{OH})_{2}\right)$. The product distribution and steady-state rates observed during ethanol conversion at $633 \mathrm{~K}$ for the catalysts are listed in Table 4.2. All catalytic reactions were conducted at low ethanol conversions $(\sim 5 \%)$ to ensure differential reactor conditions. The data confirming differential conversion for the catalytic reactions are presented in Appendix C.

Table 4.2. Product Distribution during Ethanol Coupling at $633 \mathrm{~K}$

\begin{tabular}{|c|c|c|c|c|c|c|c|c|c|}
\hline \multirow{2}{*}{ Catalyst } & \multirow{2}{*}{$\begin{array}{c}\text { Ethanol } \\
\text { Conv. } \\
(\%)\end{array}$} & \multirow{2}{*}{$\begin{array}{c}\text { Rate of } \\
\text { Ethanol } \\
\text { Conversion } \\
\left(\mathrm{mol} \mathrm{m}^{-2} \mathrm{~s}^{-1}\right)\end{array}$} & \multirow{2}{*}{$\begin{array}{c}\text { Rate of } \\
\text { AcH } \\
\text { Production } \\
\left(\mathrm{mol} \mathrm{m}^{-2} \mathrm{~s}^{-1}\right)\end{array}$} & \multirow{2}{*}{$\begin{array}{c}\text { Rate of } \\
\text { BuOH } \\
\text { Production } \\
\left(\mathrm{mol} \mathrm{m}^{-2} \mathrm{~s}^{-1}\right)\end{array}$} & \multicolumn{5}{|c|}{ Selectivity (C\%) } \\
\hline & & & & & Ethane & Ethene & $\mathrm{AcH}$ & DEE & $\mathrm{BuOH}$ \\
\hline $\mathrm{MgO}$ & 4.4 & $2.4 \times 10^{-9}$ & $1.4 \times 10^{-9}$ & $4.0 \times 10^{-10}$ & 0 & 8 & 59 & 0 & 33 \\
\hline $\mathrm{Mg}_{3}\left(\mathrm{PO}_{4}\right)_{2}$ & 5.0 & $6.5 \times 10^{-9}$ & $7.6 \times 10^{-10}$ & 0 & 0 & 36 & 12 & 52 & 0 \\
\hline$\beta-\mathrm{Ca}_{3}\left(\mathrm{PO}_{4}\right)_{2}$ & 4.2 & $2.7 \times 10^{-8}$ & $1.6 \times 10^{-8}$ & $4.7 \times 10^{-9}$ & 2 & 0 & 59 & 4 & 35 \\
\hline $\mathrm{Ca}_{10}\left(\mathrm{PO}_{4}\right)_{6} \mathrm{~F}_{2}$ & 2.7 & $2.3 \times 10^{-8}$ & $1.4 \times 10^{-8}$ & $4.3 \times 10^{-9}$ & 0 & 0 & 62 & 0 & 38 \\
\hline $\mathrm{Ca}_{10}\left(\mathrm{PO}_{4}\right)_{6}(\mathrm{OH})_{2}$ & 4.9 & $8.7 \times 10^{-8}$ & $2.4 \times 10^{-8}$ & $3.1 \times 10^{-8}$ & 0 & 0 & 28 & 0 & 72 \\
\hline $\mathrm{Sr}_{3}\left(\mathrm{PO}_{4}\right)_{2}$ & 4.2 & $1.6 \times 10^{-7}$ & $1.5 \times 10^{-7}$ & $7.2 \times 10^{-9}$ & 0 & 0 & 91 & 0 & 9 \\
\hline
\end{tabular}

$\mathrm{AcH}$ - Acetaldehyde; DEE - Diethyl ether; $\mathrm{BuOH}$ - Butanol

The hydroxyapatite $\left(\mathrm{Ca}_{10}\left(\mathrm{PO}_{4}\right)_{6}(\mathrm{OH})_{2}\right)$ catalyst exhibited the highest catalytic activity for butanol production and the highest selectivity to butanol (72\%) among all of the catalysts tested. The $\beta$-TCP and FAP catalysts were $\sim 3$ times less active and $\sim 50 \%$ less selective towards butanol, 
compared to HAP, which implies that the hydroxyl group of HAP likely plays a beneficial role in the catalysis during the coupling of ethanol to butanol. Although the catalytic activity and selectivity to butanol over $\beta$-TCP and FAP were not as impressive as those over HAP, the Guerbet coupling reaction was still observed. This observation suggests that the $\mathrm{PO}_{4}{ }^{3-}$ group is critical for the production of butanol over $\beta$-TCP and FAP and is likely the base site in the active site pair for butanol formation during ethanol coupling over HAP. These results are consistent with the water co-feeding experiments over HAP (Figure 4.8) where the inhibiting effect of water on butanol formation was likely the result of water interactions with adjacent $\mathrm{Ca}-\mathrm{PO}_{4}{ }^{3-}$ site pairs on the surface [34].

The $\mathrm{MgO}$ catalyst was the least active among all of the catalysts tested and catalyzed primarily the dehydrogenation of ethanol to acetaldehyde (59\% selectivity). The undesired byproduct, ethene, which was formed by dehydration of ethanol was also observed (8\% selectivity).

As discussed earlier, the Guerbet coupling of ethanol to butanol likely proceeds over an acid-base site pair and thus, the poor catalytic performance of $\mathrm{MgO}$ in alcohol coupling reactions has been attributed to strongly basic $\mathrm{O}^{2-}$ anions that are disproportionate in strength and accessibility to the surface Lewis acid sites provided by coordinatively unsaturated cations (i.e. $\mathrm{Mg}^{2+}$ ). These strong base sites on $\mathrm{MgO}$, as measured by $\mathrm{CO}_{2}$ adsorption microcalorimetry (Figure 4.5), also facilitate undesired ethanol dehydration to ethene via $\mathrm{E}_{1 \mathrm{cB}}$ pathways. The relative strengths of the active acid and base sites that are involved in the pair must be carefully balanced to achieve high activity and selectivity to butanol while minimizing unwanted byproduct formation.

Increasing the acid site density on the $\mathrm{MgO}$ surface or balancing the relative strengths of the acid and base sites on the surface has been beneficial for the Guerbet coupling reaction 
$[8,38]$. This optimization of acid-base strength as a strategy for improving Guerbet coupling catalysts is consistent with the results presented in Table 4.2. The total rate of ethanol conversion over the $\beta$-TCP and FAP catalysts was an order of magnitude higher than that measured over $\mathrm{MgO}$. Compared to $\mathrm{MgO}$, these materials contain base sites of much weaker strength and a significantly higher acid site density (Chapter 2). An increased number of weaker acid-base site pairs on the surface likely allows $\beta$-TCP and FAP to catalyze the ethanol conversion reaction at a significantly higher rate than highly-basic $\mathrm{MgO}$.

The critical requirement of balanced-strength acid and base sites for the Guerbet coupling reaction is clearly visible when comparing the results obtained during ethanol conversion over $\mathrm{MgO}$ and $\mathrm{Mg}_{3}\left(\mathrm{PO}_{4}\right)_{2}$. The phosphate group of $\mathrm{Mg}_{3}\left(\mathrm{PO}_{4}\right)_{2}$ is considerably less basic than $\mathrm{O}^{2-}$ anions present on the $\mathrm{MgO}$ surface so that the catalysis shifts from ethanol dehydrogenation over $\mathrm{MgO}$ towards acid-catalyzed ethanol dehydration. The $\mathrm{Mg}_{3}\left(\mathrm{PO}_{4}\right)_{2}$ catalyst exhibited characteristic acid-like behavior leading to $52 \%$ and $36 \%$ selectivity towards diethyl ether and ethene, respectively. Additionally, this material was catalytically inactive for $\mathrm{C}-\mathrm{C}$ coupling to butanol (Table 4.2).

To characterize the acid sites present on the $\mathrm{Mg}_{3}\left(\mathrm{PO}_{4}\right)_{2}$ surface, DRIFTS of adsorbed pyridine was performed. Infrared spectroscopy of pyridine is commonly used to characterize acid sites because the IR signature of pyridine coordinated to a Lewis acid site on the surface is very different from that of the pyridinium ion, i.e. when it is associated with a Brønsted acid, which permits differentiation between acid types on solid acid surfaces [39].

The DRIFTS spectrum of adsorbed pyridine on $\mathrm{Mg}_{3}\left(\mathrm{PO}_{4}\right)_{2}$ at $373 \mathrm{~K}$ is presented in Figure 4.10. Pyridine adsorbed on $\mathrm{Mg}_{3}\left(\mathrm{PO}_{4}\right)_{2}$ resulted in bands at 1608, 1576, 1491, and 1446 $\mathrm{cm}^{-1}$ which is characteristic with Lewis-type coordination with the surface [40]. The absence of 
a band at $1540 \mathrm{~cm}^{-1}$, characteristic of the pyridinium ion, indicates a lack of Brønsted acidity associated with the $\mathrm{Mg}_{3}\left(\mathrm{PO}_{4}\right)_{2}$ surface. Therefore the surface acid sites exposed on $\mathrm{Mg}_{3}\left(\mathrm{PO}_{4}\right)_{2}$ are of the Lewis-type and confirms that ethanol dehydration observed over this material was Lewis-acid catalyzed. Evidently, the base site $\left(\mathrm{PO}_{4}{ }^{3-}\right.$ group) of the acid-base site pair on $\mathrm{Mg}_{3}\left(\mathrm{PO}_{4}\right)_{2}$ was too weak relative to the Lewis acid sites provided by $\mathrm{Mg}^{2+}$, which dominated the catalyst performance favoring dehydration over coupling.

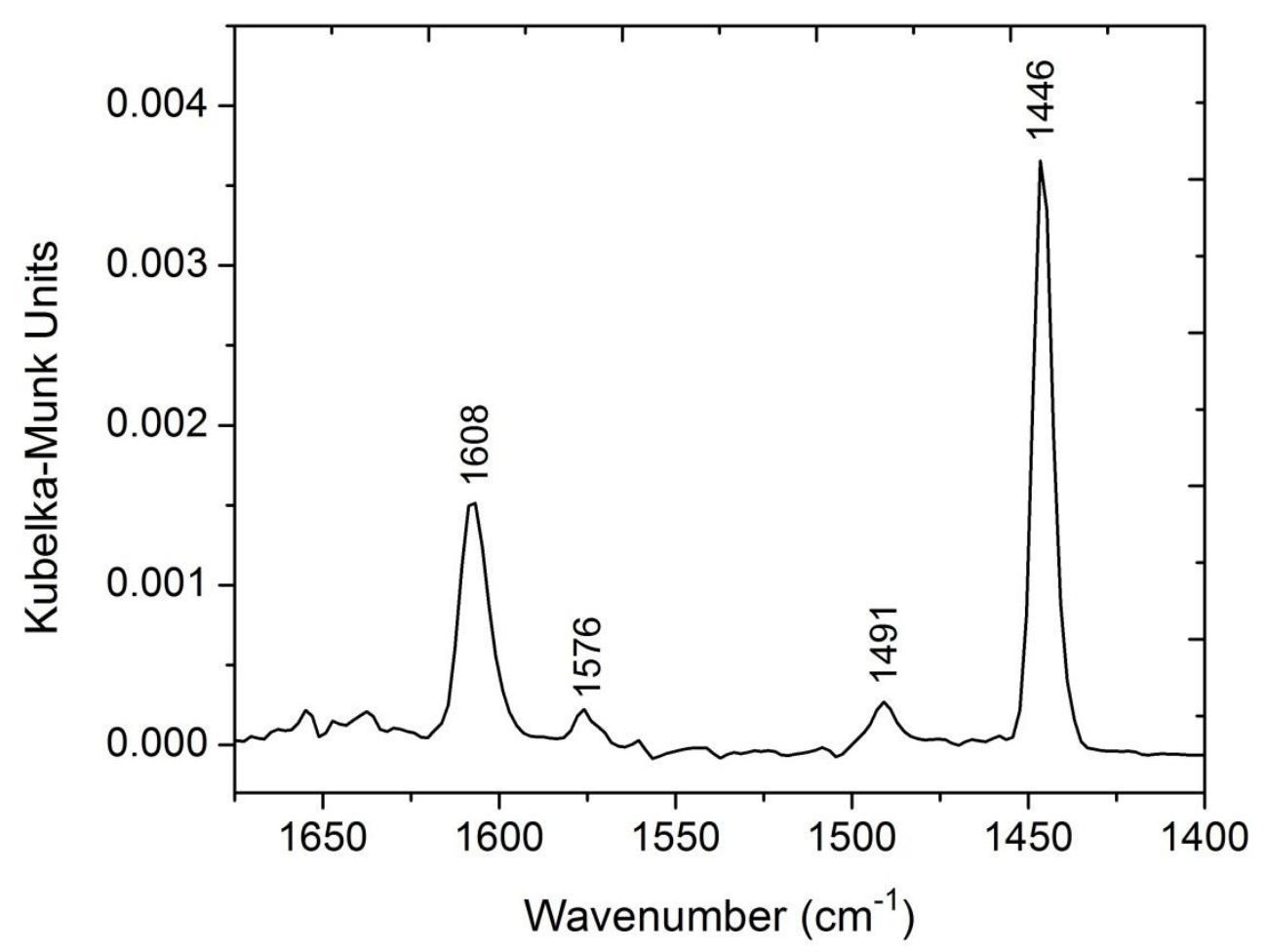

Figure 4.10. DRIFTS of adsorbed pyridine on $\mathrm{Mg}_{3}\left(\mathrm{PO}_{4}\right)_{2}$ at $373 \mathrm{~K}$ after purging with He for 20 min. The observed peaks are characteristic of pyridine coordinately bonded to Lewis acid sites. 
The influence of Lewis acidity was explored by comparing the catalytic activity during reactions of ethanol over $\mathrm{Mg}_{3}\left(\mathrm{PO}_{4}\right)_{2}, \mathrm{Ca}_{3}\left(\mathrm{PO}_{4}\right)_{2}$, and $\mathrm{Sr}_{3}\left(\mathrm{PO}_{4}\right)_{2}$. Decreasing the electronegativity of the metal cation from $\mathrm{Mg}^{2}$ to $\mathrm{Ca}^{2+}$ significantly improved the catalytic performance of the material during the Guerbet coupling reaction. The $\beta$-TCP catalyst exhibited a higher rate of ethanol conversion, lower ethanol dehydration rates, and higher selectivity to butanol (35\% selectivity), relative to $\mathrm{Mg}_{3}\left(\mathrm{PO}_{4}\right)_{2}$. The acid-catalyzed biomolecular ethanol dehydration product, diethyl ether, was observed in minor quantities over $\beta$-TCP (4\% selectivity), however the acidsites responsible for diethyl ether formation from primary alcohols have been shown to be weaker than those required for ethene formation, which is consistent with the expected decrease in Lewis acidity from $\mathrm{Mg}^{2}$ to $\mathrm{Ca}^{2+}[8]$.

The rate of ethanol conversion over the $\mathrm{Sr}_{3}\left(\mathrm{PO}_{4}\right)_{2}$ catalyst was the highest of the pure phosphate materials $\left(\mathrm{Mg}^{2}, \mathrm{Ca}^{2+}, \mathrm{Sr}^{2+}\right)$ and the product distribution was nearly all acetaldehyde (91\% selectivity). Interestingly, the $\mathrm{Sr}_{3}\left(\mathrm{PO}_{4}\right)_{2}$ catalyst was significantly more active for ethanol dehydrogenation than any of the other catalysts tested, including hydroxyapatite. The rate of acetaldehyde formation over $\mathrm{Sr}_{3}\left(\mathrm{PO}_{4}\right)_{2}$ was an order of magnitude higher than that observed over $\beta$-TCP and over two orders of magnitude higher than that observed over $\operatorname{Mg}_{3}\left(\mathrm{PO}_{4}\right)_{2}$. However, this material lead to poor selectivity towards coupled products during the reaction.

In an attempt to understand the coupling activity of $\mathrm{Sr}_{3}\left(\mathrm{PO}_{4}\right)_{2}$ we (together with Zachary Young) tested its catalytic activity in acetaldehyde condensation at $553 \mathrm{~K}$ with $5 \mathrm{kPa}$ partial pressure of acetaldehyde, and compared the results to those obtained over anatase titania $\left(\mathrm{TiO}_{2}\right)$, $\mathrm{HAP}$, and $\mathrm{MgO}$ (Table 4.3). The reaction over $\mathrm{Sr}_{3}\left(\mathrm{PO}_{4}\right)_{2}$ proceeded with $100 \%$ selectivity towards the condensation product, crotonaldehdye, with an initial rate higher than the other catalysts tested [37]. 
Table 4.3. Initial Rates of Aldol Condensation of Acetaldehyde at $553 \mathrm{~K}$

\begin{tabular}{|c|c|}
\hline Catalyst & $\begin{array}{c}\text { Initial Rate } \\
\left(\mathbf{m o l ~ m}^{-2} \mathbf{s}^{-1}\right)\end{array}$ \\
\hline $\mathrm{Sr}_{3}\left(\mathrm{PO}_{4}\right)_{2}$ & $2.8 \times 10^{-7}$ \\
\hline $\mathrm{TiO}_{2}{ }^{\mathrm{a}}$ & $1.7 \times 10^{-7}$ \\
\hline $\mathrm{HAP}^{\mathrm{a}}$ & $8.7 \times 10^{-8}$ \\
\hline $\mathrm{MgO}^{\mathrm{a}}$ & $5.6 \times 10^{-8}$ \\
\hline
\end{tabular}

${ }^{a}$ Results were previously reported by Young et al [37].

It is interesting that $\mathrm{Sr}_{3}\left(\mathrm{PO}_{4}\right)_{2}$ catalyzes aldol condensation quite readily but is a poor coupling catalyst under Guerbet coupling conditions. Related work in our labortory has shown that a weak binding affinity for actaldehyde on the titania surface is likely a favorable condition for aldol condensation, as it prevents successive coupling and rapid deativation [37]. However, weaking binding also may prevent $\mathrm{C}-\mathrm{C}$ bond formation during Guerbet coupling conditions at low partial pressures of actaledehyde when ethanol can compete for surface active sites. It is possible that acetaldehyde has a weak binding affinity for the $\mathrm{Sr}_{3}\left(\mathrm{PO}_{4}\right)_{2}$ surface and therefore preferentially desorbs into the gas-phase during ethanol conversion, preventing subsequent $\mathrm{C}-\mathrm{C}$ bond forming steps.

The weak interactions between acetaldehyde and the $\mathrm{Sr}_{3}\left(\mathrm{PO}_{4}\right)_{2}$ surface are related to the acid-base surface properties of the material. Adsorbed acetaldehyde produced during ethanol coupling may desorb or undergo base-catalyzed abstraction of the $\alpha-\mathrm{H}$ to form an adsorbed surface enolate intermediate species that leads to longer-chain condensation products. However, if the base site $\left(\mathrm{PO}_{4}{ }^{3-}\right)$ on $\mathrm{Sr}_{3}\left(\mathrm{PO}_{4}\right)_{2}$ is too weak for enolate formation acetaldehyde will desorb. This scenario does not seem to be the case as higher $\mathrm{CO}_{2}$ adsorption energies were measured on the $\mathrm{Sr}_{3}\left(\mathrm{PO}_{4}\right)_{2}$ surface from $\mathrm{CO}_{2}$ adsorption microcalorimetry compared to those measured on $\beta$ TCP, which was catalytically active for coupling (Figure 4.5). Thus it is likely that the poor coupling performance of $\mathrm{Sr}_{3}\left(\mathrm{PO}_{4}\right)_{2}$ compared to $\beta$-TCP is a result of weaker Lewis acid 
interactions between acetaldehyde and $\mathrm{Sr}^{2+}$ cations. This information is critical for the future development of effective catalytic materials for the Guerbet coupling reaction.

\subsection{Conclusions}

The catalytic conversion of ethanol was investigated over beta tricalcium phosphate $(\beta-$ $\left.\mathrm{Ca}_{3}\left(\mathrm{PO}_{4}\right)_{2}\right)$ and fluorine-substituted hydroxyapatite $\left(\mathrm{Ca}_{10}\left(\mathrm{PO}_{4}\right)_{6} \mathrm{~F}_{2}\right)$ at $633 \mathrm{~K}$ to investigate the role or function of the $\mathrm{OH}^{-}$anion of HAP. The $\beta-\mathrm{Ca}_{3}\left(\mathrm{PO}_{4}\right)_{2}$ and FAP catalysts were active for C$\mathrm{C}$ bond formation and lead to $\sim 35 \%$ selectivity towards butanol, which may suggest that the $\mathrm{PO}_{4}{ }^{3-}$ of the HAP surface is involved in the base site of the active acid-base site pair responsible for coupling. These results support water co-feeding experiments over HAP where the inhibiting effect of water on butanol formation was likely the result of water interactions with adjacent Ca$\mathrm{PO}_{4}{ }^{3-}$ site pairs on the surface.

The introduction and removal of water vapor during the steady-state gas-phase conversion of ethanol over $\mathrm{MgO}$ revealed that water dissociatively adsorbs onto Lewis acidstrong base site pairs that were catalytically active for butanol formation. Compared to the $\mathrm{MgO}$ surface, the base sites exposed on HAP are significantly weaker in strength, as measured by $\mathrm{CO}_{2}$ adsorption microcalorimetry and likely accounts for the reversible surface interactions observed between water and the HAP surface. This finding has important implications in the Guerbet coupling reaction during which water is formed as a product and may account for the significantly higher catalytic activity of HAP observed during the reaction compared to $\mathrm{MgO}$.

The Lewis acidity of the cations in the metal phosphate catalysts was also explored by investigating the catalytic performance of $\mathrm{Mg}$ - and $\mathrm{Sr}$ - phosphate in Guerbet coupling of ethanol. The $\mathrm{Mg}_{3}\left(\mathrm{PO}_{4}\right)_{2}$ catalyst exhibited a product distribution characteristic of acid catalysts, leading 
to $52 \%$ and $36 \%$ selectivity towards diethyl ether and ethene, respectively, formed via Lewisacid catalyzed ethanol dehydration. The $\mathrm{Sr}_{3}\left(\mathrm{PO}_{4}\right)_{2}$ catalyst was highly active and selective for ethanol dehydrogenation to acetaldehyde (91\% selectivity) but exhibited poor selectivity towards C-C coupling products. This observation was likely a result of weakly Lewis acidic interactions between intermediates leading to butanol formation and the $\mathrm{Sr}_{3}\left(\mathrm{PO}_{4}\right)_{2}$ surface. Evidently, the $\beta$ $\mathrm{Ca}_{3}\left(\mathrm{PO}_{4}\right)_{2}$ possesses an intermediate-strength Lewis acidity provided by surface $\mathrm{Ca}^{2+}$ cations that allow the material to effectively convert ethanol to butanol with $35 \%$ selectivity.

\subsection{References}

[1] C. Jin, M. Yao, H. Liu, C.F. Lee, J. Ji, Progress in the production and application of nbutanol as a biofuel, Renew. Sustain. Energy Rev. 15 (2011) 4080-4106.

[2] N. Savage, Fuel options: the ideal biofuel, Nature. 474 (2011) S9-S11.

[3] A.J. O’Lenick, Guerbet chemistry, J. Surfactants Deterg. 4 (2001) 311-315.

[4] S. Veibel, J. Nielsen, On the mechanism of the Guerbet reaction, Tetrahedron. 23 (1967) 1723-1733.

[5] W. Ueda, T. Kuwabara, T. Ohshida, Y. Morikawa, A low-pressure guerbet reaction over magnesium oxide catalyst, J. Chem. Soc., Chem. Commun. (1990) 1558-1559.

[6] A.S. Ndou, N. Plint, N.J. Coville, Dimerisation of ethanol to butanol over solid-base catalysts, Appl. Catal. A-Gen. 251 (2003) 337-345.

[7] T.W. Birky, J.T. Kozlowski, R.J. Davis, Isotopic transient analysis of the ethanol coupling reaction over magnesia, J. Catal. 298 (2013) 130-137.

[8] J.I. Di Cosimo, V.K. Díez, M. Xu, E. Iglesia, C.R. Apesteguía, Structure and Surface and Catalytic Properties of Mg-Al Basic Oxides, J. Catal. 178 (1998) 499-510.

[9] J. Di Cosimo, C. Apesteguía, M. Ginés, E. Iglesia, Structural requirements and reaction pathways in condensation reactions of alcohols on MgyAlOx catalysts, J. Catal. 190 (2000) 261-275. 
[10] M. León, E. Diaz, S. Ordóñez, Ethanol catalytic condensation over Mg-Al mixed oxides derived from hydrotalcites, Catal. Today. 164 (2010) 436-442.

[11] K. Gotoh, S. Nakamura, T. Mori, Y. Morikawa, Supported Alkali Salt Catalysts Active for the Guerbet Reaction between Methanol and Ethanol, Stud. Surf. Sci. Catal. 130 (2000) 2669-2674.

[12] C. Yang, Z. Meng, Bimolecular Condensation of Ethanol to 1-Butanol Catalyzed by Alkali Cation Zeolites, J. Catal. 142 (1993) 37-44.

[13] S. Ogo, A. Onda, K. Yanagisawa, Selective synthesis of 1-butanol from ethanol over strontium phosphate hydroxyapatite catalysts, Appl. Catal. A-Gen. 402 (2011) 188-195.

[14] K. Ramesh, E. Goh, Y. Ling, C.G. Gwie, T.J. White, A. Borgna, Structure and Surface Reactivity of WO $42-$, SO $42-$, PO 43 - Modified Ca- Hydroxyapatite Catalysts and Their Activity in Ethanol Conversion, J. Phys. Chem. C. 116 (2012) 18736-18745.

[15] J. Scalbert, F. Thibault-Starzyk, R. Jacquot, D. Morvan, F. Meunier, Ethanol condensation to butanol at high temperatures over a basic heterogeneous catalyst: How relevant is acetaldehyde self-aldolization?, J. Catal. 311 (2014) 28-32.

[16] T. Tsuchida, S. Sakuma, T. Takeguchi, W. Ueda, Direct Synthesis of $\mathrm{n}$-Butanol from Ethanol over Nonstoichiometric Hydroxyapatite, Ind. Eng. Chem. Res. 45 (2006) 86348642.

[17] T. Tsuchida, J. Kubo, T. Yoshioka, S. Sakuma, T. Takeguchi, W. Ueda, Reaction of ethanol over hydroxyapatite affected by Ca/P ratio of catalyst, J. Catal. 259 (2008) 183189.

[18] S. Hanspal, Z.D. Young, H. Shou, R.J. Davis, Multiproduct Steady-State Isotopic Transient Kinetic Analysis of the Ethanol Coupling Reaction over Hydroxyapatite and Magnesia, ACS Catal. (2015) 1737-1746.

[19] I.M. Hill, S. Hanspal, Z.D. Young, R.J. Davis, DRIFTS of Probe Molecules Adsorbed on Magnesia, Zirconia, and Hydroxyapatite Catalysts, J. Phys. Chem. C. 119 (2015) 91869197.

[20] C.R. Ho, S. Shylesh, A.T. Bell, Mechanism and Kinetics of Ethanol Coupling to Butanol over Hydroxyapatite, ACS Catal. 6 (2016) 939-948.

[21] S. Diallo-garcia, M. Ben Osman, J. Kra, S. Casale, C. Thomas, J. Kubo, Identification of Surface Basic Sites and Acid-Base Pairs of Hydroxyapatite, J. Phys. Chem. C. 118 (2014) 12744-12757. 
[22] T. Tsuchida, J. Kubo, T. Yoshioka, S. Sakuma, T. Takeguchi, W. Ueda, Influence of Preparation Factors on $\mathrm{Ca} / \mathrm{P}$ Ratio and Surface Basicity of Hydroxyapatite Catalyst, J. Japan Pet. Inst. 52 (2009) 51-59.

[23] I.R. Gibson, I. Rehman, S.M. Best, W. Bonfield, Characterization of the transformation from calcium-deficient apatite to $\beta$-tricalcium phosphate, J. Mater. Sci. Mater. Med. 11 (2000) 799-804.

[24] S. Loher, W.J. Stark, M. Maciejewski, A. Baiker, S.E. Pratsinis, D. Reichardt, F. Maspero, F. Krumeich, A. Biosciences, E.T.H. Hoenggerberg, C.- Zurich, Fluoro-apatite and Calcium Phosphate Nanoparticles by Flame Synthesis, Chem. Mater. 17 (2005) 36-42.

[25] R. Fabian, I. Kotsis, P. Zimany, P. Halmos, Preparation and chemical characterization of high purity fluorapatite, Talanta. 46 (1998) 1273-1277.

[26] J.C. Elliott, Structure and Chemistry of the Apatites and Other Calcium Orthophosphates, ELSEVIER SCIENCE BV, 1994.

[27] S. Bordawekar, E. Doskocil, R. Davis, Microcalorimetric study of CO2 and NH3 adsorption on Rb-and Sr-modified catalyst supports, Langmuir. 14 (1998) 1734-1738.

[28] H. Tanaka, T. Watanabe, M. Chikazawa, FTIR and TPD studies on the adsorption of pyridine , n-butylamine and acetic acid on calcium hydroxyapatite, 93 (1997) 4377-4381.

[29] D. Stošić, S. Bennici, S. Sirotin, C. Calais, J.-L. Couturier, J.-L. Dubois, A. Travert, A. Auroux, Glycerol dehydration over calcium phosphate catalysts: Effect of acidic-basic features on catalytic performance, Appl. Catal. A Gen. 447 (2012) 124-134.

[30] C.R. Ho, S. Shylesh, A.T. Bell, Mechanism and Kinetics of Ethanol Coupling to Butanol over Hydroxyapatite, ACS Catal. 6 (2016) 939-948.

[31] J.T. Kozlowski, R.J. Davis, Heterogeneous Catalysts for the Guerbet Coupling of Alcohols, ACS Catal. 3 (2013) 1588-1600.

[32] R.L. Wingad, P.J. Gates, S.T.G. Street, D.F. Wass, Catalytic Conversion of Ethanol to nButanol using Ruthenium P-N Ligand Complexes, ACS Catal. 5 (2015) 5822-5826.

[33] T. Riittonen, E. Toukoniitty, D.K. Madnani, A.-R. Leino, K. Kordas, M. Szabo, A. Sapi, K. Arve, J. Wärnå, J.-P. Mikkola, One-Pot Liquid-Phase Catalytic Conversion of Ethanol to 1-Butanol over Aluminium Oxide-The Effect of the Active Metal on the Selectivity, Catalysts. 2 (2012) 68-84.

[34] V. Bolis, C. Busco, M. Gianmario, L. Bertinetti, Y. Sakhno, P. Ugliengo, F. Chiatti, M. Corno, N. Roveri, Coordination Chemistry of Ca Sites at the Surface of Nanosized Hydroxyapatite: Interactions with $\mathrm{H} 2 \mathrm{O}$ and CO, Philisophical Trans. R. Scoiety A. 370 (2012) 1313-1336. 
[35] B. Fubini, V. Bolis, M. Bailes, F.S. Stone, The Reactivity of Oxides with Water Vapor, Solid State Ionics. 32-33 (1989) 258-272.

[36] B.C. Gates, Catalytic Chemistry, John Wiley \& Sons, Inc., 1992.

[37] Z.D. Young, S. Hanspal, R.J. Davis, Aldol Condensation of Acetaldehyde over Titania, Hydroxyapatite, and Magnesia, ACS Catal. 6 (2016) 3193-3202.

[38] M. León, E. Díaz, S. Ordóñez, Ethanol catalytic condensation over Mg-Al mixed oxides derived from hydrotalcites, Catal. Today. 164 (2011) 436-442.

[39] K. Tanabe, M. Misono, Y. Ono, H. Hattori, New Solid Acids and Bases, ELSEVIER SCIENCE BV, 1989.

[40] E.P. Parry, An Infrared Study of Pyridine Adsorbed Characterization of Surface, J. Catal. 2 (1963) 371-379. 


\section{Chapter 5:}

\section{Conclusions and Future Directions}

\subsection{Conclusions}

The Guerbet coupling reaction over calcium hydroxyapatite catalysts was investigated in this work. In particular, the acid-base surface chemistry of ethanol conversion over hydroxyapatite catalysts compared to solid bases, solid acids, and other acid-base bifunctional materials was explored. In Chapter 2, calcium hydroxyapatites (HAP) of varying chemical compositions $(\mathrm{Ca} / \mathrm{P}=1.50,1.66,1.88)$ were synthesized and investigated during the catalytic conversion of ethanol at $633 \mathrm{~K}$. The acid-base surface properties of the catalysts and product selectivities observed during the reaction were strongly influenced by the $\mathrm{Ca} / \mathrm{P}$ molar ratio of the material.

An increase in the calcium content of HAP resulted in an increase in the base site strength, as measured by $\mathrm{CO}_{2}$ adsorption microcalorimetry. High-strength base sites on Ca-rich HAP (1.88) lead to decreased catalytic activity and butanol selectivity, relative to stoichiometric HAP. In contrast, the Ca-def. HAP surface (1.50) possessed a very low concentration of weak base sites so that strong surface acid sites dominated the catalytic performance and lead to undesirable acid-catalyzed ethanol dehydration. Stoichiometric HAP exhibited a high density of intermediate-strength base sites on the surface.

Strong base sites measured over $\mathrm{CaO}$ and $\mathrm{MgO}$ dominated the acid-base site pair on the surface and catalyzed primarily dehydrogenation of ethanol to acetaldehyde and exhibited significantly lower rates and relatively poor butanol selectivity compared to the stoichiometric HAP catalyst. The relative strengths of the active acid and base sites that participate in the Guerbet coupling of ethanol must be carefully balanced to achieve high activity and selectivity to 
butanol while minimizing unwanted by-product formation. Thus, it was concluded that the excellent performance of HAP compared to the other catalyst tested was likely the result of a high density of acid-base site pairs of balanced strength that facilitate all of the steps in the Guerbet sequence.

In an effort to study stoichiometric calcium HAP in greater detail, which was shown to be the most active and selective catalyst in Chapter 2, multiproduct steady-state isotopic transient kinetic analysis (SSITKA) of the ethanol coupling reaction was used over HAP and compared to the results obtained over $\mathrm{MgO}$ to evaluate important intrinsic kinetic parameters and to gain insight into the reaction mechanism at the active site level (Chapter 3).

Multiproduct SSITKA results showed that the mean surface residence time of reactive intermediates leading to acetaldehyde was significantly shorter than that of intermediates leading to butanol on both HAP and MgO. This finding may suggest that the dehydrogenation of ethanol to acetaldehyde is fast on these surfaces compared with $\mathrm{C}-\mathrm{C}$ bond formation. Given the generally understood mechanism for Guerbet coupling of ethanol where adsorbed acetaldehyde is a key reaction intermediate, the SSITKA results revealed that a higher fraction of surface acetaldehyde produced during the reaction on $\mathrm{MgO}$ desorbed into the gas-phase while the majority of adsorbed acetaldehyde on HAP likely undergoes sequential reactions leading to butanol formation. The TOF associated with intermediates that form butanol was found to be $0.059 \mathrm{~s}^{-1}$ for $\mathrm{MgO}(653 \mathrm{~K})$ and $0.016 \mathrm{~s}^{-1}$ for HAP $(613 \mathrm{~K})$. Therefore, the higher selectivity to butanol over HAP compared with $\mathrm{MgO}$ is apparently the consequence of a much higher coverage of surface intermediates leading to butanol during the steady-state reaction.

In an attempt to identify the active site on HAP for the catalytic conversion of ethanol into butanol the reaction was investigated over beta tricalcium phosphate $\left(\beta-\mathrm{Ca}_{3}\left(\mathrm{PO}_{4}\right)_{2}\right)$ and 
fluorine-substituted hydroxyapatite $\left(\mathrm{Ca}_{10}\left(\mathrm{PO}_{4}\right)_{6} \mathrm{~F}_{2}\right)$ at $633 \mathrm{~K}$ to investigate the role or function of the $\mathrm{OH}^{-}$anion of HAP. The $\beta-\mathrm{Ca}_{3}\left(\mathrm{PO}_{4}\right)_{2}$ and FAP catalysts were both active towards butanol formation during the reaction, leading to $\sim 35 \%$ selectivity, which may suggest that the $\mathrm{PO}_{4}{ }^{3-}$ of the HAP surface is involved in the base site of the active acid-base site pair responsible for coupling. These results are consistent with those from water co-feeding experiments over HAP where the inhibiting effect of water on butanol formation was likely due to the interaction of water with adjacent $\mathrm{Ca}-\mathrm{PO}_{4}{ }^{3-}$ site pairs on the surface [1].

The introduction and removal of water vapor during the steady-state gas-phase conversion of ethanol over $\mathrm{MgO}$ revealed that cofed water dissociatively adsorbed onto Lewis acid-strong base site pairs that were catalytically active for butanol formation and that these sites were not regenerated when water was removed from the feed. Compared to the $\mathrm{MgO}$ surface, the base sites exposed on HAP are significantly weaker in strength, as measured by $\mathrm{CO}_{2}$ adsorption microcalorimetry and likely accounts for the weak and reversible surface interactions observed between water and the HAP surface during Guerbet coupling of ethanol [2]. This observation has important implications in reactions where water is formed in situ as a product such as Guerbet coupling and aldol condensation and may account for the significantly higher catalytic activity of HAP for these reactions compared to $\mathrm{MgO}$.

The influence of Lewis acidity was explored by comparing the catalytic activity during reactions of ethanol over $\mathrm{Mg}_{3}\left(\mathrm{PO}_{4}\right)_{2}, \mathrm{Ca}_{3}\left(\mathrm{PO}_{4}\right)_{2}$, and $\mathrm{Sr}_{3}\left(\mathrm{PO}_{4}\right)_{2}$. Strong Lewis acid sites on the $\mathrm{Mg}_{3}\left(\mathrm{PO}_{4}\right)_{2}$ surface $\left(\mathrm{Mg}^{2+}\right.$ cations) favored undesired ethanol dehydration to ethene (36\% selectivity) and diethyl ether (52\% selectivity) whereas the $\operatorname{Sr}_{3}\left(\mathrm{PO}_{4}\right)_{2}$ catalyst predominantly catalyzed ethanol dehydrogenation to acetaldehyde (91\% selectivity) at a rate significantly higher than those observed over the other catalytic materials. The poor selectivity to butanol 
observed during the reaction over the $\mathrm{Sr}_{3}\left(\mathrm{PO}_{4}\right)_{2}$ catalyst was likely a result of weak Lewis acid interactions between reaction intermediates and surface $\mathrm{Sr}^{2+}$ cations. Evidently, the $\beta-\mathrm{Ca}_{3}\left(\mathrm{PO}_{4}\right)_{2}$ possesses an intermediate-strength Lewis acidity provided by surface $\mathrm{Ca}^{2+}$ cations that allow the material to effectively convert ethanol to butanol with $35 \%$ selectivity. This information is critical for the future development of effective catalytic materials for the Guerbet coupling reaction.

\subsection{Future Directions}

\subsubsection{Lewis Acid Probe for Metal Phosphate Catalysts}

In Chapter 4, catalytic reactions of ethanol over $\mathrm{Mg}_{3}\left(\mathrm{PO}_{4}\right)_{2}, \mathrm{Ca}_{3}\left(\mathrm{PO}_{4}\right)_{2}$, and $\mathrm{Sr}_{3}\left(\mathrm{PO}_{4}\right)_{2}$ catalysts demonstrated the importance of Lewis acidity of the metal phosphates on the reaction. It was concluded that Lewis acid sites on the $\mathrm{Mg}_{3}\left(\mathrm{PO}_{4}\right)_{2}$ surface $\left(\mathrm{Mg}^{2+}\right.$ cations) that catalyzed undesired ethanol dehydration to ethene and diethyl ether were likely stronger than those present on the $\mathrm{Ca}_{3}\left(\mathrm{PO}_{4}\right)_{2}$ and $\mathrm{Sr}_{3}\left(\mathrm{PO}_{4}\right)_{2}$ surfaces, which thus favored the catalysis towards ethanol dehydration over coupling. Additionally, it was inferred that the inability for $\mathrm{Sr}_{3}\left(\mathrm{PO}_{4}\right)_{2}$ to undergo $\mathrm{C}-\mathrm{C}$ bond formation effectively during ethanol conversion was likely a result of weak Lewis acid interactions between reaction intermediates leading to butanol formation and surface $\mathrm{Sr}^{2+}$ cations. In order to confirm these results, Lewis acidity measurements should be performed on all three metal phosphate materials in the future. This may be achieved by adsorption microcalorimetry experiments of triethylamine (TEA) on the surfaces or DRIFTS of adsorbed CO. Ideally these experiments would allow the ranking of the Lewis acidity of the metal phosphate catalysts. 


\subsubsection{Further Investigation into Strontium Phosphate}

The Guerbet coupling reaction is a complex cascade of reactions involving dehydrogenation, aldol addition, dehydration, and hydrogenation. Thus, for a catalyst to be an effective "Guerbet" catalyst it must contain the appropriate components to facilitate all of the steps in the sequence. If different components or chemical properties of effective catalytic systems can be assigned to the individual steps of the Guerbet coupling reaction, the design and development of more successful catalysts for this reaction can be achieved. Understanding the ideal surface properties of catalysts that contribute to high rates of ethanol dehydrogenation is one such approach.

Catalytic reactions of ethanol over $\mathrm{Sr}_{3}\left(\mathrm{PO}_{4}\right)_{2}$ at $633 \mathrm{~K}$, presented in Chapter 4, revealed the exceptionally high catalytic activity and selectivity of $\mathrm{Sr}_{3}\left(\mathrm{PO}_{4}\right)_{2}$ for ethanol dehydrogenation to acetaldehyde. The rate of acetaldehyde formation over $\mathrm{Sr}_{3}\left(\mathrm{PO}_{4}\right)_{2}$ was approximately an order of magnitude higher than that observed over HAP and over two orders of magnitude higher than that observed over $\mathrm{MgO}$. It is often stated in the literature that the rate of Guerbet coupling over solid base metal oxides such as $\mathrm{MgO}$ is inhibited by the initial dehydrogenation of ethanol to acetaldehyde [3], which begs the question: What are the specific surface properties of $\mathrm{Sr}_{3}\left(\mathrm{PO}_{4}\right)_{2}$ that make it such an effective alcohol dehydrogenating catalyst compared to $\mathrm{MgO}$ ?

The dehydrogenation of neopentyl alcohol can be used as a model dehydrogenation reaction because this molecule is unable to undergo enolate formation and thus aldol condensation. Studying the dehydrogenation of neopentyl alcohol over $\mathrm{Sr}_{3}\left(\mathrm{PO}_{4}\right)_{2}$ compared to HAP and $\mathrm{MgO}$ may provide valuable insight into the dehydrogenating activity of these materials which can be used to explain reactivity trends observed during ethanol coupling. Additionally, comparing the rates of dehydrogenation of partially deuterated neopentyl alcohol to non- 
deuterated neopentyl alcohol may also help to elucidate the rate determining step of ethanol dehydrogenation. This information combined with extensive surface characterization would ideally provide important structure-function properties of the catalytic materials that would help to explain the significantly higher rates of ethanol dehydrogenation observed over $\mathrm{Sr}_{3}\left(\mathrm{PO}_{4}\right)_{2}$ compared to HAP and $\mathrm{MgO}$.

Lastly, the $\mathrm{Sr}_{3}\left(\mathrm{PO}_{4}\right)_{2}$ catalyst exhibited poor catalytic activity for C-C coupling to butanol during ethanol conversion yet was highly active during aldol condensation of acetaldehyde to crotonaldehyde. It was speculated in chapter 4 that a weak binding affinity for acetaldehyde and the $\mathrm{Sr}_{3}\left(\mathrm{PO}_{4}\right)_{2}$ surface may prevent $\mathrm{C}-\mathrm{C}$ bond formation during Guerbet coupling conditions at low partial pressures of actaledehyde when ethanol can compete for surface active sites. This hypothesis can be tested in the future by measuring the heat of acetaldehyde adsorption on the $\mathrm{Sr}_{3}\left(\mathrm{PO}_{4}\right)_{2}$ surface using adsorption microcalorimetry.

\subsubsection{Combining Multiple Single-Function Catalysts}

The majority of the work on Guerbet coupling is focused on developing multi-functional catalytic systems that can effectively facilitate all of the steps in the reaction sequence. However, another approach to maximize butanol selectivity and overall activity in ethanol coupling reactions is to combine multiple single-function catalysts. This can be employed in a single reactor using a dual catalyst bed system. For example, as discussed, above the $\mathrm{Sr}_{3}\left(\mathrm{PO}_{4}\right)_{2}$ catalyst is highly active and selective for acetaldehyde formation but is ineffective for coupling during Guerbet coupling conditions. In contrast, $\mathrm{MgO}$ couples ethanol into butanol however the rate of butanol formation over this material is likely inhibited by initial ethanol dehydrogenation steps. Therefore it would be interesting to investigate ethanol coupling over a $\mathrm{Sr}_{3}\left(\mathrm{PO}_{4}\right)_{2}$ catalyst bed 
positioned upstream of a $\mathrm{MgO}$ catalyst bed. Additionally, a physical mixture of two different “single-function" catalysts may also provide promising results.

\subsection{References}

[1] V. Bolis, C. Busco, M. Gianmario, L. Bertinetti, Y. Sakhno, P. Ugliengo, F. Chiatti, M. Corno, N. Roveri, Coordination Chemistry of Ca Sites at the Surface of Nanosized Hydroxyapatite: Interactions with $\mathrm{H} 2 \mathrm{O}$ and CO, Philisophical Trans. R. Scoiety A. 370 (2012) 1313-1336.

[2] S. Hanspal, Z.D. Young, H. Shou, R.J. Davis, Multiproduct Steady-State Isotopic Transient Kinetic Analysis of the Ethanol Coupling Reaction over Hydroxyapatite and Magnesia, ACS Catal. (2015) 1737-1746.

[3] J.T. Kozlowski, R.J. Davis, Heterogeneous Catalysts for the Guerbet Coupling of Alcohols, ACS Catal. 3 (2013) 1588-1600. 
Appendix A:

Supplemental Information for Chapter 2 
The crystal structures of the $\mathrm{MgO}$ and $\mathrm{CaO}$ catalysts, studied in Chapter 2, were confirmed by powder X-ray diffraction:

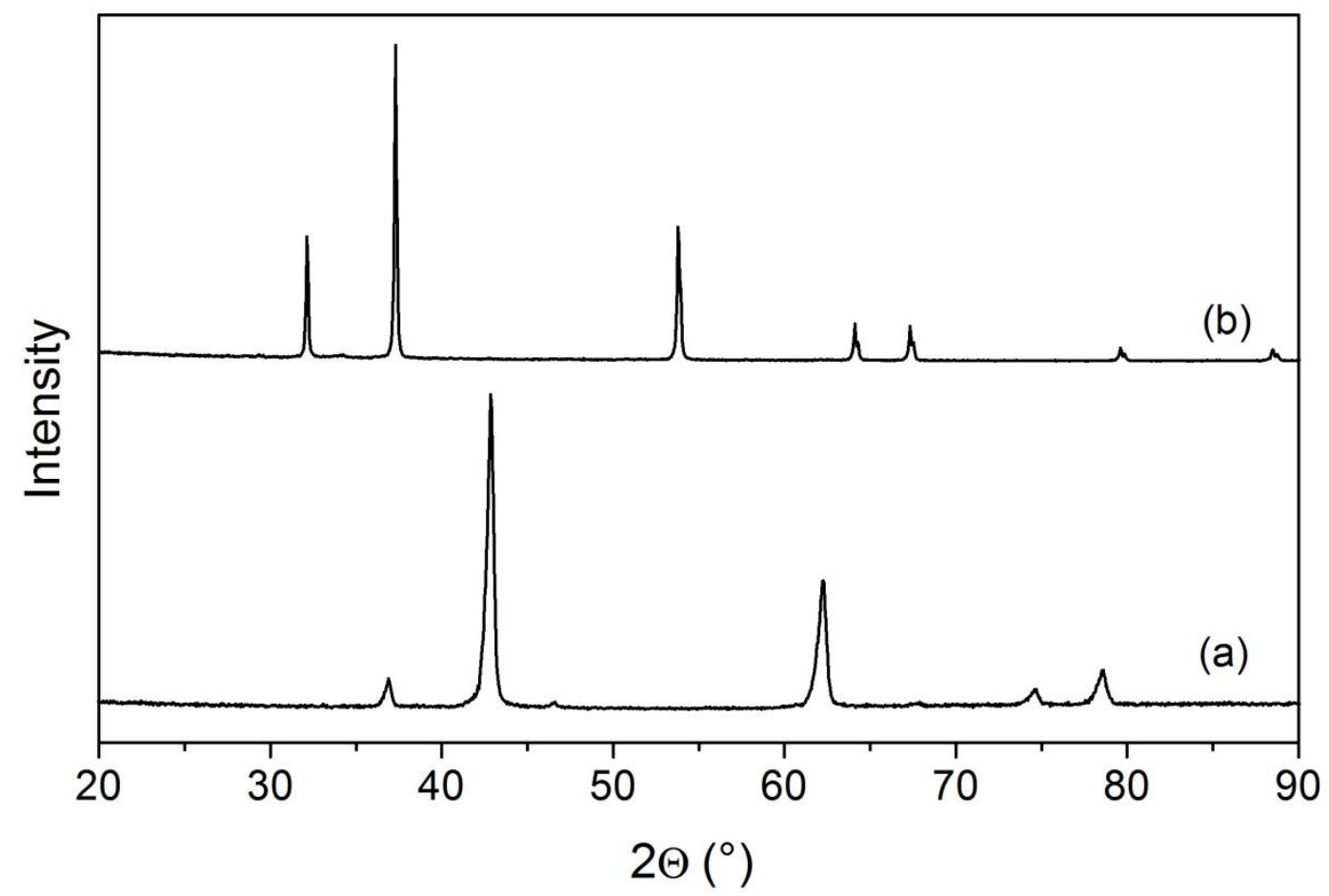

Figure A.1. Powder X-ray diffraction patterns of (a) periclase $\mathrm{MgO}$ and (b) $\mathrm{CaO}$. The patterns are consistent with refernce patterns for cubic MgO (ICDD: 00-004-0829) and cubic $\mathrm{CaO}$ (ICDD: 00-004-0777). Patterns are offset for clarity. 
Appendix B:

Supplemental Information for Chapter 3 


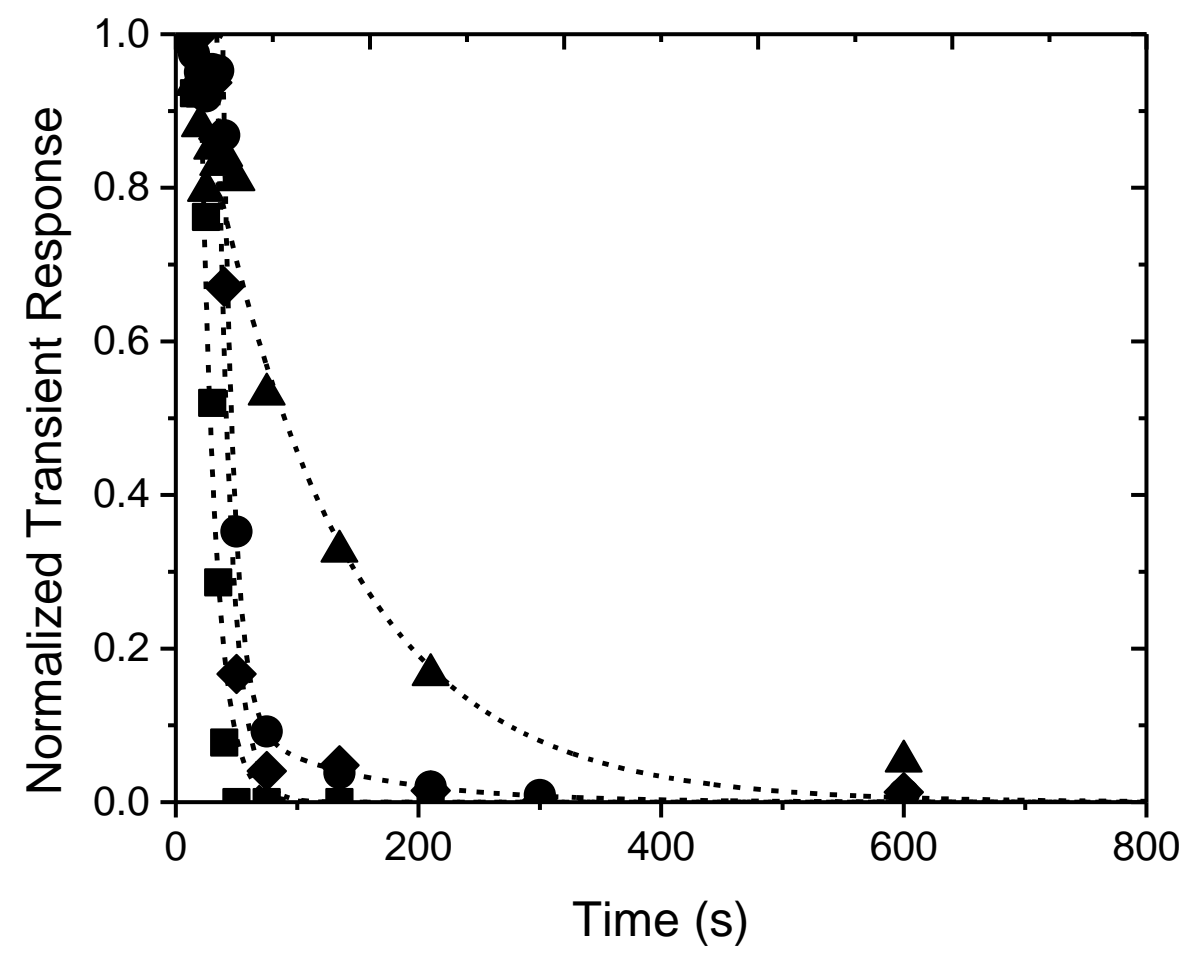

Figure B.1. Normalized isotopic transient response curves following the switch from unlabeled ethanol to doubly labeled ${ }^{13} \mathrm{C}$-labeled ethanol with a total flow of $30 \mathrm{~cm}^{3} \mathrm{~min}^{-1}$ at $653 \mathrm{~K}$ during

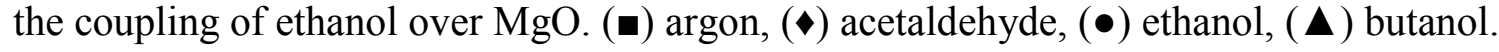




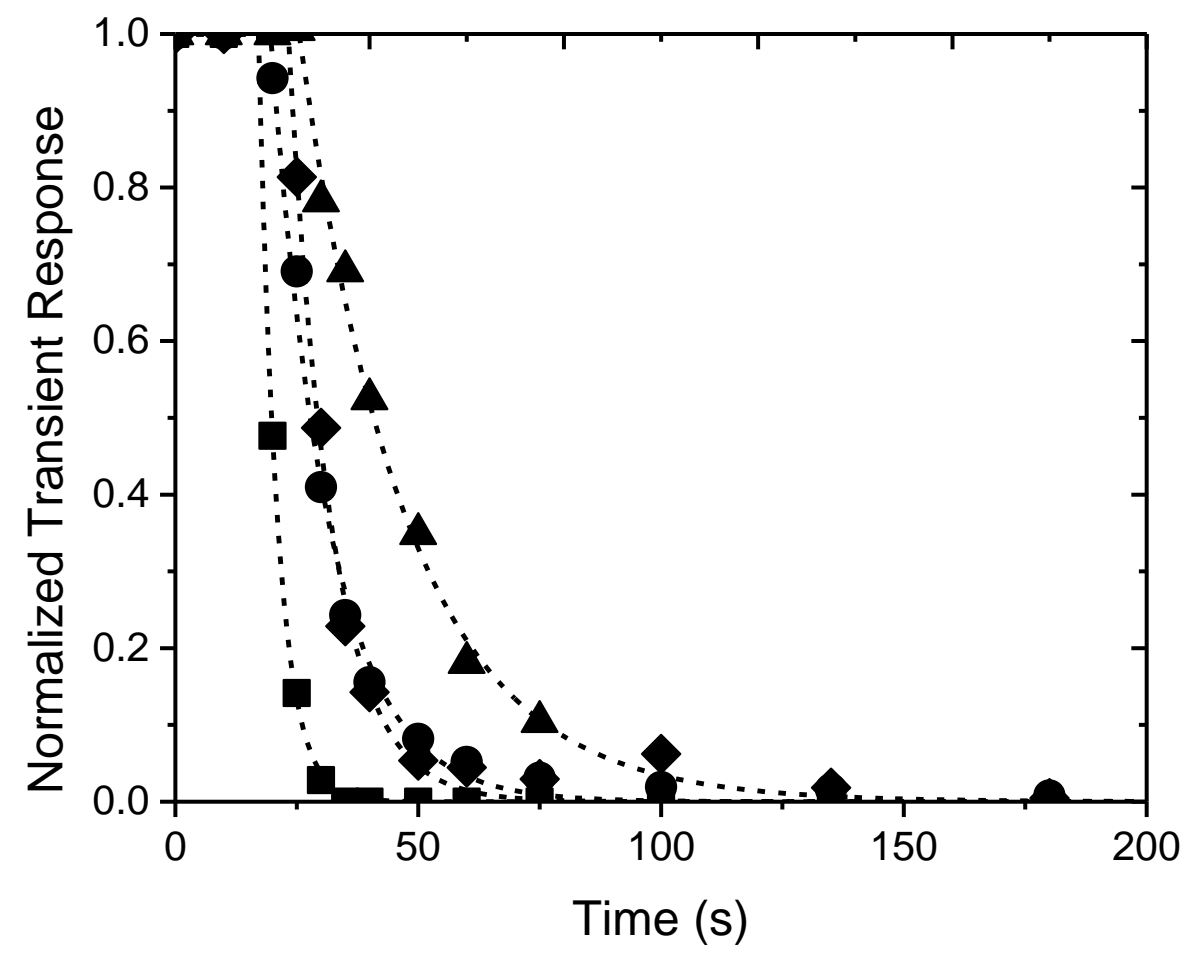

Figure B.2. Normalized isotopic transient response curves following the switch from unlabeled ethanol to doubly labeled ${ }^{13} \mathrm{C}$-labeled ethanol with a total flow of $75 \mathrm{~cm}^{3} \mathrm{~min}^{-1}$ at $653 \mathrm{~K}$ during the coupling of ethanol over $\mathrm{MgO}$. ( $\bullet$ ) argon, ( $\bullet$ acetaldehyde, $(\bullet)$ ethanol, ( $\mathbf{\Delta})$ butanol. 


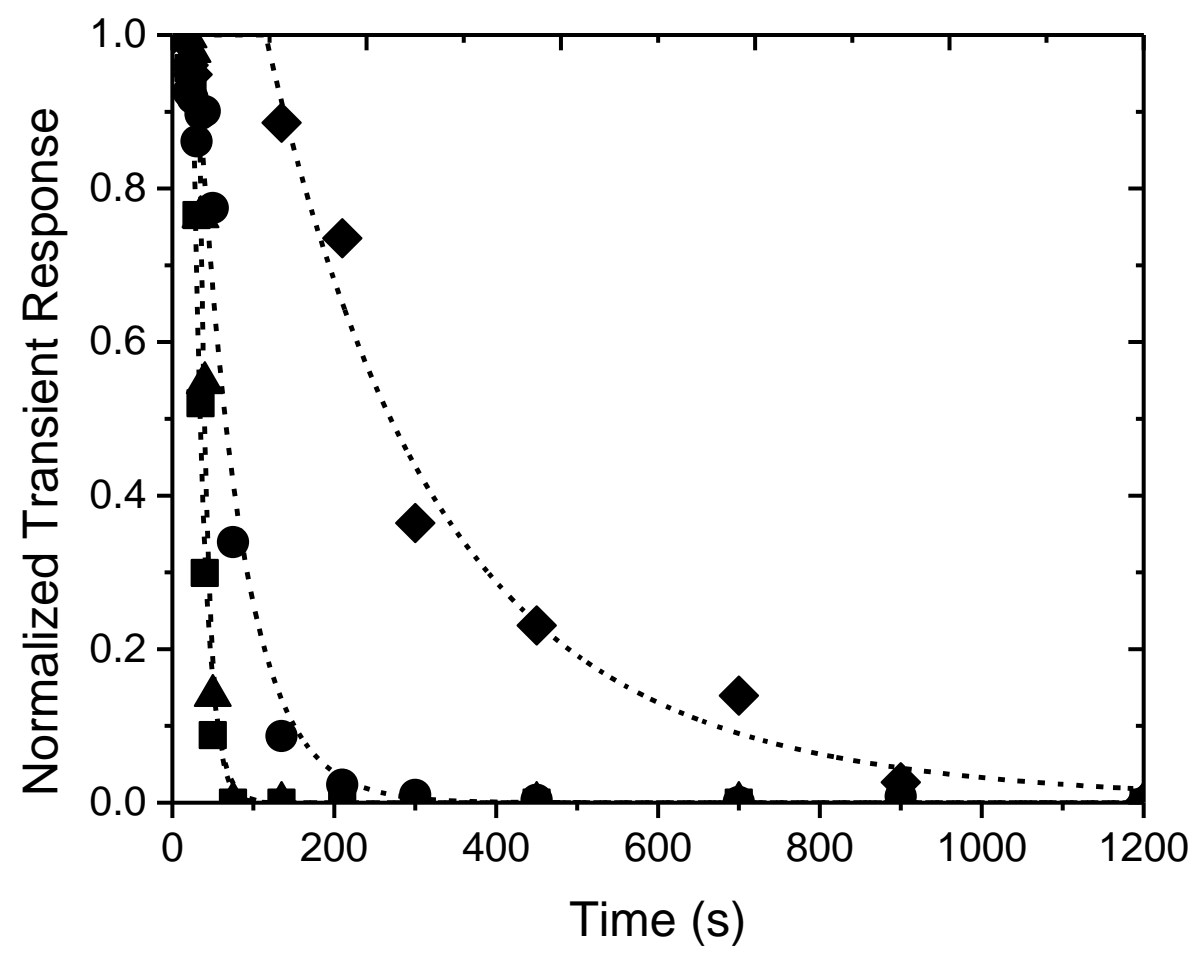

Figure B.3. Normalized isotopic transient response curves following the switch from unlabeled ethanol to doubly labeled ${ }^{13} \mathrm{C}$-labeled ethanol with a total flow of $30 \mathrm{~cm}^{3} \mathrm{~min}^{-1}$ at $613 \mathrm{~K}$ during the coupling of ethanol over stoichiometric HAP. (ם) argon, ( $\bullet)$ acetaldehyde, $(\bullet)$ ethanol, $(\boldsymbol{\Delta})$ butanol. 


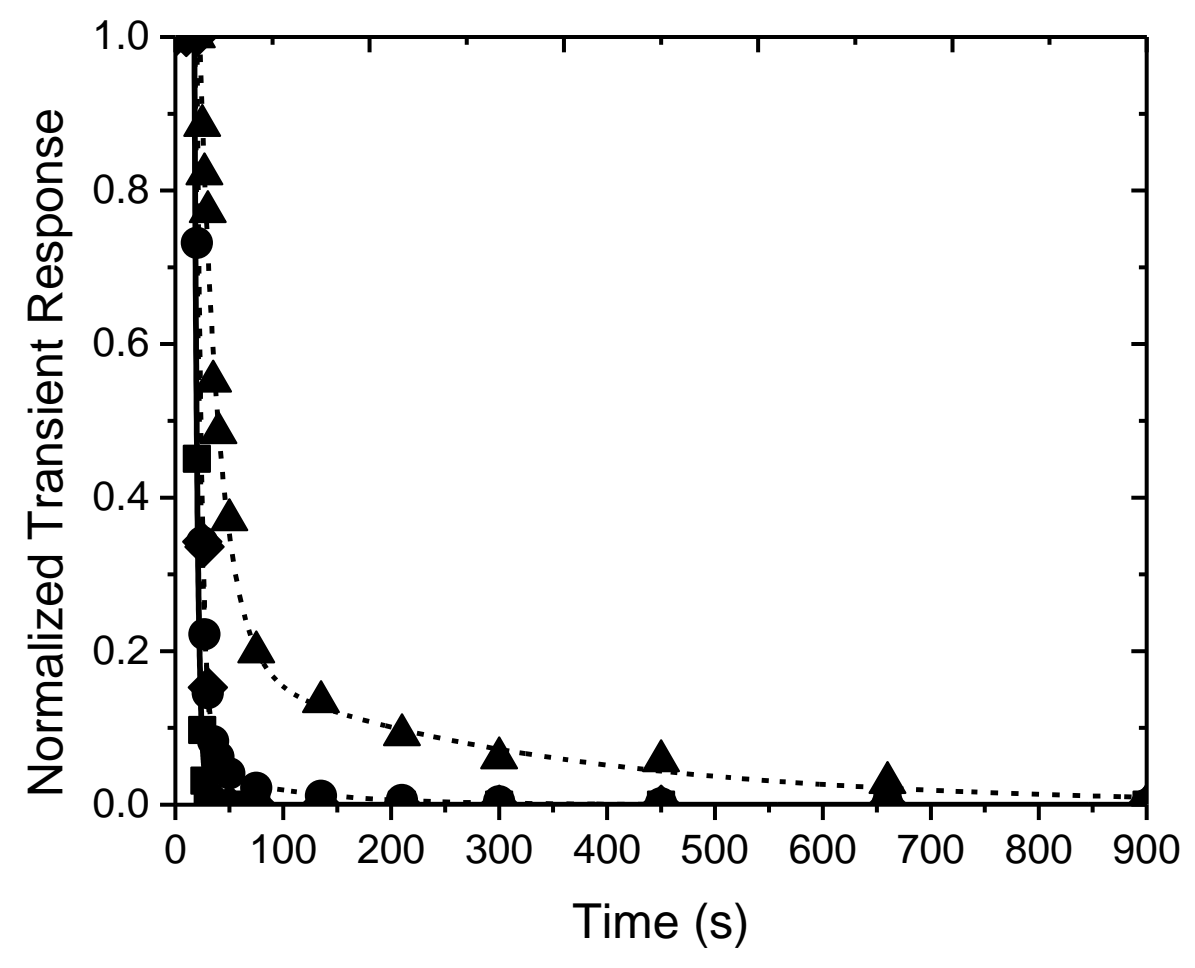

Figure B.4. Normalized isotopic transient response curves following the switch from unlabeled ethanol to doubly labeled ${ }^{13} \mathrm{C}$-labeled ethanol with a total flow of $75 \mathrm{~cm}^{3} \mathrm{~min}^{-1}$ at $613 \mathrm{~K}$ during the coupling of ethanol over stoichiometric HAP. ( $\bullet$ ) argon, $(\bullet)$ acetaldehyde, $(\bullet)$ ethanol, $(\boldsymbol{\Delta})$ butanol. 


\section{Appendix C:}

Supplemental Information for Chapter 4 


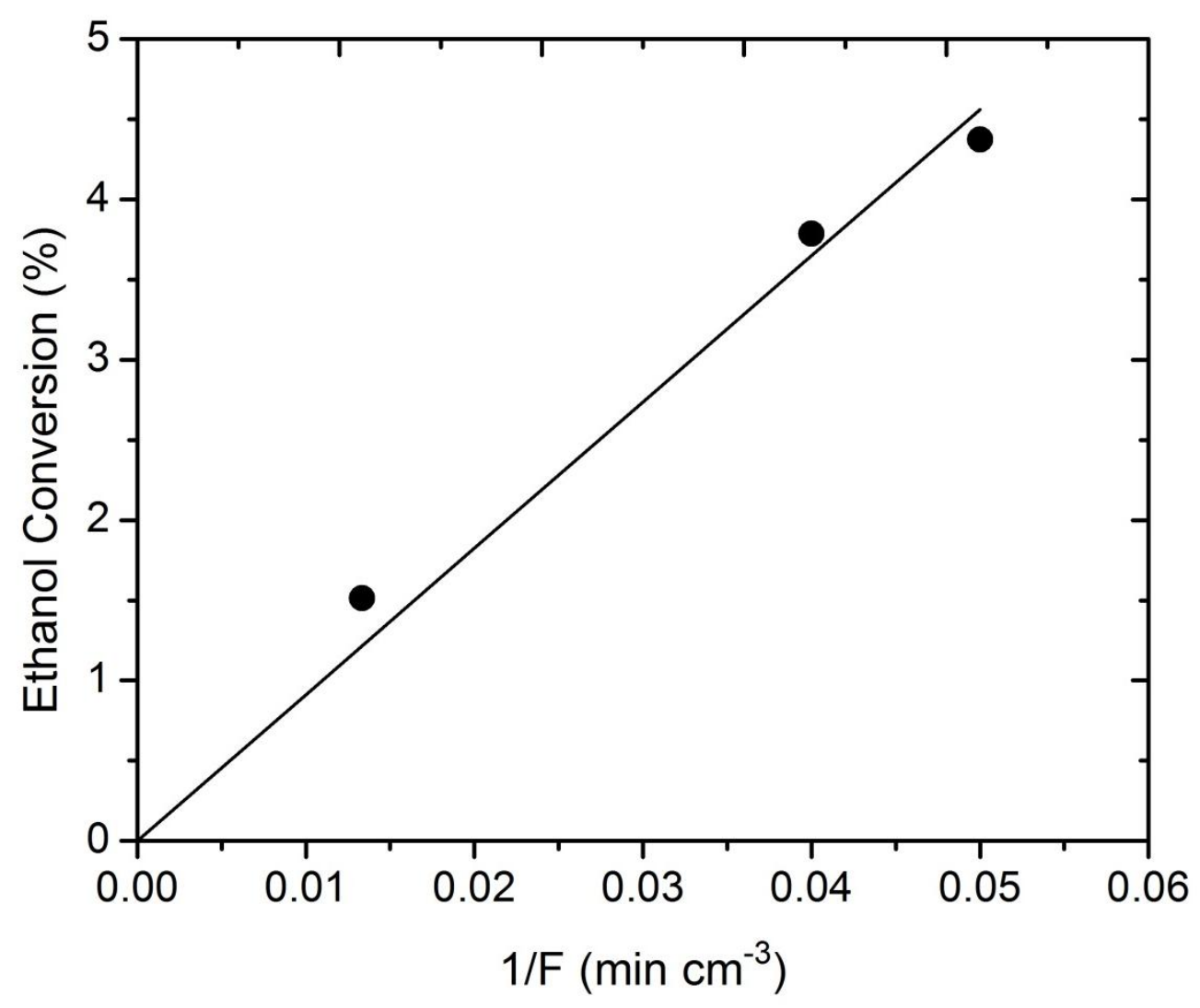

Figure C.1. Conversion of ethanol as a function of inverse reactant flowrate (proportional to reactor space time) during the Guerbet coupling of ethanol over $\mathrm{MgO}$ at $633 \mathrm{~K}$. The observed linear dependence confirms differential reactor conditions.

Table C.1: Product Distribution during the Guerbet Coupling of Ethanol over $\mathrm{MgO}$ at $633 \mathrm{~K}$

\begin{tabular}{|c|c|c|c|c|c|c|c|c|}
\hline \multirow{2}{*}{$\begin{array}{c}\text { Total } \\
\text { Flowrate } \\
\left(\mathrm{cm}^{3} \mathrm{~min}^{-1}\right)\end{array}$} & \multirow{2}{*}{$\begin{array}{c}\text { Ethanol } \\
\text { Conversion } \\
(\%)\end{array}$} & \multirow{2}{*}{$\begin{array}{c}\text { Rate of } \\
\text { Ethanol } \\
\text { Conversion } \\
\left(\mathrm{mol} \mathrm{m}^{-2} \mathrm{~s}^{-1}\right)\end{array}$} & \multicolumn{3}{|c|}{$\begin{array}{l}\text { Production Rates } \\
\left(\mathrm{mol} \mathrm{m} \mathrm{s}^{-2}\right)\end{array}$} & \multicolumn{3}{|c|}{ Selectivity (C\%) } \\
\hline & & & Ethene & $\mathrm{AcH}$ & Butanol & Ethene & $\mathrm{AcH}$ & Butanol \\
\hline 20 & 4.4 & $2.4 \times 10^{-9}$ & $1.8 \times 10^{-10}$ & $1.4 \times 10^{-9}$ & $4.0 \times 10^{-10}$ & 8 & 59 & 33 \\
\hline 25 & 3.8 & $2.6 \times 10^{-9}$ & $2.2 \times 10^{-10}$ & $1.7 \times 10^{-9}$ & $3.5 \times 10^{-10}$ & 8 & 65 & 27 \\
\hline 75 & 1.5 & $3.1 \times 10^{-9}$ & 0 & $3.1 \times 10^{-9}$ & 0 & 0 & 100 & 0 \\
\hline
\end{tabular}

$\mathrm{AcH}$ - Acetaldehyde 


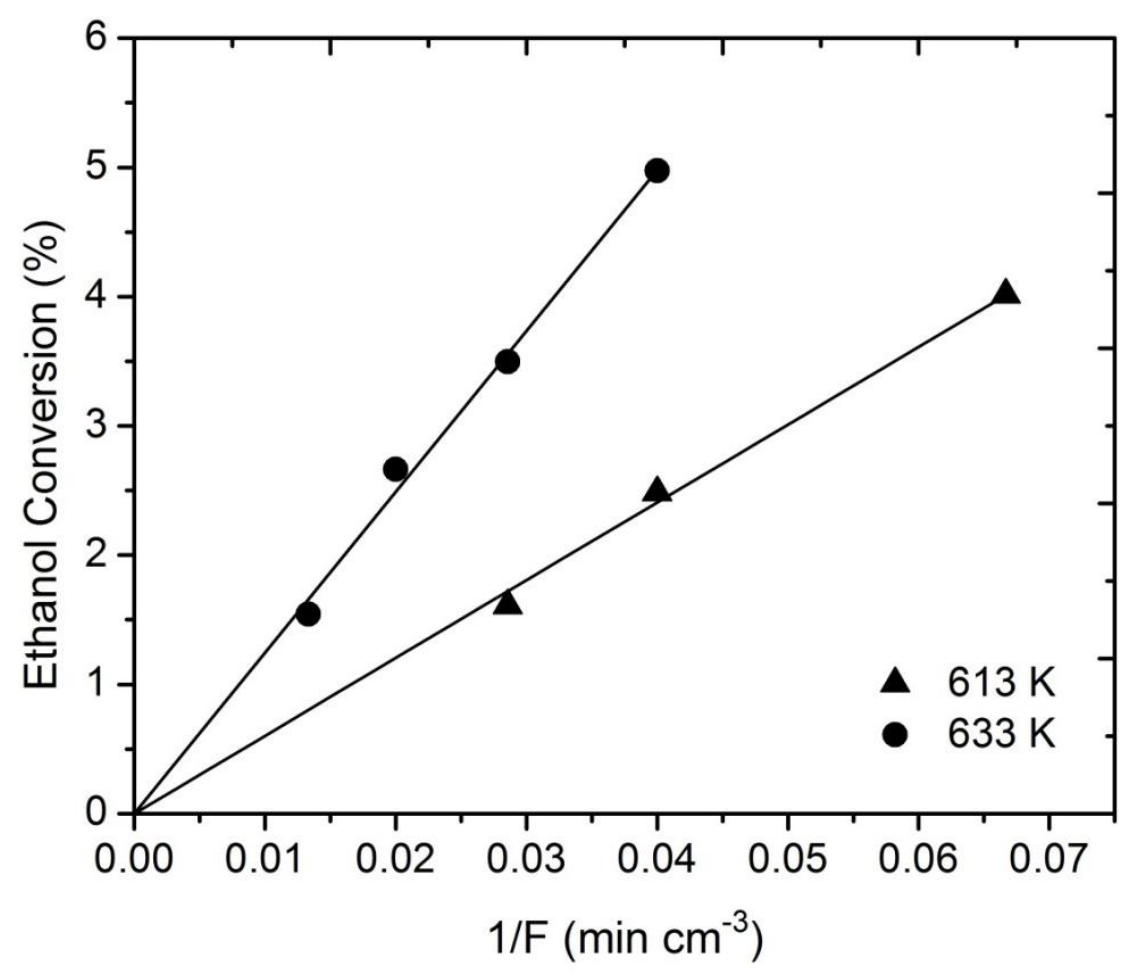

Figure C.2. Conversion of ethanol as a function of inverse reactant flowrate (proportional to reactor space time) during the Guerbet coupling of ethanol over $\mathrm{Mg}_{3}\left(\mathrm{PO}_{4}\right)_{2}$ at 613 and $633 \mathrm{~K}$. The observed linear dependence confirms differential reactor conditions at both temperatures.

Table C.2. Product Distribution during the Guerbet Coupling of Ethanol over $\mathrm{Mg}_{3}\left(\mathrm{PO}_{4}\right)_{2}$ at $613 \mathrm{~K}$

\begin{tabular}{|c|c|c|c|c|c|c|c|c|}
\hline \multirow{2}{*}{$\begin{array}{c}\text { Total } \\
\text { Flowrate } \\
\left(\mathrm{cm}^{3} \mathrm{~min}^{-1}\right)\end{array}$} & \multirow{2}{*}{$\begin{array}{c}\text { Ethanol } \\
\text { Conversion } \\
(\%)\end{array}$} & \multirow{2}{*}{$\begin{array}{c}\text { Rate of } \\
\text { Ethanol } \\
\text { Conversion } \\
\left(\mathrm{mol} \mathrm{m}^{-2} \mathrm{~s}^{-1}\right)\end{array}$} & \multicolumn{3}{|c|}{$\begin{array}{l}\text { Production Rates } \\
\left(\mathrm{mol} \mathrm{m}^{-2} \mathrm{~s}^{-1}\right)\end{array}$} & \multicolumn{3}{|c|}{ Selectivity (C\%) } \\
\hline & & & Ethene & $\mathrm{AcH}$ & DEE & Ethene & $\mathrm{AcH}$ & DEE \\
\hline 15 & 4.0 & $3.1 \times 10^{-9}$ & $9.4 \times 10^{-10}$ & $3.0 \times 10^{-10}$ & $9.4 \times 10^{-10}$ & 30 & 10 & 60 \\
\hline 25 & 2.5 & $3.2 \times 10^{-9}$ & $8.5 \times 10^{-10}$ & $3.3 \times 10^{-10}$ & $1.0 \times 10^{-9}$ & 26 & 10 & 64 \\
\hline 35 & 1.6 & $2.9 \times 10^{-9}$ & $5.1 \times 10^{-10}$ & $3.9 \times 10^{-10}$ & $1.0 \times 10^{-9}$ & 18 & 13 & 69 \\
\hline
\end{tabular}

$\mathrm{AcH}$ - Acetaldehyde; DEE - Diethyl ether

Table C.3. Product Distribution during the Guerbet Coupling of Ethanol over $\mathrm{Mg}_{3}\left(\mathrm{PO}_{4}\right)_{2}$ at $633 \mathrm{~K}$

\begin{tabular}{|c|c|c|c|c|c|c|c|c|}
\hline \multirow{2}{*}{$\begin{array}{c}\text { Total } \\
\text { Flowrate } \\
\left(\mathrm{cm}^{3} \mathrm{~min}^{-1}\right)\end{array}$} & \multirow{2}{*}{$\begin{array}{c}\text { Ethanol } \\
\text { Conversion } \\
(\%)\end{array}$} & \multirow{2}{*}{$\begin{array}{c}\text { Rate of } \\
\text { Ethanol } \\
\text { Conversion } \\
\left(\mathrm{mol} \mathrm{m}^{-2} \mathrm{~s}^{-1}\right)\end{array}$} & \multicolumn{3}{|c|}{$\begin{array}{l}\text { Production Rates } \\
\quad\left(\mathrm{mol} \mathrm{m}^{-2} \mathrm{~s}^{-1}\right)\end{array}$} & \multicolumn{3}{|c|}{ Selectivity (C\%) } \\
\hline & & & Ethene & $\mathrm{AcH}$ & DEE & Ethene & $\mathrm{AcH}$ & DEE \\
\hline 25 & 5.0 & $6.5 \times 10^{-9}$ & $2.3 \times 10^{-9}$ & $7.6 \times 10^{-10}$ & $1.7 \times 10^{-9}$ & 36 & 12 & 52 \\
\hline 35 & 3.5 & $6.4 \times 10^{-9}$ & $2.1 \times 10^{-9}$ & $8.2 \times 10^{-10}$ & $1.7 \times 10^{-9}$ & 33 & 13 & 54 \\
\hline 50 & 2.7 & $6.9 \times 10^{-9}$ & $2.3 \times 10^{-9}$ & $8.5 \times 10^{-10}$ & $1.9 \times 10^{-9}$ & 33 & 12 & 55 \\
\hline 75 & 1.5 & $6.0 \times 10^{-9}$ & $1.4 \times 10^{-9}$ & $9.3 \times 10^{-10}$ & $1.9 \times 10^{-9}$ & 23 & 15 & 62 \\
\hline
\end{tabular}

$\mathrm{AcH}$ - Acetaldehyde; DEE - Diethyl ether 


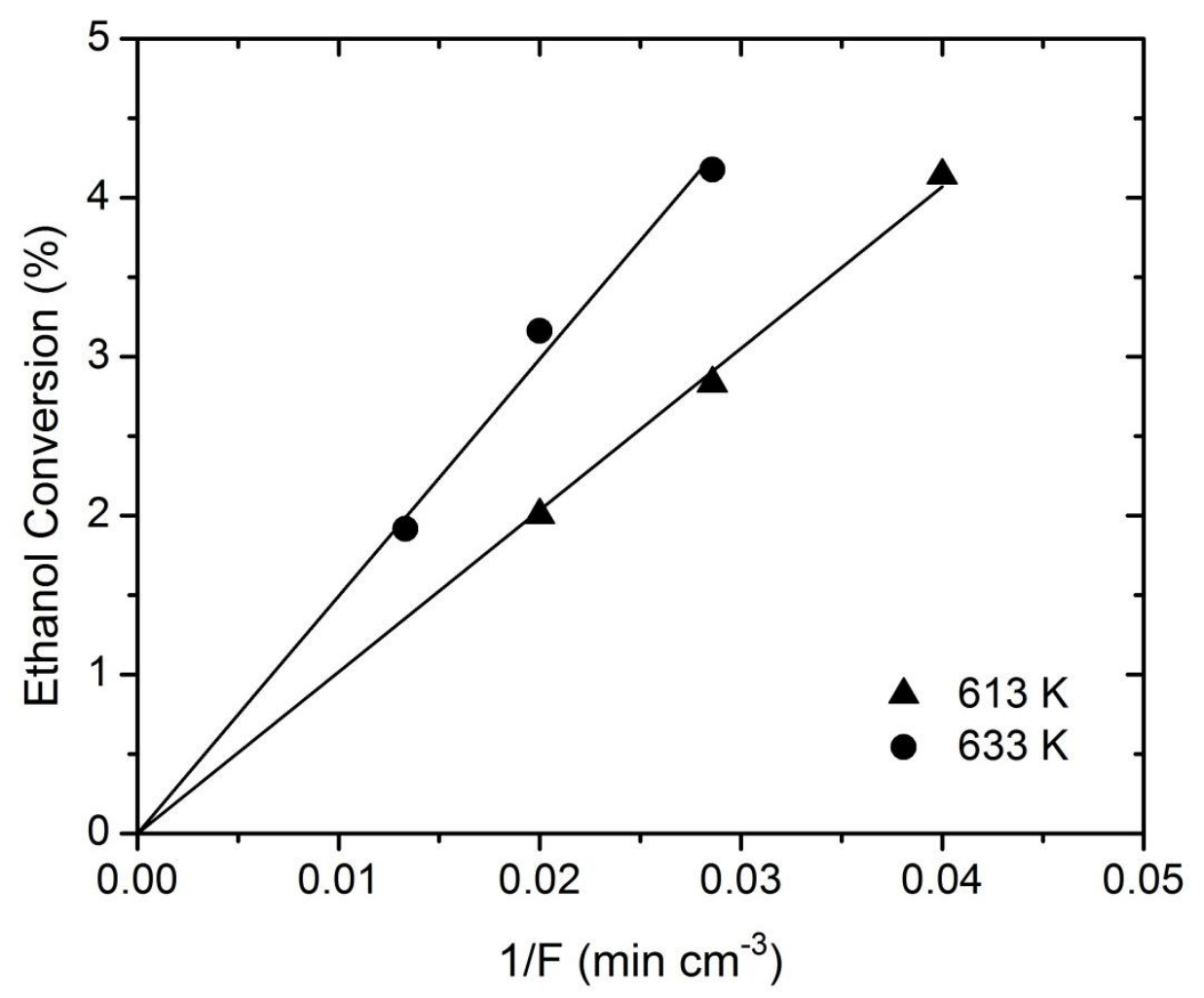

Figure C.3. Conversion of ethanol as a function of inverse reactant flowrate (proportional to reactor space time) during the Guerbet coupling of ethanol over $\beta-\mathrm{Ca}_{3}\left(\mathrm{PO}_{4}\right)_{2}$ at 613 and $633 \mathrm{~K}$. The observed linear dependence confirms differential reactor conditions at both temperatures.

Table C.4. Product Distribution during the Guerbet Coupling of Ethanol over $\beta-\mathrm{Ca}_{3}\left(\mathrm{PO}_{4}\right)_{2}$ at $613 \mathrm{~K}$

\begin{tabular}{|c|c|c|c|c|c|c|c|c|}
\hline \multirow{2}{*}{$\begin{array}{l}\text { Total } \\
\text { Flowrate } \\
\left(\mathrm{cm}^{3} \mathrm{~min}^{-1}\right)\end{array}$} & \multirow{2}{*}{$\begin{array}{c}\text { Ethanol } \\
\text { Conversion } \\
(\%)\end{array}$} & \multirow{2}{*}{$\begin{array}{c}\text { Rate of } \\
\text { Ethanol } \\
\text { Conversion } \\
\left(\mathrm{mol} \mathrm{m}^{-2} \mathrm{~s}^{-1}\right)\end{array}$} & \multicolumn{3}{|c|}{$\begin{array}{l}\text { Production Rates } \\
\qquad\left(\mathrm{mol} \mathrm{m}^{-2} \mathrm{~s}^{-1}\right)\end{array}$} & \multicolumn{3}{|c|}{ Selectivity $(\mathrm{C} \%)$} \\
\hline & & & $\mathrm{AcH}$ & DEE & Butanol & $\mathrm{AcH}$ & DEE & Butanol \\
\hline 25 & 4.1 & $1.9 \times 10^{-8}$ & $1.1 \times 10^{-8}$ & $3.3 \times 10^{-10}$ & $3.8 \times 10^{-9}$ & 57 & 4 & 39 \\
\hline 35 & 2.8 & $1.9 \times 10^{-8}$ & $1.3 \times 10^{-8}$ & 0 & $2.9 \times 10^{-9}$ & 69 & 0 & 31 \\
\hline 50 & 2.0 & $1.9 \times 10^{-8}$ & $1.4 \times 10^{-8}$ & 0 & $2.4 \times 10^{-9}$ & 74 & 0 & 26 \\
\hline
\end{tabular}

$\mathrm{AcH}$ - Acetaldehyde; DEE - Diethyl ether

Table C.5. Product Distribution during the Guerbet Coupling of Ethanol over $\beta-\mathrm{Ca}_{3}\left(\mathrm{PO}_{4}\right)_{2}$ at $633 \mathrm{~K}$

\begin{tabular}{|c|c|c|c|c|c|c|c|c|c|c|}
\hline \multirow{2}{*}{$\begin{array}{c}\text { Total } \\
\text { Flowrate } \\
\left(\mathrm{cm}^{3} \mathrm{~min}^{-1}\right)\end{array}$} & \multirow{2}{*}{$\begin{array}{c}\text { Ethanol } \\
\text { Conv. } \\
(\%)\end{array}$} & \multirow{2}{*}{$\begin{array}{c}\text { Rate of } \\
\text { Ethanol } \\
\text { Conversion } \\
\left(\mathrm{mol} \mathrm{m}^{-2} \mathrm{~s}^{-1}\right)\end{array}$} & \multicolumn{4}{|c|}{$\begin{array}{l}\text { Production Rates } \\
\left(\mathrm{mol} \mathrm{m}^{-2} \mathrm{~s}^{-1}\right)\end{array}$} & \multicolumn{4}{|c|}{ Selectivity (C\%) } \\
\hline & & & Ethane & $\mathrm{AcH}$ & DEE & Butanol & Ethane & $\mathrm{AcH}$ & DEE & $\mathrm{BuOH}$ \\
\hline 35 & 4.2 & $2.7 \times 10^{-8}$ & $5.9 \times 10^{-10}$ & $1.6 \times 10^{-8}$ & $5.7 \times 10^{-10}$ & $4.7 \times 10^{-9}$ & 2 & 59 & 4 & 35 \\
\hline 50 & 3.2 & $3.0 \times 10^{-8}$ & 0 & $2.0 \times 10^{-8}$ & $6.4 \times 10^{-10}$ & $4.2 \times 10^{-9}$ & 0 & 67 & 4 & 29 \\
\hline 75 & 1.9 & $2.7 \times 10^{-8}$ & 0 & $2.1 \times 10^{-8}$ & 0 & $2.7 \times 10^{-9}$ & 0 & 80 & 0 & 20 \\
\hline
\end{tabular}

$\mathrm{AcH}$ - Acetaldehyde; DEE - Diethyl ether; $\mathrm{BuOH}$ - Butanol 


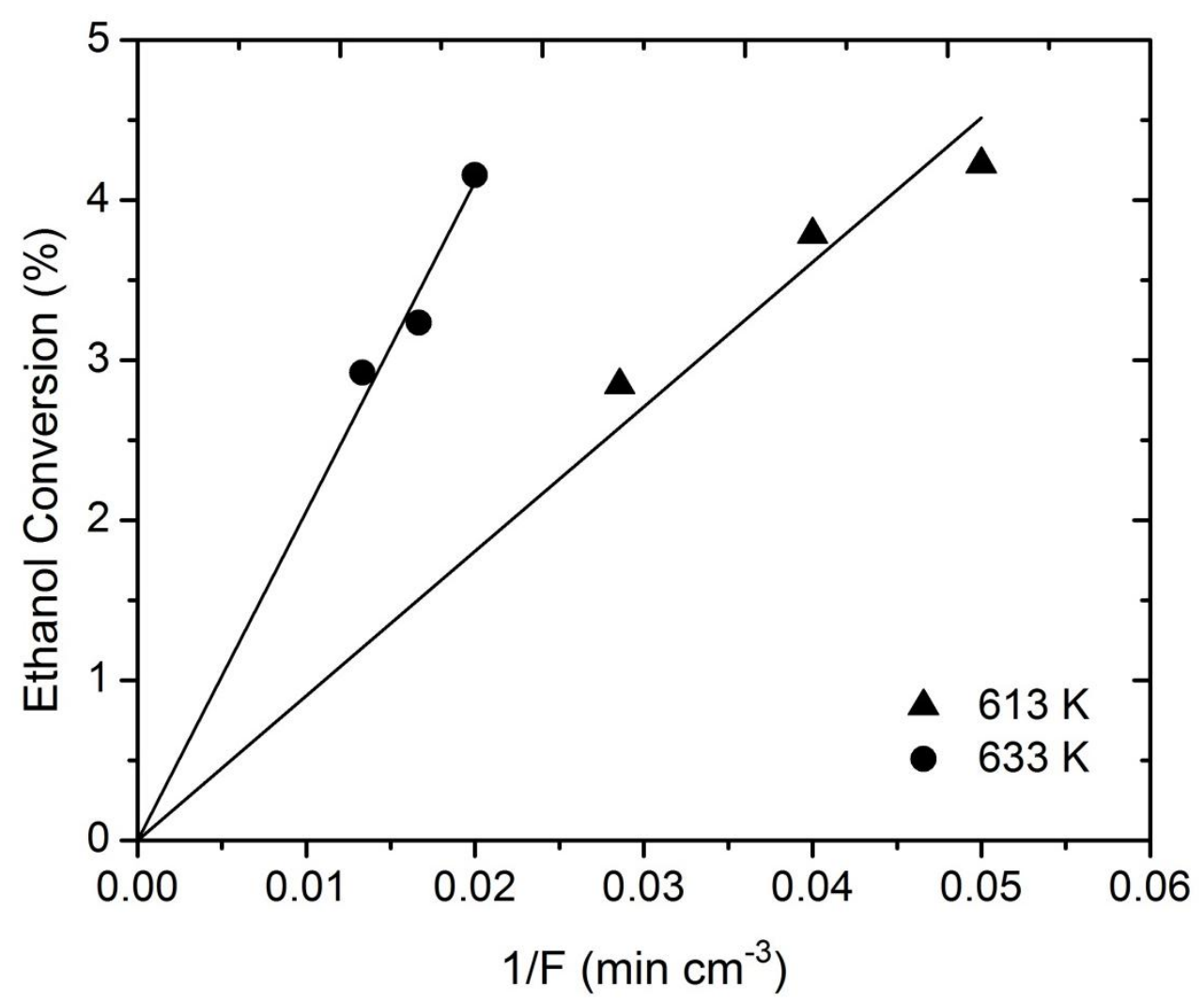

Figure C.4. Conversion of ethanol as a function of inverse reactant flowrate (proportional to reactor space time) during the Guerbet coupling of ethanol over $\mathrm{Sr}_{3}\left(\mathrm{PO}_{4}\right)_{2}$ at 613 and $633 \mathrm{~K}$. The observed linear dependence confirms differential reactor conditions at both temperatures.

Table C.6. Product Distribution during the Guerbet Coupling of Ethanol over $\mathrm{Sr}_{3}\left(\mathrm{PO}_{4}\right)_{2}$ at $613 \mathrm{~K}$

\begin{tabular}{|c|c|c|c|c|c|c|}
\hline \multirow{2}{*}{$\begin{array}{c}\text { Total } \\
\text { Flowrate } \\
\left(\mathrm{cm}^{3} \mathrm{~min}^{-1}\right)\end{array}$} & \multirow{2}{*}{$\begin{array}{c}\text { Ethanol } \\
\text { Conversion } \\
(\%)\end{array}$} & \multirow{2}{*}{$\begin{array}{c}\text { Rate of } \\
\text { Ethanol } \\
\text { Conversion } \\
\left(\mathrm{mol} \mathrm{m}^{-2} \mathrm{~s}^{-1}\right)\end{array}$} & \multicolumn{2}{|c|}{$\begin{array}{l}\text { Production Rates } \\
\quad\left(\mathrm{mol} \mathrm{m}^{-2} \mathrm{~s}^{-1}\right)\end{array}$} & \multicolumn{2}{|c|}{ Selectivity (C\%) } \\
\hline & & & $\mathrm{AcH}$ & Butanol & $\mathrm{AcH}$ & Butanol \\
\hline 20 & 4.2 & $6.7 \times 10^{-8}$ & $5.7 \times 10^{-8}$ & $4.6 \times 10^{-9}$ & 86 & 14 \\
\hline 25 & 3.8 & $7.5 \times 10^{-8}$ & $6.4 \times 10^{-8}$ & $5.4 \times 10^{-9}$ & 86 & 14 \\
\hline 35 & 2.8 & $7.8 \times 10^{-8}$ & $7.2 \times 10^{-8}$ & $3.4 \times 10^{-9}$ & 91 & 9 \\
\hline
\end{tabular}

$\mathrm{AcH}$ - Acetaldehyde

Table C.7. Product Distribution during the Guerbet Coupling of Ethanol over $\mathrm{Sr}_{3}\left(\mathrm{PO}_{4}\right)_{2}$ at $633 \mathrm{~K}$

\begin{tabular}{|c|c|c|c|c|c|c|}
\hline \multirow{2}{*}{$\begin{array}{c}\text { Total } \\
\text { Flowrate } \\
\left(\mathrm{cm}^{3} \mathrm{~min}^{-1}\right)\end{array}$} & \multirow{2}{*}{$\begin{array}{c}\text { Ethanol } \\
\text { Conversion } \\
(\%)\end{array}$} & \multirow{2}{*}{$\begin{array}{c}\text { Rate of } \\
\text { Ethanol } \\
\text { Conversion } \\
\left(\mathrm{mol} \mathrm{m}^{-2} \mathrm{~s}^{-1}\right)\end{array}$} & \multicolumn{2}{|c|}{$\begin{array}{l}\text { Production Rates } \\
\qquad\left(\mathrm{mol} \mathrm{m}^{-2} \mathrm{~s}^{-1}\right)\end{array}$} & \multicolumn{2}{|c|}{ Selectivity (C\%) } \\
\hline & & & $\mathrm{AcH}$ & Butanol & $\mathrm{AcH}$ & Butanol \\
\hline 50 & 4.2 & $1.6 \times 10^{-7}$ & $1.5 \times 10^{-7}$ & $7.2 \times 10^{-9}$ & 91 & 9 \\
\hline 60 & 3.2 & $1.5 \times 10^{-7}$ & $1.5 \times 10^{-7}$ & $3.2 \times 10^{-9}$ & 96 & 4 \\
\hline 75 & 2.9 & $1.7 \times 10^{-7}$ & $1.7 \times 10^{-7}$ & $3.4 \times 10^{-9}$ & 96 & 4 \\
\hline
\end{tabular}

$\mathrm{AcH}$ - Acetaldehyde 
Appendix D:

Co-Authored Work 


\title{
D.1. DRIFTS of Probe Molecules Adsorbed on Magnesia, Zirconia, and Hydroxyapatite Catalysts
}

This work was previously published as: I.M. Hill, S. Hanspal, Z.D. Young, and R.J. Davis, "DRIFTS of Probe Molecules Adsorbed on Magnesia, Zirconia and Hydroxyapatite Catalysts," J. Phys. Chem. C, 2015, 119, 9186-9197.

\begin{abstract}
Acid sites, base sites, and acid-base site pairs on zirconia, magnesia, and hydroxyapatite were investigated using diffuse reflectance FT-IR spectroscopy (DRIFTS) to evaluate the interaction of various adsorbed probe molecules with their surfaces. The DRIFTS spectra were recorded under continuous flow conditions at atmospheric total pressure during a temperatureprogrammed thermal ramp. Lewis acidity was assessed by observing the various pyridine ring mode conformations and the peak shift associated with adsorption of CO. Basicity was probed by the adsorption of $\mathrm{CO} 2$ to form carbonates and bicarbonates on the samples. The acid-base bifunctional nature of the oxides was explored by adsorption of acetylene and glycine. As expected, zirconia exposed the strongest Lewis acid sites of the three samples, whereas magnesia exhibited the strongest basic sites. In contrast, hydroxyapatite had a poor affinity for all probe molecules used in this study based on temperature-programmed desorption experiments, indicating the presence of only weak acid and base sites on the surface, which might account for its high catalytic activity and unique selectivity in the Guerbet coupling of ethanol to butanol.
\end{abstract}




\title{
D.2. Aldol Condensation of Acetaldehyde over Titania, Hydroxyapatite, and Magnesia
}

This work was previously published as: Z.D. Young, S. Hanspal, and R.J. Davis, "Aldol Condensation of Acetaldehyde over Titania, Hydroxyapatite, and Magnesia," ACS Catalysis, 2016, 6, 3193-3202.

\begin{abstract}
The kinetics of aldol condensation of acetaldehyde were studied over anatase titania $\left(\mathrm{TiO}_{2}\right)$, hydroxyapatite (HAP), and magnesia (MgO). Reactions were carried out in a fixed-bed reactor with a total system pressure of $220 \mathrm{kPa}$ at temperatures between 533 and $633 \mathrm{~K}$ and acetaldehyde partial pressures between 0.05 and $50 \mathrm{kPa}$. Crotonaldehyde was the only product observed over all three catalysts, and severe catalyst deactivation occurred at acetaldehyde partial pressures of 5 $\mathrm{kPa}$ or greater. The aldol condensation reaction over all three catalysts was first order at low acetaldehyde partial pressure and approached zero order at high acetaldehyde partial pressure. No kinetic isotope effect (KIE) was observed with fully deuterated acetaldehyde reacting over $\mathrm{TiO}_{2}$ or $\mathrm{HAP}$, implying that $\mathrm{C}-\mathrm{H}$ bond activation is not kinetically relevant. These measurements are consistent with a mechanism in which adsorption and desorption steps are kinetically significant during the reaction. Characterization of the catalysts by adsorption microcalorimetry of acetaldehyde and ethanol and diffuse reflectance Fourier transform infrared spectroscopy of adsorbed acetaldehyde, crotonaldehyde, and acetic acid revealed a very high reactivity of these catalysts, even at low temperatures.
\end{abstract}

